\title{
Multi-objective thermal design optimization of plate frame heat exchangers through global best algorithm
}

\author{
Oguz Emrah TURGUTa,*

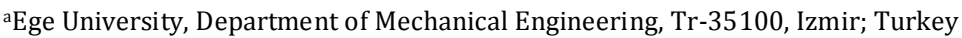

\section{A R T I C L E IN F O}

Article history:

Received 26 November 2016

Received in revised form 15 May 2017

Accepted 02 June 2017

Keywords:

Decision making methods

Multi-objective optimization

Optimization algorithms

Plate frame heat exchangers

Thermal design

\begin{abstract}
A B S T RAC T
This study deals with thermal design of plate frame heat exchangers based on Global Best Algorithm. By utilizing some basic perturbation schemes adopted from Differential Search and Differential Evolution, Global Best Algorithm aims to obtain optimum solution of any optimization problem with intensifying on exploitation of the promising solutions rather than exploring of the unvisited paths of the search domain. Firstly, optimization performance of the proposed algorithm has been benchmarked against variety of well-known optimization algorithms by means of 16 different highly challenging optimization test functions. Then, the proposed method is put into practice to acquire the optimal values of the design variables those optimize the considered problem objectives including overall heat transfer coefficient, total cost and weight of the plate frame heat exchangers separately as well as simultaneously. Considerable improvement in objective function values is observed as compared to preliminary design in single objective manner. Pareto frontier is constructed for dual and triple objective and best optimal solution among the curve is selected by means of the widely-known decision making methods of LINMAP, TOPSIS, and Shannon's entropy theory. Optimal results obtained from each decision making theory are compared with respect to their corresponding deviation indexes and the best one is preferred. A sensitivity analysis is then performed to study the vibrational influences of some design parameters on the considered objective functions. It is observed that selected design variables has a significant effect on problem objectives.
\end{abstract}

\section{Introduction}

Heat exchangers are devices that transfer heat from hot fluid to cold fluid by means of the temperature differences between two mediums. They have been frequently used in various kind of industrial applications including power plants, air conditioning, and chemical industry, etc. Among different types of heat exchangers available in the market, shell and tube heat exchangers and plate frame heat exchangers are the most prevalent types those having plenty of advantages over the other type of heat exchangers. Effortful investigation on the performance improvement of plate frame (gasketed) heat exchangers started in the early of 1930s (Kakaç et al., 2012).

However, researchers taken part in these projects had been restricted by their associated companies in order to keep the experimental works and their related outcomes confidential.

* Corresponding author.

E-mail address: oeturgut@hotmail.com 
Moreover, heat transfer coefficient and pressure drop correlations developed as an outcome of the experimental studies did not work for different type of heat exchanger geometries and characteristics as they were correlated by their own measurements. Therefore, unlike shell and tube heat exchangers those having plentiful information about their design procedures, developments and improvements on the design of gasketed heat exchangers has not been risen to desirable levels due to the insufficient knowledge on the available design data.

There are many features of gasketed heat exchangers which can be considered to be advantageous over the other types. Any internal leakage to the outside can be easily detected and fixed. They are accessible to comfort various design possibilities of plate geometries and pass arrangements. Due to the relatively small hydraulic diameters and imposed turbulent effects, very high and efficient heat transfer rates can be achieved through their utilization. In spite of being compact and having lower weight rates compared to the different other types of heat exchangers, they possess a large heat transfer surface area up to $1500 \mathrm{~m}^{2}$. However, their performance is limited to constructional characteristics of the gaskets and the plates (Kakaç et al., 2012). They are not efficient in using as air coolers as well as condensing applications. These hindrances can be shown as a drawback on their utilization in many other industries.

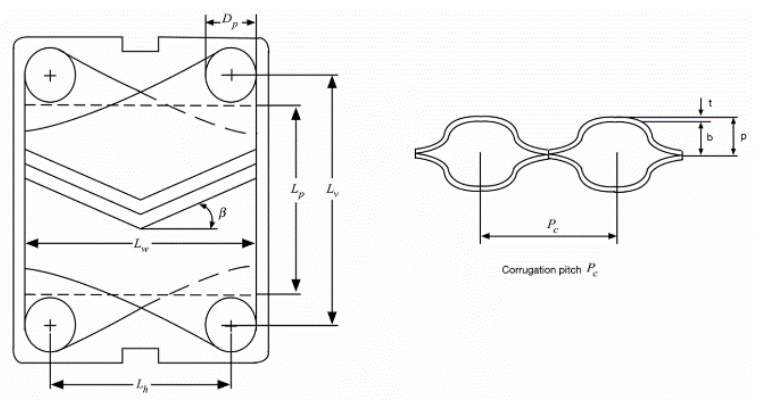

Fig. 1 Schematic demonstration of a chevron plate with main dimensions

A conventional plate frame heat exchanger is comprised of corrugated plates stamped to each other placed in a frame as shown in Fig. 1. Gaskets are used to avert the internal leakages between adjacent plates but a favourable compression of $\% 25$ of its original size should be maintained in order to prevent local distortions on a thin plate by procuring firm joints. Hot and cold fluids flow through the adjacent spaces between plates and are steered into these channels by corner ports (Najafi and Najafi, 2010). These corrugated channels not only ensure the high heat transfer rates thanks to the occurrence of turbulent flow, but also increase the heat transfer efficiency due to the large heat transfer area enhanced by the corrugations on the channel walls (Najafi and Najafi, 2010). Constructional design of a typical plate frame heat exchanger has not been changed over the past of eighty years. However, upper limits of working pressures and temperatures of these type of devices have been altered to some extent as a result of the exhaustive and comprehensive studies those pave the way to attain successful design parameters. Therefore, it is possible to limit maximum pressures up to $2.5 \mathrm{MPa}$ while conventional design pressure is near 1.0 $\mathrm{MPa}$. Considering the corrosion phenomenon, which is very essential in PFHEs, a designer should give a much more care on this issue compared to shell and tube heat exchangers as the plates are very thin in comparison to the tube thickness of shell and tube heat exchangers. Upper limit of corrosion allowance is considerably diminished for PFHEs and therefore utilization of recommended values for tubular types for extreme corrosive conditions become useless in gasketed heat exchanger. Stainless steel are the most commonly used plate material due to its extreme ability to cope with high temperatures. Chevron type plate heat exchangers are the most widely utilized devices among their alternatives (Martin, 1996). As a result, researchers have made numerous experimental and theoretical studies on successful modelling of chevron type plate heat exchangers with subject to several design constraints. Focke (1986) pioneered these studies by proposing an optimization strategy to find optimal parameters of PHFEs. It was found that number of possible optimum points increases with increasing number of imposed design constraints. Besides, it was suggested that using different types chevron plates could improve the performance of the heat exchanger which is indeed a trade-off between pumping power and heat transfer efficiency. Following this optimization approach, multi-pass design considerations were taken into account rather than single pass design since single pass arrangement deteriorates the originality and the applicability of the proposed modelling procedure. Obeying these tendencies, some researchers used conventional $\varepsilon$-NTU method to mathematically model the plate frame exchanger. For instance, Zaleski and Klepacka (1992) proposed a novel calculation procedure for plate heat exchanger based on the variable effects of number of transfer units and thermal efficiencies on the heat transfer performance. They suggested a plausible pathway to select suitable heat exchanger based on the comprehensive analysis made on 150 different configuration alternatives. Kandlikar and Shah (1989) reported the outcomes of the exhaustive studies based on the Gauss-Seidel iteration finite difference analysis of multi pass arrangements. On the basis of the best heat transfer efficiency rates obtained for each different configuration, variety of design factors including temperature effectiveness, log mean temperature difference correction factor which is in control of the number of heat transfer units, heat capacity rate ratio, and number of thermal plates are presented in tabular form to give design options for researchers. However these studies also revealed that implementation of $\varepsilon$-NTU procedure burden huge amount of computational load as well as increasing computation time to unexpected and unfeasible levels. Therefore, designers chose alternative ways to fulfil these design requirements. In order to conquer these mentioned drawbacks, Wang and Sunden (2003) proposed a solution strategy for plate frame heat exchangers with and without considering pressure drop specifications. When compared to former design strategies based upon $\varepsilon$-NTU, proposed procedure ensures pressure drop values within allowable limits with a rational and straightforward way also taking into account of all heat exchanger design parameters. Gut and Pinto (2004) used screening method to attain optimal configurations of plate frame heat exchangers considering heat transfer area as an objective function to be minimized with several imposed constraints on number of channels ,pressure drops, flow velocities, etc. Intended solution strategy is constructed on a search methodology through which infeasible and sub-optimal solutions are iteratively eliminated. Optimization results 
showed that proposed screening method has the capability of obtaining set of optimal solutions with a very reduced computational load.

Apart from aforementioned studies those mostly relied on numerical investigations on heat exchanger design, there has been made a plethora of experimental approaches in heat exchanger modelling. Gut et al. (2004) proposed a parameter estimation methodology to obtain a relevant heat transfer coefficient relying upon retrieved experimental data for multi pass arrangements. Numerical results obtained from multi pass design were compared with those of single pass arrangements and comparison outcomes revealed that the correlations obtained from experimental data has a close relationship with the flow configurations as well as flow distribution patterns. Galeaozzo et al. (2006) presented a comparison between the results of CFD modelling and the outcomes of experimental procedure for variety of flow arrangements for plate frame heat exchangers. They found that experimental data are in line with CFD results. Jassim et al. (2006) investigated heat transfer and pressure drop characteristics of chevron and bumpy plate heat exchangers designated for vertical upward flows with using R134a as a refrigerant. They developed a two phase pressure drop correlation based upon their measurements and found that the predictions obtained from the proposed correlation are within $15 \%$ of experimental data. Luan et al. (2008) designed a novel corrugation plate heat exchanger and showed that flow resistance of the working fluid was decreased by $50 \%$ while overall heat transfer coefficient rates were decreased about $25 \%$ as compared to the conventional chevron type design. In addition, they observed that flow path blockage can be avoided with utilizing such plate configurations. Han et al. (2010) evaluated the usage of chevron corrugated plate heat exchangers in a simulated platform and simultaneously obtained three dimensional temperature, velocity and pressure fields. They compared the numerical results with the experimental data and observed that the tendencies of outside temperature values agree with those of pressure drop rates. Gherasim et al. (2011) experimentally studied the distribution of the thermal and hydraulic fields in a chevron plate heat exchanger under laminar and turbulent flow conditions. Experimental investigations on various heat exchanger parameters reveal that present study obtain the intermediate values between the corresponding extremes formerly reported approaches on this issue. Tiwari et al. (2013) undertook an experimental study toexplore the tendencies and inclinations of pressure drop and heat transfer characteristics of a chevron type plate heat exchanger which uses $\mathrm{CeO}_{2}$ nanofluid as a coolant. Experimental studies were made with an aim to obtain optimal values of nanofluid concentrations under different flow rates and working temperatures. Measurements retained from experimental studies showed that using nanofluid in the process significantly enhances heat transfer rates with negligible rises in pressure drop values. Tiwari et al. (2013) extended their aforementioned former research by studying the effects of three different nanofluids including $\mathrm{CeO}_{2}, \mathrm{Al}_{2} \mathrm{O}_{3}$, $\mathrm{TiO}_{2}$, and $\mathrm{SiO}_{2}$ on heat transfer efficiencies for different flow rates and various range of concentration. Experimental studies reveal that $\mathrm{CeO}_{2}$ /water gives the most heat transfer enhancement rates among other options with relatively imposing lower pressure drop values.

Last decade has also witnessed the utilization of metaheuristic optimization algorithms on thermal and economic design of heat exchangers. Specifically, genetic algorithm (Selbas et al., 2006; Guo et al., 2009; Fettaka et al., 2013; Ponce-Ortega et al., 2009; Khosravi et al., 2015; Amini and Bazargan, 2014) has been intensively benefited by many researchers as a favourable option for optimum thermal design. However, there has also been plenty of proposed stochastic optimization based solution strategy for modelling various type of heat exchangers most of which outperforms genetic algorithm with respect to their optimization performance. These are generally nature inspired problem solving methodologies those taking advantage of the stochasticity and unpredictability of the unevenly distributed random numbers. For instance, Artificial Bee Colony algorithm, mimics the intelligent foraging behaviours of the working honey bees, was used to retain the optimal parameters of shell and tube heat exchanger through the minimization of total cost of system equipment consisting of capital investment and pumping costs (Sahin et al., 2011). Particle swarm optimization is another widely used metaheuristic optimizer in order to optimize shell and tube heat exchangers in terms of thermo-economic considerations (Patel and Rao, 2011). Additionally, there has been many attempts to model and design various type of heat exchangers through relatively new emerged optimizers such as Cuckoo Search (Asadi et al., 2014), Biogeography Based Optimization (Hadidi and Nazari, 2013), Imperialist Competitive Algorithm (Hadidi et al., 2013), Firefly Algorithm (Mohanty, 2016a), Gravitational Search Algorithm (Mohanty, 2016b), Teaching Learning Based Optimization (Patel and Savsani, 2014; Rao and Patel, 2013; Rao and Waghmare, 2015). In this study, it is aimed to determine the optimal design parameters of plate frame heat exchangers through utilizing the promising merits of Global Best Algorithm (GBEST)(Turgut and Coban, 2016). Referring to the fundamental concepts taking part in previous studies accomplished by Najafi and Najafi (2010) and Hajabdollahi et al. (2013), this study benefits the ultimate search performance and unpredictable probing characteristics structured by the chaotic sequences of Logistic map possessed thoroughly by the proposed GBEST to attain the optimal configuration of a plate frame heat exchanger in a single and multi-objective manner. Total cost of heat exchanger, overall heat transfer coefficient, and heat exchanger weight are selected objectives to be optimized. Different from former aforementioned studies referred above, this study considers the effects of chevron angles on heat transfer by taking them as decision variables. Case study taken from Kakaç et al. (2012) is meticulously solved by Global Best optimizer as well as some of diligent metaheuristic algorithms such as Artificial Cooperative Search (Civicioglu, 2013), Bat Algorithm (Yang, 2010) and Quantum behaved Particle Swarm Optimization (Sun et al., 2004a, b) in order to benchmark the efficiency and accuracy of the proposed algorithm. Outcomes of these methods are compared with those of the preliminary design and influences of governing heat exchanger parameters on each others are explicitly investigated by virtue of the sensitivity analysis. It is understood that GB EST is able to maintain accurate solutions within a reasonable computation time when compared to other remaining benchmarked algorithms. In addition, pareto curve constructed by GBEST procures uniformly distributed non dominated solutions on the frontier without violating prescribed boundary restrictions. Triple objective and dual objective optimization for plate heat exchangers will be maintained by GBEST and optimal solution on the pareto curve will be selected by the 
renowned decision making methods of LINMAP, TOPSIS, and Shannon's entropy theory.

\section{Thermal modelling of plate frame heat exchangers}

Plate heat exchangers have plenty of construction-specific mathematical modelling procedures those can suit various different heat duties and design requirements as their nature. As mentioned in introduction section, they have limited modelling options those have been restricted by manufacturers who have developed their own solution methods applicable to thermal design of plate heat exchangers. However, there has been many published promising studies on predicting heat transfer and pressure drop rates for two or three decades but most of them are correlated for their own measurements which may lead to inaccurate design outcomes in use of generalized conditions.

In plate frame heat exchanger design, enlargement factor and mean channel gap are two major factors those can greatly affect the thermal performance. Enlargement factor can be defined as an enhancement of the developed length with respect to projected length and formulated by the following equation (Kakaç et al., 2012).

$\psi=\frac{\text { developed length }}{\text { projected length }}$

This parameter generally varies between 1.15 and 1.25 , and typical value for this factor is around 1.17 (Edwards et al. 1974). Essentially, this value is the ratio of actual area (Aact) designated by the manufacturer to the projected area of the plate $\left(A_{p}\right)$ and can be redefined by the following formulation (Kakaç et al., 2012).

$$
\psi=\frac{A_{a c t}}{A_{p}}
$$

Where Ap can be calculated by the multiplication of projected plate length $\left(\mathrm{L}_{\mathrm{p}}\right)$ and plate width $\left(\mathrm{L}_{w}\right)$ by means of the below given equation

$$
A_{p}=L_{p} \times L_{w}
$$

Abovementioned projected plate length and plate width can be approximately estimated as a function of port diameter $\left(D_{p}\right)$, vertical $\left(\mathrm{Lv}_{\mathrm{v}}\right)$ and horizontal $(\mathrm{Lh})$ distances between ports and formulated by the following equations

$$
\begin{aligned}
& L_{p} \approx L_{v}-D_{p} \\
& L_{w} \approx L_{h}+D_{p}
\end{aligned}
$$

Mean flow channel gap (b) is formed by the two consecutive plates those are clamped into each other and mathematically defined as

$$
b=p-t
$$

Where $\mathrm{p}$ is the plate pitch and $\mathrm{t}$ is the plate thickness. The plate pitch $\mathrm{p}$ can be determined from the equation defined as a ratio between compact plate pack length $\left(\mathrm{L}_{\mathrm{c}}\right)$ and total number of plates $\left(\mathrm{N}_{\mathrm{t}}\right)$ with the below given formulation

$$
p=\frac{L_{c}}{N_{t}}
$$

Following that, hydraulic channel diameter can be calculated as

$$
\begin{aligned}
& D_{h c}=\frac{4 \times(\text { Actual channel flow area })}{\text { Wetted surface perimeter }} \\
& D_{h c}=\frac{4 b L_{w}}{2\left(b+L_{w} \psi\right)} \approx \frac{2 b}{\psi}
\end{aligned}
$$

on the basis of the assumption that $b \ll \mathrm{L}_{\mathrm{w}}$. In order to determine the corresponding heat transfer coefficient and pressure drop, a mathematical model based on the tabular values given in Table 1 proposed by Kumar (1984) is utilized. The proposed model can be expressed with its pure form by the following equation

$$
\frac{h \cdot D_{h c}}{k}=C_{h}\left(\frac{D_{h c} G}{\mu}\right)^{n}\left(\frac{c_{p} \mu}{k}\right)^{1 / 3}\left(\frac{\mu}{\mu_{w}}\right)^{0.17}
$$

Where the equation coefficients $\mathrm{Ch}_{\mathrm{h}}$ and $\mathrm{n}$, thoroughly dependent on chevron angle and the magnitude of Reynolds number, are tabulated in Table 1. Reynolds number for hot and cold sides can be represented as

$\operatorname{Re}=\frac{G \cdot D_{h c}}{\mu}$

Where $\mathrm{G}$ is the mass velocity and can be defined by

$G=\frac{\dot{m}}{N_{c p} \cdot b \cdot L_{w}}$

In Eq (12), $\mathrm{N}_{\mathrm{cp}}$ stands for the number of channels per pass and expressed by the following equation

$N_{c p}=\frac{N_{t}-1}{2 N_{p}}$

Where $\mathrm{N}_{\mathrm{p}}$ symbolizes number of passes while $\mathrm{N}_{\mathrm{t}}$ is number of plates. Finally, overall heat transfer coefficient for fouled surfaces is calculated based on the above mentioned expressions with given formulation below

$$
\frac{1}{U}=\frac{1}{h_{\text {hot }}}+\frac{1}{h_{\text {cold }}}+\frac{t}{k_{\text {plate }}}+R_{\text {hot }}+R_{\text {cold }}
$$

Where $h_{\text {hot }}$ and $\mathrm{h}_{\text {cold }}$ are respectively heat transfer coefficients for hot and cold sides; kplate is heat conductivity of the plate material; and $\mathrm{R}_{\text {hot }}$ and $\mathrm{R}_{\text {cold }}$ are correspondingly fouling factor for cold and hot side surfaces. 
Bitlis Eren University Journal of Science and Technology 7(1) (2017) 33-73

Table 1. Tabular $\mathrm{C}_{\mathrm{h}}$ and $\mathrm{n}$ values as a function of Reynolds number and chevron angles for the proposed heat transfer coefficient and pressure drop correlations by Kumar (1984)

\begin{tabular}{|c|c|c|c|c|c|c|}
\hline \multirow[t]{2}{*}{ Chevron angle } & \multicolumn{3}{|c|}{ Heat transfer coefficient } & \multicolumn{3}{|c|}{ Pressure drop coefficient } \\
\hline & $\begin{array}{l}\text { Reynolds } \\
\text { Number }\end{array}$ & $C_{h}$ & n & $\begin{array}{l}\text { Reynolds } \\
\text { Number }\end{array}$ & $\mathrm{K}_{\mathrm{p}}$ & $\mathbf{m}$ \\
\hline \multirow[t]{3}{*}{$\leq \mathbf{3 0}$} & $\leq 10$ & 0.718 & 0.349 & $<10$ & 50.000 & 1.000 \\
\hline & $>10$ & 0.348 & 0.663 & $10-100$ & 19.400 & 0.589 \\
\hline & & & & $>100$ & 2.990 & 0.183 \\
\hline \multirow[t]{3}{*}{45} & $<10$ & 0.718 & 0.349 & $<15$ & 47.000 & 1.000 \\
\hline & $10-100$ & 0.400 & 0.598 & $15-300$ & 18.290 & 0.652 \\
\hline & $>100$ & 0.300 & 0.663 & $>300$ & 1.441 & 0.206 \\
\hline \multirow[t]{3}{*}{50} & $<20$ & 0.630 & 0.333 & $<20$ & 34.000 & 1.000 \\
\hline & $20-300$ & 0.291 & 0.591 & $20-300$ & 11.250 & 0.631 \\
\hline & $>300$ & 0.130 & 0.732 & $>300$ & 0.772 & 0.161 \\
\hline \multirow[t]{3}{*}{60} & $<20$ & 0.562 & 0.326 & $<40$ & 24.000 & 1.000 \\
\hline & $20-400$ & 0.306 & 0.529 & $40-400$ & 3.240 & 0.457 \\
\hline & $>400$ & 0.108 & 0.703 & $>400$ & 0.760 & 0.215 \\
\hline \multirow[t]{3}{*}{$\geq 65$} & $<20$ & 0.562 & 0.326 & $<50$ & 24.000 & 1.000 \\
\hline & $20-500$ & 0.331 & 0.503 & $50-500$ & 2.800 & 0.451 \\
\hline & $>500$ & 0.087 & 0.718 & $>500$ & 0.639 & 0.213 \\
\hline
\end{tabular}


Pressure drop in heat exchanger is an essential design objective whose structural importance needs to be fully comprehended and should be evaluated in different points of view in consequence of its close relationship with overall heat transfer coefficient. Considering a heat exchanger with a fixed heat load, any increase in flow velocity will cause an improvement in heat transfer rates to some degree. However, this increase will give a rise to pressure drop rates which eventually increase total running cost. Therefore, a designer should be aware of this contradictive relationship between total cost and heat transfer coefficient in order to attain cost effective heat exchanger modelling while keeping heat transfer rates as high as possible. Total pressure drop is comprised of channel pressure drop caused by the friction $\left(\Delta \mathrm{P}_{\mathrm{f}}\right)$ and pressure drop occurred in port ducts $\left(\Delta \mathrm{P}_{\mathrm{p}}\right)$. Frictional pressure drop can be formulated by the following equation

$$
\Delta P_{f}=4 f \frac{L_{v} N_{p}}{D_{h c}} \frac{G^{2}}{2 \rho}\left(\frac{\mu_{b}}{\mu_{w}}\right)^{-0.17}
$$

Where friction factor $(f)$ parameter is expressed in the following form

$$
f=\frac{K_{p}}{\operatorname{Re}^{m}}
$$

Tabular values of $K_{p}$ and $m$ are given in Table 1. Port pressure drop occur between the inlet and outlet of the corresponding ports and is mathematically expressed by the following equation

$$
\begin{aligned}
& \Delta P_{p}=1.4 N_{p} \frac{G_{p}^{2}}{2 \rho} \\
& G_{p}=\frac{4 \dot{m}}{\pi D_{p}^{2}}
\end{aligned}
$$

Where $\mathrm{D}_{\mathrm{p}}$ is port diameter and $\dot{m}$ is the total mass flow rate flowing through the ducts. Finally, total pressure drop becomes:

$$
\Delta P_{\text {total }}=\Delta P_{f}+\Delta P_{p}
$$

Total cost of heat exchanger, which is considered as an optimization objective to be minimized, is another case needs to be elaborately dealt with and should be given an intense care if it is to sustain cost effective heat exchanger design. Total cost is the summation of investment cost $\left(\mathrm{C}_{\mathrm{inv}}\right)$ involving of the cost of heat transfer surface area and operational cost $\left(\mathrm{C}_{\text {oper }}\right)$ comprised of the pumping expenditures to circulate the working fluid throughout the heat exchanger. Total cost of heat exchanger is calculated with the below given series of equations (Hajabdollahi et al., 2013)

$$
\begin{aligned}
& C_{\text {total }}=a f \times C_{i n v}+C_{\text {oper }} \\
& C_{\text {inv }}=90 \cdot A_{\text {tot }}^{0.6}
\end{aligned}
$$

$$
\begin{aligned}
C_{\text {oper }} & =\frac{k_{e l} \cdot \tau}{\eta}\left(\left(\frac{\dot{m}}{\rho} \Delta P\right)_{h}+\left(\frac{\dot{m}}{\rho} \Delta P\right)_{c}\right) \\
a f & =\frac{r}{1-(1+r)^{-y}}
\end{aligned}
$$

\section{Global Best Algorithm}

This study evaluates the applicability of the formerly proposed Global Best Algorithm on thermal design of plate frame heat exchangers in terms of single and multi-objective considerations. As mentioned before, GBEST was developed by the author of this study and was previously applied on thermal modelling of heat pipes and spiral heat exchangers with serving highly appreciated outcomes with regards to solution efficiency and accuracy. In addition, its optimization success in widely accepted constrained and unconstrained benchmark problems is still studied and on progress to be published. Proposed algorithm benefits from the perturbation schemes adopted from Differential Search (Civicioglu, 2012) and Differential Evolution (Storn and Price, 1997) algorithms in order to reach the optimum solution of the problem. Different from most of the available stochastic-based optimization methods in the literature, GBEST tries to reach the optimal solution by probing around the so far obtained best solution (mainly through intensification) rather than the balanced effects of intensification and diversification phases. These terms are frequently used in optimization literature with such an aim to express the search characteristics of the mentioned optimization algorithm. Optimization algorithms are generally based on these contradictory, but yet supplementary phenomena through which structural features of the optimizer are shaped to some extent with utilizing their idiosyncratic merits. However, there is no explicit information about how to combine these phases in order to yield more favourable results. Basically, intensification (exploitation) phase aims to find the global optimum point by exploiting the promising points on the search domain while diversification (exploration) phase visits undiscovered and unexplored paths of the search space with a view to attain more fruitful solution samples whose best ones are to be used in upcoming iterations. GBEST also takes advantage of the ergodicity and unpredictability of sequential chaotic numbers produced by the famous Logistic map (May, 1976) rather than random numbers generated by Gaussian uniform distribution. Very efficient and distinctive random number sequences can be produced by this chaotic map, with the below given simple yet effective formulation:

$$
y(t+1)=4 \times y(t) \times(1-y(t))
$$

Where $y(0) \notin\{0.0,0.25,0.50,0.75,1.0\}$. Initialization of the algorithm is commenced with formation of D-dimensional $\mathrm{N}$ elements of trial matrices, $X$ and $X_{o l d}$, with the below given procedure. 


$$
\begin{aligned}
& \text { for } \mathrm{i}=1 \text { to } \mathrm{N} \\
& \qquad \begin{aligned}
\text { for } \mathrm{j} & =1 \text { to } \mathrm{D} \\
& \mathrm{X}_{i, j}=\operatorname{low}_{j}+\left(u p_{j}-\operatorname{low}_{j}\right) \times \phi_{1, i, j} \\
& \mathrm{X}_{\text {old }, i, j}=\operatorname{low}_{j}+\left(u p_{j}-\text { low }_{j}\right) \times \phi_{2, i, j}
\end{aligned}
\end{aligned}
$$

end

end

Where low and up respectively represent the lower and upper bounds of the search space; $\phi$ symbolizes a chaotic number generated by Logistic map. After completing this early phase of the algorithm, all individuals in $X_{\text {old }}$ matrix are evaluated and the most promising solution vector is selected and named hereinafter Gbest solution. Global Best Algorithm is divided into two major sections. First section utilizes the adjustment equations inspired by the Differential Search Algorithm while second phase benefits some useful merits of the well-known Differential Evolution algorithm as well as exploiting advantageous search characteristics of the ensemble learning strategy. Then, first section of the algorithm is introduced by the below given novel perturbation scheme

$$
V_{i, j}=G_{\text {best }, j}+\left(2.0 \times\left(\phi_{3, i, j}-0.5\right)\right) \times\left(G_{\text {best }, j}-X_{\text {old }, i, j}\right)
$$

Where $\mathrm{V}_{\mathrm{i}, \mathrm{j}}$ are the perturbed matrix individuals produced by the controlled influences of $X_{\text {old }}$ matrix elements and G $G_{\text {best }}$ solution vector. Following that, boundary control mechanism will come into practice to restrict violated solutions into the defined boundaries

$$
\begin{aligned}
& \text { for } i=1 \text { to } \mathrm{N} \\
& \qquad \begin{array}{r}
\text { for } i=1 \text { to } D \\
\text { if }\left(\left(V_{i, j}<\operatorname{low}_{j}\right) \|\left(V_{i, j}>u p_{j}\right)\right) \\
\quad V_{i, j}=\operatorname{low}_{j}+\left(u p_{j}-\operatorname{low} w_{j}\right) \times \operatorname{rand}(0,1)
\end{array}
\end{aligned}
$$

end

end

end

Where rand $(0,1)$ is a uniformly distributed Gaussian random number generated between 0 and 1 . Matrix elements of $X_{\text {old }}$ are updated by the following sub-algorithm

$$
\begin{aligned}
& \text { for } \mathrm{i}=1 \text { to } \mathrm{N} \\
& \text { if }\left(\operatorname{func}\left(V_{i}\right)<\operatorname{func}\left(X_{\text {old }, i}\right)\right) \\
& \qquad \text { for } j=1 \text { to } \mathrm{D} \\
& \qquad X_{\text {old }, i, j}=V_{i, j} \\
& \text { end } \\
& \text { end } \\
& \text { end }
\end{aligned}
$$

After that, new Gbest solution is decided to be utilized in upcoming adjustment schemes. Based on its success in
Differential Search algorithm on producing diverse solutions within a single population matrix, randperm() function is practiced to shuffle the order of $X_{\text {old }}$ elements in order to generate a perturbed $X_{\text {old } 2}$ matrix and consequently build up a new $V$ population with following schemes below formulated

$$
X_{\text {old } 2}=\operatorname{randperm}\left(X_{\text {old }}\right)
$$

$V_{i, j}=G_{b e s t, j}+\left(2.0 \times\left(\phi_{4, i, j}-0.5\right)\right) \times\left(X_{\text {old }, i, j}-X_{\text {old } 2, i, j}\right)$

Numerical experiments made on benchmark algorithms showed that utilization of randperm $($ function along with the integration of the differences between $X_{\text {old }}$ and $X_{\text {old } 2}$ population members into Eq.(30) considerably increase the solution diversity with a negligible incurred computational burden. Finally, solution update on Gest will be maintained and first phase of the algorithm is concluded with the boundary check mechanism applied on $X_{\text {old }}$ matrix elements.

Second phase of the algorithm begins with setting the updated $X_{\text {old }}$ population members into $X$ population by evaluating their fitness qualities. That is, if corresponding fitness value of any $X$ old population member is better than that of the $X$ member population then this member is replaced with the population member with having a lower quality fitness rate. Basic manipulation schemes of the Differential Evolution algorithm along with the promising features of ensemble learning methodology will be cooperatively used to enhance the search capacity of the algorithm. Ensemble learning is previously utilized in Particle Swarm Optimization (Zhao et al., 2011; Zhang and Ding, 2011) and variants of Differential Evolution algorithms (Yu and Zhang, 2011; Novoa-Hernandez et al., 2013; Liang and Suganthan, 2005) in order to strengthen the probing performance of the optimizer. Ensemble learning strategy gives options to a user who is in charge to choose suitable algorithm parameter values for a specific optimization problem. This process is a kind of tedious task, particularly to the cases for which a priori problem dependent knowledge does not exist. If the user has no experience on scaling the control parameters of algorithm, automated environment created by this strategy eliminates the exhaustive trial-anderror based parameter tuning routine while easing the computational load burdened by this process. Global Best Algorithm adopts some basic encoding schemes of Differential Algorithm to construct a self-adaptation scheme to produce fruitful offspring individuals by maintaining a collective communication platform between population individuals. Global Best Algorithm mutually uses mutation strategies DE/best/1 (Storn, 1996) and DE/best/2 (Storn, 1996) those aim to exploit promising areas of the search domain and GBEST combines them into a single perturbation scheme in order to avoid premature convergence and sustain solution diversity. Mentioned mutation schemes can be formulated as

$$
\begin{aligned}
& \text { DE/best/1: } V_{i}=G_{\text {best }}+F \times\left(X_{r 1}-X_{r 2}\right) \\
& \text { DE/best/2: } V_{i}=G_{\text {best }}+F_{1} \times\left(X_{r 1}-X_{r 2}\right)+F_{2} \times\left(X_{r 3}-X_{r 4}\right)
\end{aligned}
$$

Indices $r_{1}, r_{2}, r_{3}, r_{4}$ are different from each other and defined in the range between 1 and $\mathrm{N}$. The parameter $\mathrm{F}$ is the scaling factor which determines the scale magnitude of difference between different mutated solution vectors. Different 
proposals have been made on assigning a value of this parameter. These proposed values varies between 0.5 to 1.2 (Storn and Price, 1997; Gamperle et al., 2002; Rönkkönen et al., 2005), however this parameter is set to a uniformly distributed Gaussian random number generated between 0.0 and 1.0 after comprehensive investigations on widely known constrained and unconstrained optimization benchmark problems. Traditional DE algorithm benefits from target vector $X_{i}=\left\{x_{i, 1}, x_{i, 2}, \ldots, x_{i, D}\right\}$ accompanied with the mutant vector $V_{i, j}=$ $\left\{v_{i, 1}, v_{i, 2}, \ldots, v_{i, D}\right\}$ to produce trial vector $U_{i}=\left\{u_{i, 1}, u_{i, 2}, \ldots, u_{i, D}\right\}$ by virtue of the crossover operation. Literature comprises two different types of crossover operators such as binomial (uniform) and exponential (two point modulus) operators. Between them, binomial operator is more applied one which is simply expressed by the below defined encoding scheme

$u_{i, j}=\left\{\begin{array}{cc}v_{i, j} & \text { if }(\operatorname{rand}(0,1) \leq C R) \|\left(j=j_{\text {rand }}\right), j=1,2, \ldots, D \\ x_{i, j} & \text { otherwise }\end{array}\right.$

In above equation, CR stands for the crossover probability that decides the number of decision variables those allowed to be transferred from mutant vector to trial vector; $j_{\text {rand }}$ is an integer valued algorithm parameter defined in the range $[1, N]$. It is also crucial to successfully define the relevant parameter tuning process of crossover probability (CR) in order to maintain diversity in the population. Although there has been made plenty of study those are related to giving a favourable value for CR for different kind of problems, it seems that there are no explicit compromise on assigning a suitable parameter value for CR according to the outcomes of the studies published by various researchers. Some studies (Storn, 1996; Storn and Price, 1997; Gamperle et al., 2002) claimed that assigning smaller values to $\mathrm{CR}$ could lead to higher convergence capabilities while some others asserted that $\mathrm{CR}=$ 0.1 is a plausible value to initialize encoding scheme. According to the previous studies dealing with the benchmark against great numbers of constrained and unconstrained optimization test functions, $C R \in(0.45,0.55)$ is set as an initial value for crossover probability.

Merits of the ensemble learning strategy was previously mentioned in above paragraphs. Ensemble learning demands using different mutation strategies along with their associated algorithm parameters for different optimization problems in order to sustain solution diversity as well as to maintain quick convergence. In the context of ensemble learning, the idea suggests that it would be beneficial to use various type of mutation strategies with complementary parameter settings rather than using a single mutation strategy as it has been traditionally implemented in a basic Differential Evolution algorithm. With the given advantages mentioned above, this strategy has become a hot-spot for researchers dealing with evolutionary algorithms (Qin et al., 2009; Gong et al., 2011; Jia et al., 2013). GBEST proposed a simple, but yet effective ensemble learning strategy with a below given procedure through which mutation strategies are assigned to population members

$$
\begin{gathered}
\text { for } i=1 \text { to } \mathrm{N} \\
\text { if }(i \% 2==0) \\
\text { Employ DE/best/1 } \\
\text { else }
\end{gathered}
$$

Employ DE/best/2

end

end

Where $\mathrm{N}$ is the population size; DE/best/1 and DE/best/2 are mutation schemes formulated respectively in Eq.(31) and Eq. (32). On the course of iterations, crossover probability (CR) and scaling factor (F) are adjusted by the self-adaptation scheme proposed by Brest et al. (2006) with a little modification into the usage of $F$. In this implementation procedure, $\mathrm{F}$ is set to uniformly distributed random number produced in the range $[0,1]$. As proposed in earlier sections, initial value of $C R \in(0.45,0.55)$ and the algorithm parameter $\sigma=\operatorname{rand}(0,1)$ are set and then a random number is generated between 0 and 1 . If the produced number's value is smaller than $\tau$, then a new CR value is reset in the range between 0.0 and 1.0 else CR remains same. Following this phase, boundary check and solution update mechanisms will be applied on the perturbed individuals. Population individuals those violated boundaries are restricted to their prescribed limits by the evolutionary boundary handling mechanism proposed by Gandomi and Yang (2012). This advantageous handling scheme benefits the virtues of the global best solution and formulated by the given procedure

$$
\begin{aligned}
& \text { for } j=1 \text { to } \mathrm{D} \\
& \text { if } x_{j}<\text { low }_{j} \\
& x_{j}=\operatorname{rand}_{1}(0,1) \times \operatorname{low}_{j}+\left(1-\operatorname{rand}_{1}(0,1)\right) \times G_{\text {best }, j} \\
& \text { else if } x_{j}>u p_{j} \\
& x_{j}=\operatorname{rand}_{2}(0,1) \times u p_{j}+\left(1-\operatorname{rand}_{2}(0,1)\right) \times G_{\text {best }, j}
\end{aligned}
$$

end

Where rand $(0,1)$ is uniformly distributed random number produced between 0 and 1 , Gest is the global best solution obtained over the undergoing iterations, low and up respectively symbolize the lower and upper bounds of the search span. Pseudo-code given in Table 2 will help readers to comprehend the whole process by summarizing the proposed algorithm in a nutshell. 
Table 2. Pseudo code of Global Best Algorithm

Initialize algorithm parameters

$f(x)$ : Optimization objective (D - dimensional )

$\mathrm{N}$ : Population size

low and up : Lower and upper bounds of the search space

Maxiter : Maximum number of iterations

$\mathrm{CR}$ and $\sigma$ : Crossover probability and its associated parameter

Initialize $X$ and $X_{\text {old }}$ populations randomly with the procedure given in Eq. (25)

Produce sequential chaotic numbers generated by the Logistic map formulated in Eq.(24)

Find the best solution vector $\left(\mathrm{G}_{\text {best }}\right.$ ) amongst the trial population of $\mathrm{X}_{\text {old }}$

Set iteration counter (iter) $=1$

While (iter < Maxiter)

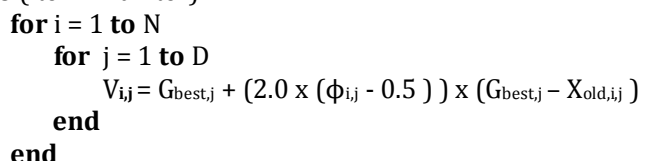

Apply boundary control mechanism given in Eq. (27)

Update $\mathrm{X}_{\text {old }}$ population with the sub-algorithm given in Eq.(28)

Perform randperm 0 function to generate new trial population $\left(\mathrm{X}_{\text {old2 }}\right)$

$\mathrm{X}_{\mathrm{old} 2}=$ randperm $\left(\mathrm{X}_{\text {old }}\right)$

Produce chaotic random numbers generated by Logistic map $\left(\phi_{2, \mathrm{i}, \mathrm{j}}\right)$

for $\mathrm{i}=1$ to $\mathrm{N}$

for $\mathrm{j}=1$ to $\mathrm{D}$

end

$\mathrm{X}=\mathrm{G}_{\text {best }, \mathrm{j}}+\left(2.0 \times\left(\phi_{2, \mathrm{i}, \mathrm{j}}-0.5\right)\right) \times\left(\mathrm{X}_{\mathrm{old}, \mathrm{i}, \mathrm{j}}-\mathrm{X}_{\mathrm{old} 2 \mathrm{i}, \mathrm{j}}\right)$

end

Apply boundary control mechanism given in Eq. (27)

Update $\mathrm{X}_{\text {old }}$ population with the sub-algorithm given in Eq.(28)

for $\mathrm{i}=1$ to $\mathrm{N}$

if ${\left.\operatorname{~} \operatorname{rand}_{1}(0,1)<\tau\right)}$

$\mathrm{CR}=\operatorname{rand}_{2}(0,1)$

end

Determine X population indices such that $i \neq r_{1} \neq r_{2} \neq r_{3} \neq r_{4}$

if $(\mathrm{i} \% 2==0)$

$\mathrm{j}_{\text {rand }}=\operatorname{randint}(1, \mathrm{D})$

for $\mathrm{j}=1$ to $\mathrm{D}$

$\mathrm{F}_{1}=\operatorname{rand}_{3}(0,1)$

if $\left(\operatorname{rand}_{4}(0,1)<C R\right) \|\left(j==j_{\text {rand }}\right)$

end

$X_{\text {trial, }, \mathrm{i}, \mathrm{j}}=\mathrm{G}_{\text {best }, \mathrm{j}}+\mathrm{F}_{1} \times\left(\mathrm{X}_{\mathrm{r} 1 \mathrm{j}}-\mathrm{X}_{\mathrm{r} 2, \mathrm{j}}\right)$

end

else

$\mathrm{j}_{\text {rand }}=\operatorname{randint}(1, \mathrm{D})$

for $\mathrm{j}=1$ to $\mathrm{D}$

$F_{1}=\operatorname{rand}_{5}(0,1), \quad F_{2}=\operatorname{rand}_{6}(0,1)$

if $\left(\operatorname{rand}_{7}(0,1)<C R\right) \|\left(j==\mathrm{j}_{\text {rand }}\right)$

$X_{\text {trial,i,j }}=G_{\text {best }, j}+F_{1} X\left(X_{r 1, j}-X_{r 2, j}\right)+F_{2} x\left(X_{r 3, j}-X_{r 4, j}\right)$

end

end

end

end

Practice evolutionary boundary constraint handling scheme given in Eq.(35)

Update $\mathrm{X}$ population with the new generated $\mathrm{X}_{\text {trial }}$

Update the chaotic sequences of $\varphi_{1}$ and $\varphi_{2}$

Copy the population members of $\mathrm{X}$ whose fitness values are better than tho se of $\mathrm{X}_{\text {old }}$

to $\mathrm{X}_{\text {old }}$ population

Determine the Gbest solution from $\mathrm{X}_{\text {old }}$ population

end

iter++

Output Gbest solution 


\section{Numerical benchmark on global best algorithm}

This section compares the optimization performance of the proposed GBEST by virtue of the well-respected, highly capable, and mostly metaheuristic optimizers of Backtracking Search Algorithm (BSA) [Civicioglu, 2013], Intelligent tuned Harmony Search (ITHS) (Yadav et al., 2012), Bat Algorithm (BAT) (Yang, 2010), Quantum behaved Particle Swarm Optimization (QPSO) (Sun et al., 2004a, b), Big Bang - Big Crunch Optimization (BB-BC) [Erol and Eksin, 2006], Differential Search Algorithm (DS) (Civicioglu, 2012), MothFlame Optimization (MOTH) (Mirjalili, 2015), Bird Mating Optimization (BMO) (Askerzadeh, 2014) and Multiverse Optimization Algorithm (MVO) (Mirjalili et al., 2016). Numerical experiments have been conducted on the Windows 764 bit laptop computer with Intel Core i7 3.8 Ghz and $16 \mathrm{~GB}$ RAM. Aforementioned optimizers have intrinsic features of their own and try to emulate nature inspired phenomena in order to find optimum solution of any optimization problem. For instance, BSA is a recently-developed optimization algorithm which is based on the merits of natural selection mechanisms mostly benefited in variety of evolutionary algorithms. These are namely selection, mutation and crossover mechanisms. This method has also a such advantageous feature that it has no control parameters to be tuned during the iterations. ITHS is an improved version of a famous optimization method of Harmony Search (Geem et al., 2013) which is constructed on the musical inspiration of the musician who seeks a favourable harmony by polishing the notes and pitches during the improvisation process. This algorithm contains harmony memory consideration rate (HMCR) control parameter with a view to benefit from the adjusted harmony memory members and this parameter is set to 0.95 for this optimization case. BAT is a nature inspired optimization method which is built on the echolocation behaviours of the micro-bats. It has several algorithm parameters to be tuned iteratively, including the loudness $A_{i}$ and the pulse emission rate $r_{i}$. These parameters have been respectively initialized as 1.5 and 0.5 . In addition, constants algorithm parameters $\alpha$ and $\gamma$ are fixed to 0.9. QPSO is a variant of well-known swarm intelligence based Particle Swarm
Optimization (PSO) (Kennedy and Eberhart, 1995) and developed on the aim of reaching the optimum solution on any optimization case by means of the dynamical quantum behaviour of the particles in the swarm population. It has few algorithm parameters those of which are constant and iteration dependent. Constant control parameters (social and cognitive factors) are set to 2.0. Iteratively changing adjustable parameter called contraction-expansion factor is initialized to 1.5 and descends to 0.5 on the course of iterations. BB-BC optimizer is mainly based on the propounded theories related to the evolution of the universe. Algorithm at hand inherits two different perturbation methods named after Big Bang and Big Crunch mechanisms. Big Bang phase is charged with generating random variables within predefined ranges while Big Crunch procedure is concerned with manipulating randomly defined individuals through the basic perturbation schemes. This method also has a few of algorithm parameters those are related to adjust the search space limits called $\alpha$ and $\beta$. These parameters are correspondingly set to 0.4 and 0.8 . DS algorithm successfully imitates the Brownian-like random movement of population individuals embarking on a migration in order to find more sustainable and fruitful habitats to live in. Algorithm has no adjustable parameter to be tuned. A relatively recent nature inspired optimization method called MOTH emulates the navigation strategy of the moths which can be simply called "transverse orientation". According to the results of the numerical experiments given in the reference study [60], the optimization performance of the MOTH is found to be satisfactory and has been utilized in this study as a benchmark optimizer. It is noteworthy to add that MOTH is a parameter-free optimization strategy and does not bother any kind of tedious parameter tuning process. BMO is inspired by the mating strategies of the bird species during the mating season and contains no tunable parameters. MVO is established on a three fundamental concepts of cosmology called white hole, black hole and worm hole which are respectively responsible for exploration, exploitation and local search. This optimizer does not contain any adjustable control parameter. 
Bitlis Eren University Journal of Science and Technology 7(1) (2017) 33-73

Table 3. Numerical formulations of the optimization benchmark functions

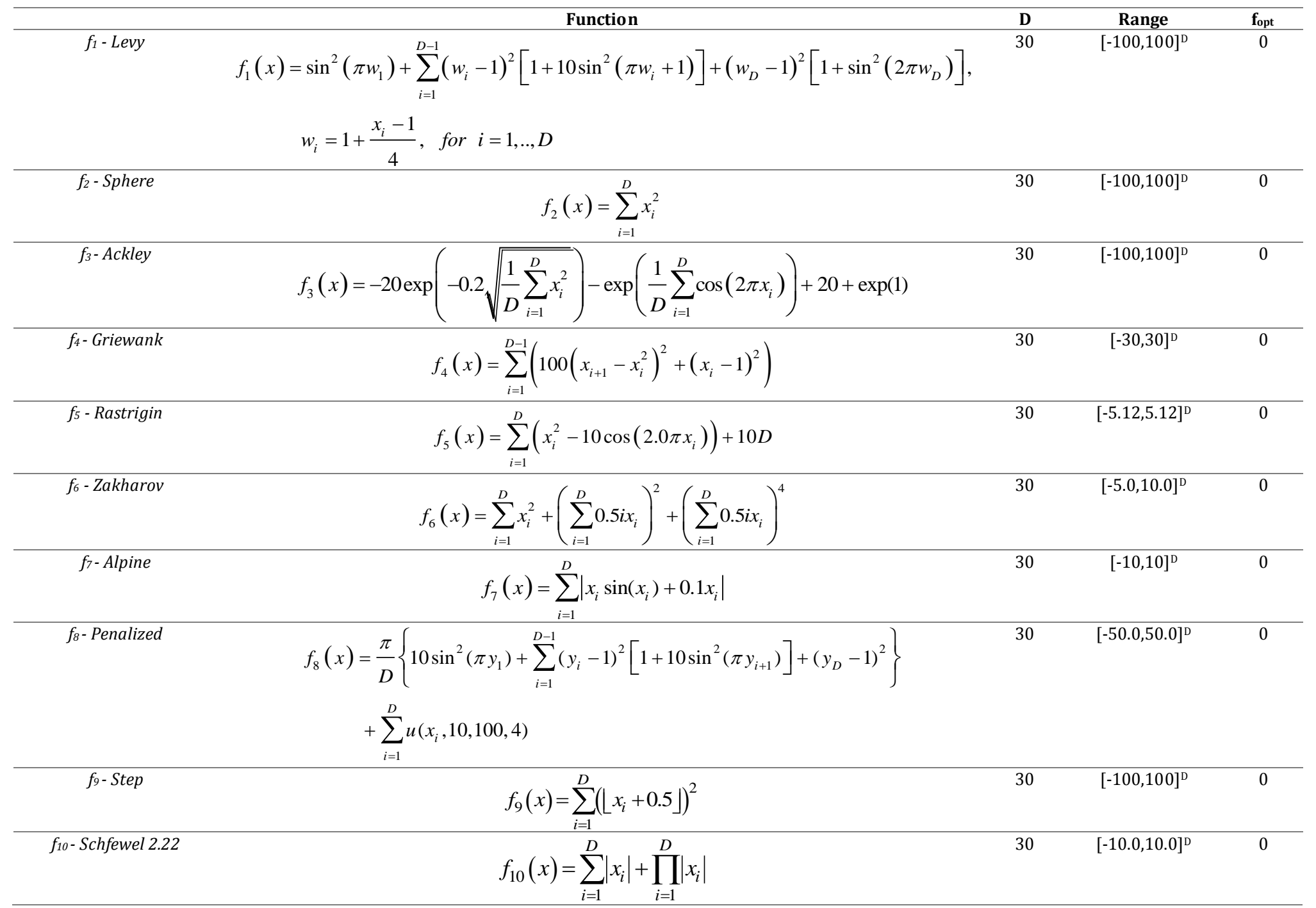




\begin{tabular}{|c|c|c|c|c|}
\hline$f_{11}-$ Brown & $f_{11}(x)=\sum_{i=1}^{D-1}\left(x_{i}^{2}\right)^{\left(x_{i}^{2}+1\right)}+\left(x_{i+1}^{2}\right)^{\left(x_{i}^{2}+1\right)}$ & 30 & {$[-1.0,4.0]^{\mathrm{D}}$} & 0 \\
\hline $\begin{array}{c}f_{12}-\text { Streched V Sine } \\
\text { Wave }\end{array}$ & $f_{12}(x)=\sum_{i=1}^{D-1}\left(x_{i+1}^{2}+x_{i}^{2}\right)^{0.25}\left[\sin ^{2}\left\{50\left(x_{i+1}^{2}+x_{i}^{2}\right)^{0.1}\right\}+0.1\right]$ & 30 & {$[-10.0,10.0]^{\mathrm{D}}$} & 0 \\
\hline$f_{13}-$ Quintic & $f_{13}(x)=\sum_{i=1}^{D}\left|x_{i}^{5}-3 x_{i}^{4}+4 x_{i}^{3}+2 x_{i}^{2}-10 x_{i}-4\right|$ & 30 & {$[-10.0,10.0]^{\mathrm{D}}$} & 0 \\
\hline$f_{14}-$ Powell Singular & $f_{14}(x)=\sum_{i=1}^{D-2}\left(x_{i-1}+10 x_{i}\right)^{2}+5\left(x_{i+1}-x_{i+2}\right)^{2}+\left(x_{i}-2 x_{i+1}\right)^{4}+10\left(x_{i-1}-x_{i+2}\right)^{4}$ & 30 & {$[-4.0,5.0]^{\mathrm{D}}$} & 0 \\
\hline$f_{15}-$ Csendes & $f_{15}(x)=\sum_{i=1}^{D} x_{i}^{6}\left(2+\frac{1}{\sin \left(x_{i}\right)}\right)$ & 30 & {$[-1.0,1.0]^{\mathrm{D}}$} & 0 \\
\hline$f_{16}-$ Schaffer & $f_{16}(x)=\sum_{i=1}^{D} 0.5+\frac{\sin ^{2}\left(\sqrt{x_{i}^{2}+x_{i+1}^{2}}\right)-0.5}{\left[1+0.001\left(x_{i}^{2}+x_{i+1}^{2}\right)\right]^{2}}$ & 30 & {$[-100.0,100.0]^{\mathrm{D}}$} & 0 \\
\hline
\end{tabular}


Table 4. Statistical results of the optimization algorithms

\begin{tabular}{|c|c|c|c|c|}
\hline & Best & Std.dev. & Mean & Worst \\
\hline \multicolumn{5}{|l|}{$f_{1}$ Levy } \\
\hline GBEST & 3.86E-09 & $1.54 \mathrm{E}-09$ & $4.61 \mathrm{E}-09$ & $1.02 \mathrm{E}-08$ \\
\hline BSA & $9.14 \mathrm{E}-09$ & $1.24 \mathrm{E}-08$ & 2.19E-08 & $5.77 \mathrm{E}-08$ \\
\hline ITHS & $5.09 \mathrm{E}-03$ & 2.32E-02 & 2.77E-02 & $9.34 \mathrm{E}-02$ \\
\hline BAT & 3.73E-05 & $2.08 \mathrm{E}+01$ & $2.04 \mathrm{E}+01$ & $6.71 \mathrm{E}+01$ \\
\hline QPSO & $7.26 \mathrm{E}+00$ & $5.45 \mathrm{E}+00$ & $1.43 \mathrm{E}+01$ & $3.23 \mathrm{E}+01$ \\
\hline BBBC & $2.36 \mathrm{E}+01$ & $8.85 E+00$ & $4.09 \mathrm{E}+01$ & $6.54 \mathrm{E}+01$ \\
\hline DS & $1.10 \mathrm{E}+01$ & $5.17 \mathrm{E}+00$ & $2.03 E+01$ & $3.15 E+01$ \\
\hline MOTH & $4.06 \mathrm{E}+00$ & $3.61 \mathrm{E}+00$ & $9.84 \mathrm{E}+00$ & $1.64 \mathrm{E}+01$ \\
\hline BMO & $2.32 \mathrm{E}-01$ & $6.15 \mathrm{E}+00$ & $5.07 \mathrm{E}+00$ & $2.92 \mathrm{E}+01$ \\
\hline MVO & $9.23 \mathrm{E}-05$ & $4.18 \mathrm{E}+00$ & $4.45 \mathrm{E}+00$ & $1.83 \mathrm{E}+01$ \\
\hline \multicolumn{5}{|c|}{$f_{2}$ Sphere } \\
\hline GBEST & $0.00 \mathrm{E}+00$ & $2.15 \mathrm{E}-12$ & $9.75 E-13$ & 8.57E-12 \\
\hline BSA & $7.77 \mathrm{E}-10$ & 2.71E-09 & $4.45 \mathrm{E}-09$ & $1.11 \mathrm{E}-08$ \\
\hline ITHS & $3.90 \mathrm{E}-05$ & $4.34 \mathrm{E}-02$ & $4.20 \mathrm{E}-02$ & 2.32E-01 \\
\hline BAT & $2.91 \mathrm{E}-05$ & $3.24 \mathrm{E}+00$ & $4.89 \mathrm{E}+00$ & $1.10 \mathrm{E}+01$ \\
\hline QPSO & $6.08 \mathrm{E}+00$ & $5.07 \mathrm{E}+00$ & $1.25 \mathrm{E}+01$ & $2.23 \mathrm{E}+01$ \\
\hline BBBC & $8.60 \mathrm{E}-05$ & $1.78 \mathrm{E}-05$ & $1.29 \mathrm{E}-04$ & $1.65 \mathrm{E}-04$ \\
\hline DS & $9.28 \mathrm{E}+00$ & $4.79 \mathrm{E}+00$ & $1.87 \mathrm{E}+01$ & $2.95 \mathrm{E}+01$ \\
\hline MOTH & $1.21 \mathrm{E}-19$ & $2.68 \mathrm{E}-09$ & $8.10 \mathrm{E}-10$ & $9.71 \mathrm{E}-09$ \\
\hline BMO & $1.68 \mathrm{E}-03$ & $1.99 \mathrm{E}-02$ & $1.43 \mathrm{E}-02$ & 1.19E-01 \\
\hline MVO & $3.16 \mathrm{E}-05$ & $1.86 \mathrm{E}-05$ & $6.12 \mathrm{E}-05$ & $1.20 \mathrm{E}-04$ \\
\hline \multicolumn{5}{|c|}{$f_{3}$ Ackley } \\
\hline GBEST & $4.44 \mathrm{E}-16$ & 4.06E-08 & $4.24 \mathrm{E}-08$ & $9.94 \mathrm{E}-08$ \\
\hline BSA & $1.06 \mathrm{E}-07$ & $1.73 \mathrm{E}-07$ & $3.05 \mathrm{E}-07$ & $8.76 \mathrm{E}-07$ \\
\hline ITHS & $8.64 \mathrm{E}-04$ & $4.68 \mathrm{E}-02$ & 7.02E-02 & 2.37E-01 \\
\hline BAT & $1.72 \mathrm{E}+01$ & $7.28 \mathrm{E}-01$ & $1.97 \mathrm{E}+01$ & $2.10 \mathrm{E}+01$ \\
\hline QPSO & $3.77 \mathrm{E}+00$ & $2.65 \mathrm{E}+00$ & $8.60 \mathrm{E}+00$ & $1.31 \mathrm{E}+01$ \\
\hline BBBC & $3.12 \mathrm{E}-02$ & $4.14 \mathrm{E}-03$ & $3.94 \mathrm{E}-02$ & $4.72 \mathrm{E}-02$ \\
\hline DS & $9.29 \mathrm{E}+00$ & $1.13 \mathrm{E}+00$ & $1.17 \mathrm{E}+01$ & $1.35 \mathrm{E}+01$ \\
\hline MOTH & $3.41 \mathrm{E}-13$ & $1.03 \mathrm{E}-11$ & $6.09 \mathrm{E}-12$ & $3.47 \mathrm{E}-11$ \\
\hline BMO & $1.35 \mathrm{E}-02$ & $6.32 \mathrm{E}-02$ & $1.05 \mathrm{E}-01$ & $3.24 \mathrm{E}-01$ \\
\hline MVO & $1.29 \mathrm{E}-02$ & $3.40 \mathrm{E}-03$ & $1.91 \mathrm{E}-02$ & $3.00 \mathrm{E}-02$ \\
\hline \multicolumn{5}{|c|}{$f_{4}$ Griewank } \\
\hline GBEST & $0.00 \mathrm{E}+00$ & $2.46 \mathrm{E}-13$ & $1.18 \mathrm{E}-13$ & $1.00 \mathrm{E}-12$ \\
\hline BSA & 1.23E-09 & 4.07E-08 & $2.98 \mathrm{E}-08$ & $1.81 \mathrm{E}-07$ \\
\hline ITHS & 2.39E-06 & $1.71 \mathrm{E}-02$ & $8.48 \mathrm{E}-03$ & $6.22 \mathrm{E}-02$ \\
\hline BAT & $7.78 \mathrm{E}-01$ & $5.62 \mathrm{E}-02$ & $1.03 \mathrm{E}+00$ & $1.08 \mathrm{E}+00$ \\
\hline QPSO & $2.56 \mathrm{E}-01$ & $2.01 \mathrm{E}-01$ & $8.08 \mathrm{E}-01$ & $1.02 \mathrm{E}+00$ \\
\hline $\mathrm{BBBC}$ & $1.86 \mathrm{E}-05$ & $1.42 \mathrm{E}-02$ & $1.13 \mathrm{E}-02$ & 6.72E-02 \\
\hline DS & $9.48 \mathrm{E}-01$ & $2.26 \mathrm{E}-02$ & $9.88 \mathrm{E}-01$ & $1.01 \mathrm{E}+00$ \\
\hline MOTH & $3.51 \mathrm{E}-14$ & $1.62 \mathrm{E}-01$ & $4.92 \mathrm{E}-02$ & $6.99 \mathrm{E}-01$ \\
\hline BMO & $5.14 \mathrm{E}-04$ & $1.09 \mathrm{E}-02$ & $1.38 \mathrm{E}-02$ & $5.71 \mathrm{E}-02$ \\
\hline MVO & $1.52 \mathrm{E}-05$ & $9.11 \mathrm{E}-03$ & $6.46 \mathrm{E}-03$ & $3.44 \mathrm{E}-02$ \\
\hline \multicolumn{5}{|c|}{$f_{5}$ Rastrigin } \\
\hline GBEST & $0.00 \mathrm{E}+00$ & 9.87E-08 & $3.42 \mathrm{E}-08$ & $3.45 \mathrm{E}-07$ \\
\hline BSA & $2.36 \mathrm{E}-09$ & 9.97E-08 & $4.90 \mathrm{E}-08$ & $4.81 \mathrm{E}-07$ \\
\hline ITHS & $1.72 \mathrm{E}-01$ & $2.22 \mathrm{E}+01$ & $2.72 \mathrm{E}+01$ & $6.79 \mathrm{E}+01$ \\
\hline BAT & $1.05 \mathrm{E}+02$ & $4.44 \mathrm{E}+01$ & $1.98 \mathrm{E}+02$ & $2.85 \mathrm{E}+02$ \\
\hline QPSO & $5.31 \mathrm{E}+01$ & $2.10 \mathrm{E}+01$ & $8.51 \mathrm{E}+01$ & $1.30 \mathrm{E}+02$ \\
\hline BBBC & $1.30 \mathrm{E}+02$ & $5.01 \mathrm{E}+01$ & $2.13 \mathrm{E}+02$ & $3.36 \mathrm{E}+02$ \\
\hline DS & $1.44 \mathrm{E}+02$ & $1.62 \mathrm{E}+01$ & $1.90 \mathrm{E}+02$ & $2.14 \mathrm{E}+02$ \\
\hline MOTH & $3.18 \mathrm{E}+01$ & $1.43 \mathrm{E}+01$ & $7.35 \mathrm{E}+01$ & $9.01 \mathrm{E}+01$ \\
\hline BMO & $4.93 \mathrm{E}+01$ & $2.57 \mathrm{E}+01$ & $1.03 \mathrm{E}+02$ & $1.56 \mathrm{E}+02$ \\
\hline MVO & $3.98 \mathrm{E}+01$ & $1.68 \mathrm{E}+01$ & $7.72 \mathrm{E}+01$ & $1.07 \mathrm{E}+02$ \\
\hline \multicolumn{5}{|c|}{$f_{6}$ Zakharov } \\
\hline GBEST & $0.00 \mathrm{E}+00$ & 9.09E-07 & $3.32 \mathrm{E}-07$ & $4.70 \mathrm{E}-06$ \\
\hline BSA & $1.48 \mathrm{E}+02$ & $3.32 \mathrm{E}+01$ & $2.20 \mathrm{E}+02$ & $2.68 \mathrm{E}+02$ \\
\hline
\end{tabular}




\begin{tabular}{|c|c|c|c|c|}
\hline ITHS & $1.92 \mathrm{E}-05$ & $6.52 \mathrm{E}-02$ & 3.55E-02 & $3.56 \mathrm{E}-01$ \\
\hline BAT & $3.83 \mathrm{E}+01$ & $1.37 \mathrm{E}+06$ & $7.16 \mathrm{E}+05$ & $5.97 \mathrm{E}+06$ \\
\hline QPSO & $1.40 \mathrm{E}+01$ & $3.91 \mathrm{E}+01$ & $6.81 \mathrm{E}+01$ & $1.95 \mathrm{E}+02$ \\
\hline $\mathrm{BBBC}$ & $1.54 \mathrm{E}+02$ & $7.56 \mathrm{E}+01$ & $2.81 \mathrm{E}+02$ & $4.55 \mathrm{E}+02$ \\
\hline DS & $3.08 \mathrm{E}+01$ & $1.81 \mathrm{E}+01$ & $6.36 \mathrm{E}+01$ & $1.01 \mathrm{E}+02$ \\
\hline MOTH & 1.79E-08 & 1.98E-02 & 5.18E-03 & $8.70 \mathrm{E}-02$ \\
\hline BMO & $1.20 \mathrm{E}-01$ & 5.99E-01 & 8.79E-01 & $2.97 \mathrm{E}+00$ \\
\hline MVO & $2.87 \mathrm{E}-04$ & $2.89 \mathrm{E}-04$ & 7.99E-04 & $1.50 \mathrm{E}-03$ \\
\hline \multicolumn{5}{|c|}{$f_{7}$ Alpine } \\
\hline GBEST & $0.00 \mathrm{E}+00$ & 9.87E-08 & $3.42 \mathrm{E}-08$ & $3.45 \mathrm{E}-07$ \\
\hline BSA & 1.10E-03 & $6.76 \mathrm{E}-04$ & $2.18 \mathrm{E}-03$ & $3.43 \mathrm{E}-03$ \\
\hline ITHS & 2.23E-03 & 2.67E-01 & 1.17E-01 & $1.22 \mathrm{E}+00$ \\
\hline BAT & $8.08 \mathrm{E}+00$ & $6.53 E+00$ & $1.78 \mathrm{E}+01$ & $3.29 \mathrm{E}+01$ \\
\hline QPSO & $1.14 \mathrm{E}+00$ & $1.70 \mathrm{E}+00$ & $4.02 \mathrm{E}+00$ & $6.76 \mathrm{E}+00$ \\
\hline $\mathrm{BBBC}$ & $2.92 \mathrm{E}+00$ & $3.67 \mathrm{E}+00$ & $8.88 \mathrm{E}+00$ & $1.64 \mathrm{E}+01$ \\
\hline DS & $1.20 \mathrm{E}+01$ & $2.31 \mathrm{E}+00$ & $1.72 \mathrm{E}+01$ & $2.20 \mathrm{E}+01$ \\
\hline MOTH & $2.41 \mathrm{E}-14$ & $5.55 \mathrm{E}-07$ & 2.43E-07 & $1.97 \mathrm{E}-06$ \\
\hline BMO & $1.52 \mathrm{E}+00$ & $2.91 \mathrm{E}+00$ & $5.49 \mathrm{E}+00$ & $1.29 \mathrm{E}+00$ \\
\hline MVO & $4.02 \mathrm{E}-01$ & $1.22 \mathrm{E}+00$ & $1.64 \mathrm{E}+00$ & $6.60 \mathrm{E}+00$ \\
\hline \multicolumn{5}{|c|}{$f_{8}$ Penalized1 } \\
\hline GBEST & 9.01E-11 & $1.11 \mathrm{E}-14$ & $9.01 \mathrm{E}-11$ & $9.01 \mathrm{E}-11$ \\
\hline BSA & $1.45 \mathrm{E}-10$ & $1.46 \mathrm{E}-10$ & $3.35 \mathrm{E}-10$ & $6.69 \mathrm{E}-10$ \\
\hline ITHS & 4.07E-07 & $2.33 \mathrm{E}-04$ & $2.19 \mathrm{E}-04$ & $7.05 \mathrm{E}-04$ \\
\hline BAT & 4.53E-03 & $3.26 \mathrm{E}-01$ & $7.22 \mathrm{E}-01$ & $1.43 \mathrm{E}+00$ \\
\hline QPSO & $3.62 \mathrm{E}-02$ & $2.03 \mathrm{E}-01$ & $3.30 \mathrm{E}-01$ & 8.82E-01 \\
\hline $\mathrm{BBBC}$ & 9.92E-02 & $3.50 \mathrm{E}-01$ & 7.49E-01 & $1.36 \mathrm{E}+00$ \\
\hline DS & 2.19E-01 & $2.38 \mathrm{E}-01$ & $6.14 \mathrm{E}-01$ & $1.26 \mathrm{E}+00$ \\
\hline MOTH & 9.01E-11 & $1.34 \mathrm{E}-14$ & $9.01 \mathrm{E}-11$ & $9.02 \mathrm{E}-11$ \\
\hline BMO & $1.64 \mathrm{E}-05$ & $2.71 \mathrm{E}-02$ & 7.03E-03 & $1.34 \mathrm{E}-01$ \\
\hline MVO & $1.35 \mathrm{E}-06$ & $7.52 \mathrm{E}-07$ & $2.15 \mathrm{E}-06$ & $3.97 \mathrm{E}-06$ \\
\hline \multicolumn{5}{|l|}{$f_{9}$ Step } \\
\hline GBEST & $3.62 \mathrm{E}-14$ & $4.21 \mathrm{E}-11$ & $1.76 \mathrm{E}-11$ & $1.60 \mathrm{E}-10$ \\
\hline BSA & $3.36 \mathrm{E}-09$ & 8.13E-09 & $1.75 \mathrm{E}-08$ & $4.07 \mathrm{E}-08$ \\
\hline ITHS & 3.92E-05 & 1.19E-02 & 9.69E-03 & 7.92E-02 \\
\hline BAT & $1.37 \mathrm{E}-05$ & $3.24 \mathrm{E}+00$ & $3.19 \mathrm{E}+00$ & $1.23 \mathrm{E}+01$ \\
\hline QPSO & $2.39 \mathrm{E}+00$ & $8.47 E+00$ & $1.52 \mathrm{E}+01$ & $4.06 \mathrm{E}+01$ \\
\hline BBBC & $8.72 \mathrm{E}-05$ & 1.53E-05 & $1.23 \mathrm{E}-04$ & $1.75 \mathrm{E}-04$ \\
\hline DS & $8.26 \mathrm{E}+00$ & $5.34 \mathrm{E}+00$ & $1.75 \mathrm{E}+01$ & $3.08 \mathrm{E}+01$ \\
\hline MOTH & 1.98E-19 & $7.08 \mathrm{E}-05$ & $2.05 \mathrm{E}-05$ & $2.65 \mathrm{E}-04$ \\
\hline BMO & $9.47 \mathrm{E}-04$ & $2.08 \mathrm{E}-02$ & $1.58 \mathrm{E}-02$ & $9.75 \mathrm{E}-02$ \\
\hline MVO & $2.27 \mathrm{E}-05$ & $1.74 \mathrm{E}-05$ & $5.54 \mathrm{E}-05$ & $1.05 \mathrm{E}-04$ \\
\hline \multicolumn{5}{|c|}{$f_{10}$ Schwefel 2.22} \\
\hline GBEST & $0.00 \mathrm{E}+00$ & 8.27E-07 & 4.03E-07 & $3.83 \mathrm{E}-06$ \\
\hline BSA & 6.63E-05 & $2.70 \mathrm{E}-05$ & $1.00 \mathrm{E}-04$ & $1.69 \mathrm{E}-04$ \\
\hline ITHS & $4.42 \mathrm{E}-02$ & 4.17E-01 & 7.53E-01 & $1.94 \mathrm{E}+00$ \\
\hline BAT & $8.05 \mathrm{E}+01$ & $2.12 \mathrm{E}+06$ & $1.31 \mathrm{E}+06$ & $9.75 \mathrm{E}+06$ \\
\hline QPSO & $8.81 \mathrm{E}+00$ & $7.86 \mathrm{E}+00$ & $2.38 \mathrm{E}+01$ & $3.69 \mathrm{E}+01$ \\
\hline BBBC & $4.30 \mathrm{E}+01$ & $5.19 \mathrm{E}+03$ & $1.79 \mathrm{E}+03$ & $2.21 \mathrm{E}+04$ \\
\hline DS & $1.77 \mathrm{E}+01$ & $6.04 \mathrm{E}+00$ & $3.04 \mathrm{E}+01$ & $4.07 \mathrm{E}+01$ \\
\hline MOTH & $5.43 \mathrm{E}-13$ & $2.19 \mathrm{E}-05$ & $6.13 \mathrm{E}-06$ & $8.53 \mathrm{E}-05$ \\
\hline BMO & $3.22 \mathrm{E}-01$ & $4.74 \mathrm{E}+00$ & $1.99 \mathrm{E}+00$ & $3.74 \mathrm{E}+01$ \\
\hline MVO & 7.77E-02 & 5.09E-02 & $1.48 \mathrm{E}-01$ & $2.95 \mathrm{E}-01$ \\
\hline \multicolumn{5}{|c|}{$f_{11}$ Brown } \\
\hline GBEST & $0.00 \mathrm{E}+00$ & $1.62 \mathrm{E}-10$ & $6.28 \mathrm{E}-11$ & $5.81 \mathrm{E}-10$ \\
\hline BSA & $5.22 \mathrm{E}-08$ & $9.45 \mathrm{E}-02$ & $7.76 \mathrm{E}-02$ & $3.42 \mathrm{E}-01$ \\
\hline ITHS & $4.11 \mathrm{E}-04$ & $8.20 \mathrm{E}-02$ & 1.11E-01 & $3.53 \mathrm{E}-01$ \\
\hline BAT & $5.03 E+03$ & $1.56 \mathrm{E}+28$ & $5.45 \mathrm{E}+27$ & $6.40 \mathrm{E}+28$ \\
\hline QPSO & $1.38 \mathrm{E}+02$ & $3.62 \mathrm{E}+05$ & $1.02 \mathrm{E}+05$ & $1.40 \mathrm{E}+06$ \\
\hline BBBC & $9.73 \mathrm{E}-02$ & $2.33 E+06$ & $6.72 \mathrm{E}+05$ & $1.11 \mathrm{E}+06$ \\
\hline DS & $7.20 \mathrm{E}+01$ & $5.72 \mathrm{E}+06$ & $1.51 \mathrm{E}+06$ & $3.60 \mathrm{E}+07$ \\
\hline MOTH & $2.11 \mathrm{E}-16$ & $6.66 \mathrm{E}-08$ & $2.04 \mathrm{E}-08$ & $2.51 \mathrm{E}-07$ \\
\hline
\end{tabular}




\begin{tabular}{|c|c|c|c|c|}
\hline BMO & $6.15 \mathrm{E}-02$ & $5.91 \mathrm{E}-02$ & 7.78E-01 & $2.29 \mathrm{E}+00$ \\
\hline MVO & $1.72 \mathrm{E}-04$ & $1.91 \mathrm{E}-04$ & $4.86 \mathrm{E}-04$ & $9.22 \mathrm{E}-04$ \\
\hline \multicolumn{5}{|c|}{$f_{12}$ Streched V Sine Wave } \\
\hline GBEST & 1.53E-21 & $6.02 \mathrm{E}-03$ & $4.43 \mathrm{E}-03$ & $1.53 \mathrm{E}-02$ \\
\hline BSA & $2.15 \mathrm{E}+00$ & $5.05 \mathrm{E}+00$ & $6.95 E+00$ & $2.07 \mathrm{E}+01$ \\
\hline ITHS & $1.69 \mathrm{E}+00$ & $4.22 \mathrm{E}+00$ & $9.31 \mathrm{E}+00$ & $2.38 \mathrm{E}+01$ \\
\hline BAT & $5.78 \mathrm{E}+01$ & $6.86 \mathrm{E}+00$ & $7.35 \mathrm{E}+01$ & $8.61 \mathrm{E}+01$ \\
\hline QPSO & $3.13 E+01$ & $5.50 \mathrm{E}+00$ & $4.18 \mathrm{E}+01$ & $5.18 \mathrm{E}+01$ \\
\hline BBBC & $1.08 \mathrm{E}+02$ & $7.45 \mathrm{E}-04$ & $1.08 \mathrm{E}+02$ & $1.08 \mathrm{E}+02$ \\
\hline DS & $4.49 \mathrm{E}+01$ & $1.64 \mathrm{E}+00$ & $4.82 \mathrm{E}+01$ & $5.14 \mathrm{E}+01$ \\
\hline MOTH & $3.35 \mathrm{E}+01$ & $7.17 \mathrm{E}+00$ & $4.35 \mathrm{E}+01$ & $5.32 \mathrm{E}+01$ \\
\hline BMO & $3.94 \mathrm{E}+01$ & $8.59 \mathrm{E}+00$ & $5.74 \mathrm{E}+01$ & $7.18 \mathrm{E}+01$ \\
\hline MVO & $1.55 \mathrm{E}+01$ & $6.35 \mathrm{E}+00$ & $2.52 \mathrm{E}+01$ & $3.88 \mathrm{E}+01$ \\
\hline \multicolumn{5}{|c|}{$f_{13}$ Quintic } \\
\hline GBEST & 9.79E-13 & $3.26 \mathrm{E}-04$ & $1.05 \mathrm{E}-04$ & $1.44 \mathrm{E}-03$ \\
\hline BSA & $1.03 \mathrm{E}-01$ & $1.07 \mathrm{E}+01$ & $5.38 \mathrm{E}+00$ & $8.49 E+01$ \\
\hline ITHS & $1.66 \mathrm{E}-06$ & $1.84 \mathrm{E}+01$ & $1.23 \mathrm{E}+01$ & $7.34 \mathrm{E}+01$ \\
\hline BAT & $3.34 \mathrm{E}+01$ & $7.80 \mathrm{E}+03$ & $1.35 \mathrm{E}+04$ & $3.83 E+05$ \\
\hline QPSO & $1.86 \mathrm{E}+02$ & $2.76 \mathrm{E}+03$ & $2.82 \mathrm{E}+03$ & $1.08 \mathrm{E}+04$ \\
\hline BBBC & $2.78 \mathrm{E}+00$ & $1.16 \mathrm{E}+01$ & $2.15 E+01$ & $5.09 \mathrm{E}+01$ \\
\hline DS & $1.18 \mathrm{E}+02$ & $4.76 \mathrm{E}+02$ & $7.91 \mathrm{E}+02$ & $2.05 E+03$ \\
\hline MOTH & $5.65 \mathrm{E}-11$ & $4.17 \mathrm{E}-05$ & $1.56 \mathrm{E}-05$ & $2.06 \mathrm{E}-04$ \\
\hline BMO & $4.73 \mathrm{E}+00$ & $7.13 \mathrm{E}+00$ & $1.42 \mathrm{E}+01$ & $3.67 \mathrm{E}+01$ \\
\hline MVO & $3.08 \mathrm{E}+00$ & $4.86 \mathrm{E}+00$ & $9.12 \mathrm{E}+00$ & $2.52 \mathrm{E}+01$ \\
\hline \multicolumn{5}{|c|}{$f_{14}$ Powell Singular } \\
\hline GBEST & 9.98E-13 & $1.64 \mathrm{E}-05$ & $8.87 \mathrm{E}-06$ & $5.78 \mathrm{E}-05$ \\
\hline BSA & $1.10 \mathrm{E}-04$ & $2.59 \mathrm{E}-04$ & $5.47 \mathrm{E}-04$ & $1.20 \mathrm{E}-03$ \\
\hline ITHS & 3.30E-02 & $6.65 E+00$ & $7.93 E+00$ & $3.15 E+01$ \\
\hline BAT & $4.11 \mathrm{E}+03$ & $1.09 \mathrm{E}+05$ & $1.94 \mathrm{E}+05$ & $5.51 \mathrm{E}+05$ \\
\hline QPSO & $5.64 \mathrm{E}+03$ & $1.19 \mathrm{E}+04$ & $2.51 \mathrm{E}+04$ & $5.17 \mathrm{E}+04$ \\
\hline BBBC & $6.68 \mathrm{E}-02$ & $4.06 \mathrm{E}+02$ & $1.37 E+02$ & $2.16 \mathrm{E}+03$ \\
\hline DS & $7.05 E+03$ & $9.49 \mathrm{E}+03$ & $2.35 \mathrm{E}+04$ & $5.47 \mathrm{E}+04$ \\
\hline MOTH & $1.86 \mathrm{E}-07$ & $9.48 \mathrm{E}-05$ & $2.86 \mathrm{E}-05$ & $4.67 \mathrm{E}-04$ \\
\hline BMO & $9.89 \mathrm{E}-01$ & $3.97 \mathrm{E}+01$ & $2.18 \mathrm{E}+01$ & $3.25 E+02$ \\
\hline MVO & $4.02 \mathrm{E}-01$ & $1.13 \mathrm{E}-01$ & $1.68 \mathrm{E}-01$ & $5.04 \mathrm{E}-01$ \\
\hline \multicolumn{5}{|c|}{$f_{15}$ Csendes } \\
\hline GBEST & $2.44 \mathrm{E}-40$ & $9.12 \mathrm{E}-13$ & $2.37 \mathrm{E}-13$ & $3.77 \mathrm{E}-12$ \\
\hline BSA & $1.64 \mathrm{E}-23$ & $5.41 \mathrm{E}-05$ & $1.06 \mathrm{E}-05$ & $5.33 \mathrm{E}-04$ \\
\hline ITHS & $2.39 \mathrm{E}-15$ & $1.85 \mathrm{E}-05$ & $8.24 \mathrm{E}-06$ & $9.47 \mathrm{E}-05$ \\
\hline BAT & $7.38 \mathrm{E}+01$ & $7.13 \mathrm{E}+04$ & $1.30 \mathrm{E}+05$ & $2.82 E+05$ \\
\hline QPSO & $1.74 \mathrm{E}+02$ & $2.06 \mathrm{E}+04$ & $1.74 \mathrm{E}+04$ & $1.05 E+05$ \\
\hline BBBC & $9.28 \mathrm{E}-13$ & $1.77 \mathrm{E}-01$ & $3.20 \mathrm{E}-02$ & $1.09 \mathrm{E}+00$ \\
\hline DS & $5.81 \mathrm{E}+02$ & $3.94 \mathrm{E}+03$ & $4.91 \mathrm{E}+03$ & $1.84 \mathrm{E}+04$ \\
\hline MOTH & $2.47 \mathrm{E}-08$ & $9.66 \mathrm{E}+00$ & $1.93 \mathrm{E}+00$ & $5.02 \mathrm{E}+01$ \\
\hline BMO & $3.51 \mathrm{E}-06$ & $2.42 \mathrm{E}-03$ & $1.32 \mathrm{E}-03$ & $1.29 \mathrm{E}-02$ \\
\hline MVO & $1.45 \mathrm{E}-13$ & $1.49 \mathrm{E}-10$ & $6.71 \mathrm{E}-11$ & $5.99 \mathrm{E}-10$ \\
\hline \multicolumn{5}{|c|}{$f_{16}$ Schaffer } \\
\hline GBEST & $0.00 \mathrm{E}+00$ & $4.65 \mathrm{E}-03$ & $6.22 \mathrm{E}-03$ & $9.71 \mathrm{E}-03$ \\
\hline BSA & $9.71 \mathrm{E}-03$ & $3.57 \mathrm{E}-02$ & $4.48 \mathrm{E}-02$ & $1.26 \mathrm{E}-01$ \\
\hline ITHS & $9.71 \mathrm{E}-03$ & $1.54 \mathrm{E}-02$ & $2.09 \mathrm{E}-02$ & 7.81E-02 \\
\hline BAT & 4.69E-02 & $1.80 \mathrm{E}-02$ & $9.70 \mathrm{E}-02$ & $1.78 \mathrm{E}-02$ \\
\hline QPSO & $6.20 \mathrm{E}-03$ & $5.50 \mathrm{E}-03$ & $1.59 \mathrm{E}-02$ & $2.81 \mathrm{E}-02$ \\
\hline BBBC & $7.13 \mathrm{E}-02$ & $2.47 \mathrm{E}-02$ & $1.25 \mathrm{E}-01$ & $1.70 \mathrm{E}-01$ \\
\hline DS & $3.72 \mathrm{E}-02$ & $6.93 \mathrm{E}-17$ & $3.72 \mathrm{E}-02$ & $3.72 \mathrm{E}-02$ \\
\hline MOTH & 2.39E-02 & 7.31E-03 & $4.19 \mathrm{E}-02$ & 6.19E-02 \\
\hline BMO & $1.10 \mathrm{E}-02$ & $4.09 \mathrm{E}-03$ & $1.93 \mathrm{E}-02$ & $2.71 \mathrm{E}-02$ \\
\hline MVO & $3.12 \mathrm{E}-03$ & $7.65 \mathrm{E}-04$ & $3.78 \mathrm{E}-03$ & $4.66 \mathrm{E}-03$ \\
\hline
\end{tabular}



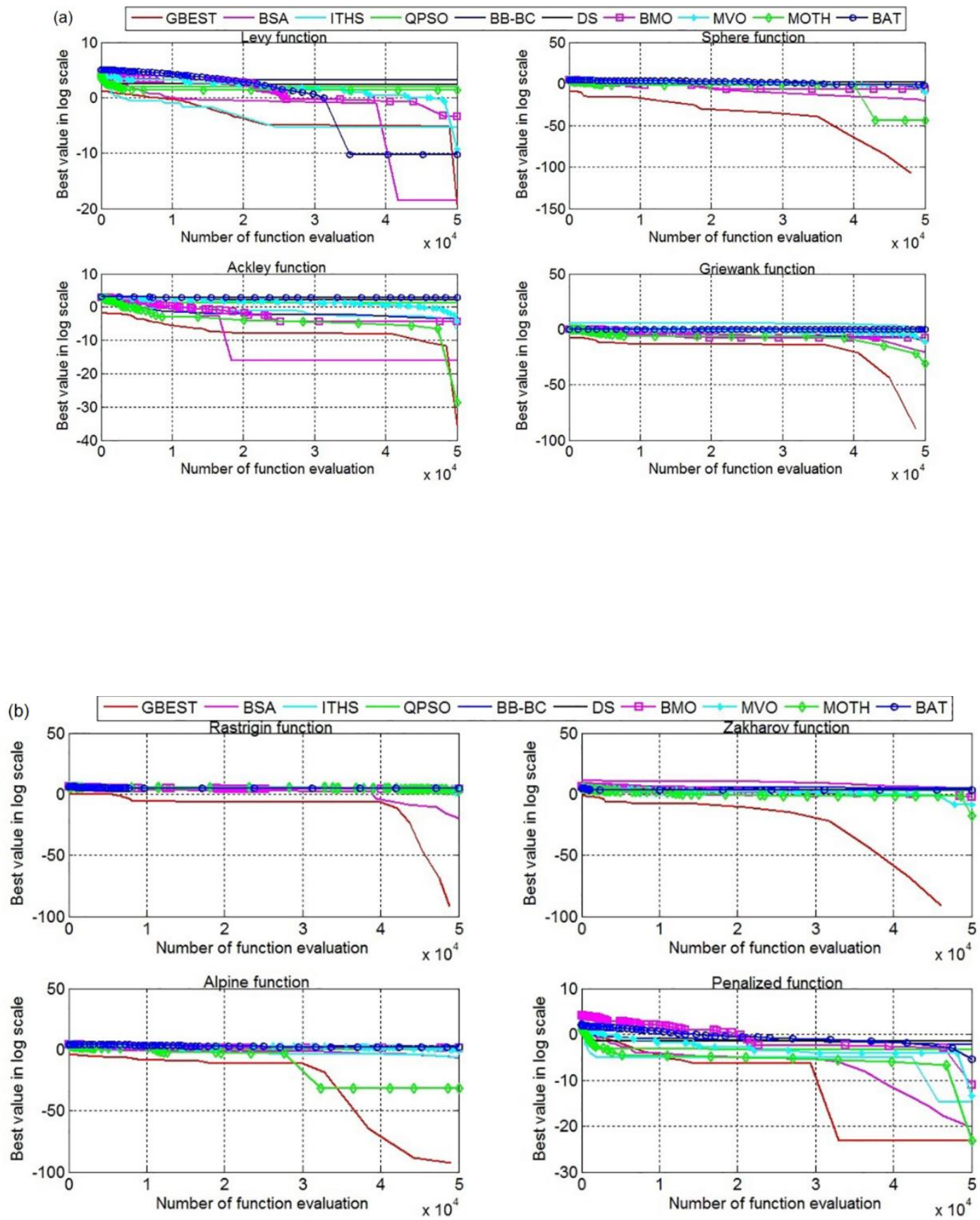

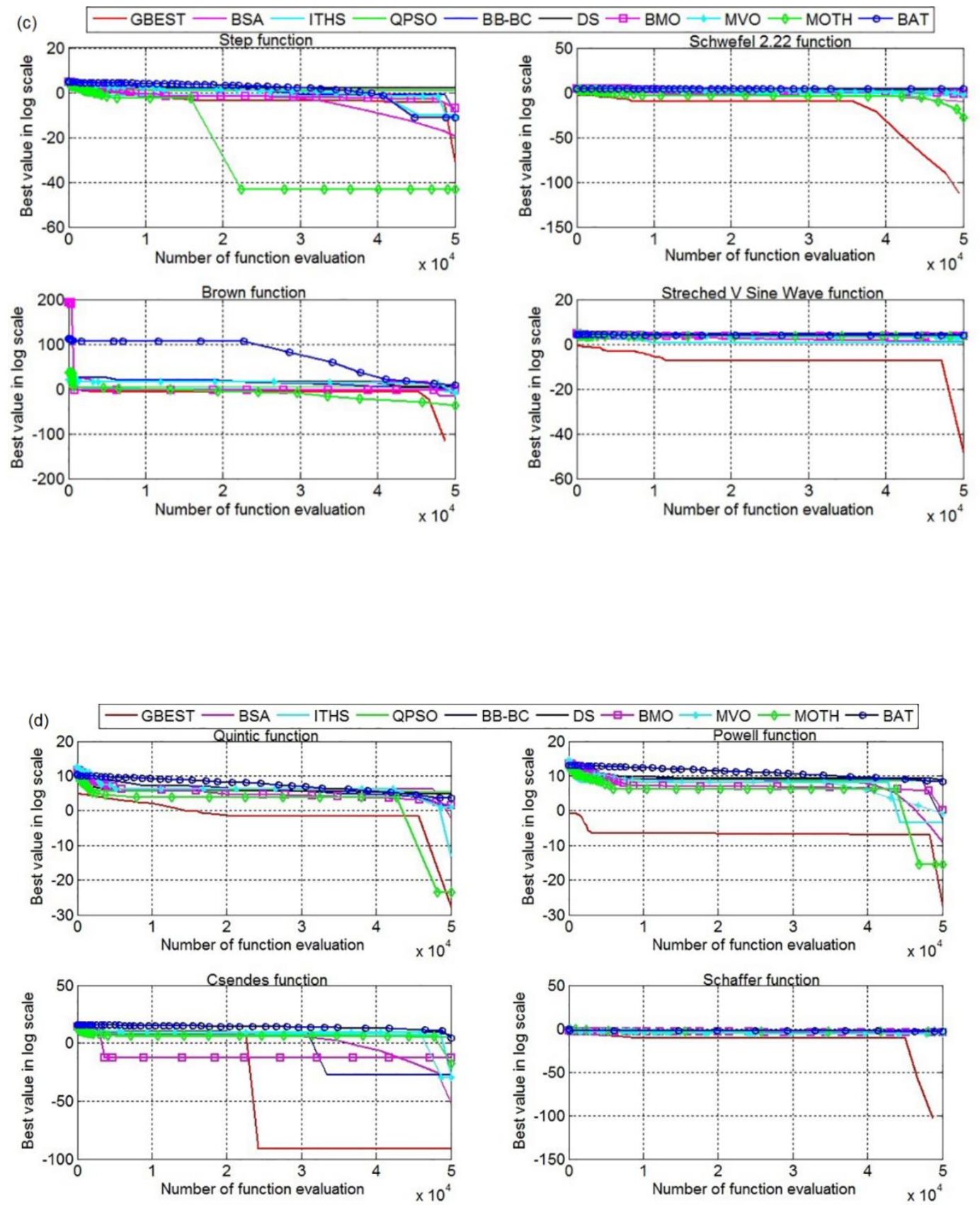

Fig. 2 Convergence histories of the objective functions for all compared algorithms

Global convergence performance of GBEST is tested with the widely utilized 16 test functions with 30 dimensions formulated in Table 3. Some of these functions are unimodal while remaining ones are multimodal. Unimodal test functions have only one local extremum point defined in the search span as multimodal test functions have plenty of local extremum points accompanied with one global optimum between predefined search ranges. Table 4 reports the statistical results of the compared algorithms for aforementioned 16 different optimization benchmark functions. 50000 function evaluations along with 30 algorithm runs have been performed to account for the stochastic nature of the algorithms. It can be clearly observed that GBEST finds the global optimum solutions of Sphere, Griewank, Rastrigin, Zakharov, Alpine, Schwefel 2.22, Brown, and Schaffer test functions and therefore outperforms the remaining optimization algorithms with respect to solution accuracy and consistency. Same optimum solution has been found by GBEST and MOTH for Penalized1 function, however standard deviation value obtained from GBEST is slightly lower than that of MOTH which indicates that GBEST is more consistent. Optimal solution found by MOTH for Step function is much better than the solution found by GBEST, nevertheless corresponding mean deviation values show that GBEST is more accurate. 
GBEST obtains semi-optimal solutions of Levy, Ackley, Penalized1, Streched V Sine Wave, Quintic, Powell, and Csendes optimization test functions and surpasses compared algorithm with regards to solution efficiency. Fig. 2 (a-d) evaluates the ability of the mentioned optimizers to avoid getting trapped in local optimum points. Quick convergence can be observed nearly for all optimization cases for GBEST such that GBEST is on the brink of reaching the global optimum solution while other methods are far away from desired point. For most cases, GBEST reaches the optimum solution after several gradual decreases, proving its capability to jump over the semi-optimal points on the search space. These convergence tendencies obtained from the numerical experiments reveal that GBEST outperforms all compared optimization algorithms in global convergence ability.

\section{Results and Discussion}

The effectiveness of the proposed Global Best Algorithm will be evaluated against the literature case study obtained from Kakaç et al. (2012) with a view to retain the optimal configuration of a plate frame heat exchanger considering both single- and multi-objective design assessments. Results retrieved from the GBEST will be compared with the reputed metaheuristic optimization methodologies of Artificial Cooperative Search (Civicioglu, 2013), Bat Algorithm (Yang, 2010), Quantum behaved Particle Swarm Optimization (Sun et al., 2004a, b) as well as with the preliminary results of Kakaç et al. (2012). Software codes are implemented in Java environment and simulations are performed on a computer with having $2.5 \mathrm{GHz} \mathrm{CPU}$ and 6.0 GB RAM. 50 different algorithm runs along with 100,000 function evaluations have been made for each optimizer in order to account for the inherent stochastic nature of the compared algorithms. GBEST will be separately applied on to acquire the minimum total cost, minimum total weight, and maximum overall of heat transfer coefficient of plate frame heat exchangers. Case study deals with modelling a plate frame heat exchanger having the heat load of $12,000 \mathrm{~kW}$ under the imposed pressure drop constraints. Such modelling includes a meticulous evaluation of design objectives to be optimized separately as well as simultaneously. Heat exchanger material is selected to be stainless steel (SS304) having a density of $8000 \mathrm{~kg} / \mathrm{m}^{3}$. Maximum pressure drop for both hot and cold sides is limited up to $300.0 \mathrm{kPa}$. Table 5 tabulates the working conditions of the plate frame heat exchanger which undergoes an optimization process Plate thickness $(\mathrm{t})$, enlargement factor $(\psi)$, port diameter $\left(D_{p}\right)$, plate pack length $\left(L_{c}\right)$, vertical distance between ports $\left(\mathrm{Lv}_{\mathrm{v}}\right)$, horizontal distance between ports $\left(\mathrm{Lh}_{\mathrm{h}}\right)$, chevron angle $(\beta)$, and number of plates in the compact pack
$\left(\mathrm{N}_{\mathrm{t}}\right)$ are considered as design variables to be iteratively adjusted through GBEST until the end of optimization process. Total number of passes for both hot and cold sides are set to one $\left(\mathrm{N}_{\mathrm{p}}=1\right)$. Table 6 reports the corresponding upper and lower bounds of these mentioned decision variables operating parameters of the plate frame heat exchanger are considered as it was previously used in Hajabdollahi et al. (2013) with the below listed specifications: pump efficiency $=0.6$, unit cost of electricity $(\$ / \mathrm{MWh})=60.0$, total operation hour in a year (hour) $=5000$, annual discount rate $=10 \%$, and depreciation time (year) $=10$. In order to reflect prescribed imposed constraints into the optimization objectives, conventional strategy for constraint handling mechanism called static penalty method is utilized. Multi objective constraint optimization with using mentioned static penalty method can be formulated by

$\arg \min f_{i}(\vec{x})+\sum_{k=1}^{m} P\left[g_{k}(\vec{x})\right]^{2}$

with subject to:

$f_{i}(\vec{x}) \in\left[f_{1}(\vec{x}), f_{2}(\vec{x}), \ldots, f_{n}(\vec{x})\right], \quad i=1,2, \ldots, n$

$g_{k}(\vec{x}) \leq 0, k=1,2, \ldots, m$

$x_{\min } \leq x_{j} \leq x_{\max }, \quad j=1,2, \ldots, D$

Where $f_{i}(\mathrm{x})$ is n number of objectives to be optimized, $g_{k}(\mathrm{x})$ is the $\mathrm{m}$ number of problem constraints, $\vec{x}$ is D-dimensional decision variable set, and $P$ is the static penalty factor which eliminates unfeasible solutions in the search space. A careful attention should be given in assigning relevant values to penalty factor. Assigning lower values of $P$ during the course of iterations may not disregard the violated constraints which causes inefficiencies in exploring unvisited paths of the search domain. Similarly, assigning higher values of $\mathrm{P}$ as iterations proceed may prompt algorithm to redundantly insist on visited and explored sections of the search space leading to unintended burden on computational load as well as increasing the running time of the algorithm. Therefore, a trialand- error procedure is conducted on assigning proper values for static penalty factor $P$ which is mainly based on the former numerical experiments made on objective function at hand. 
Table 5. Specifications of thermal working conditions (Kakac et al., 2012)

\begin{tabular}{lll}
\hline \multicolumn{1}{l}{ System parameters } & Hot fluid & Cold fluid \\
\hline Working fluid & Wastewater & Cooling water \\
\hline Flow rates $(\mathrm{kg} / \mathrm{s})$ & 140.0 & 140.0 \\
\hline Inlet temperature $\left({ }^{\circ} \mathrm{C}\right)$ & 65.0 & 22.0 \\
\hline Outlet temperature $\left({ }^{\circ} \mathrm{C}\right)$ & 45.0 & 42.0 \\
\hline Maximum allowed pressure drop $(\mathrm{kPa})$ & 300.0 & 300.0 \\
\hline Fouling resistance $\left(\mathrm{m}^{2} . \mathrm{K} / \mathrm{W}\right)$ & 0.00005 & 0.0 \\
\hline Specific heat $(\mathrm{J} / \mathrm{kg} \cdot \mathrm{K})$ & 4183 & 4178 \\
\hline Viscosity $(\mathrm{Pa} . \mathrm{s})$ & $5.09 \mathrm{e}-4$ & $7.66 \mathrm{e}-4$ \\
\hline Thermal conductivity $(\mathrm{W} / \mathrm{m} . \mathrm{K})$ & 0.645 & 0.617 \\
\hline Density $\left(\mathrm{kg} / \mathrm{m}^{3}\right)$ & 985.0 & 995.0 \\
\hline Prandtl number & 3.31 & 5.19
\end{tabular}

Table 6. Upper and lower limits of design variables

\begin{tabular}{lll}
\hline Decision variables & Lower bound & Upper bound \\
\hline Plate thickness, $\mathrm{t}(\mathrm{m})$ & 0.0005 & 0.0012 \\
\hline Enlargement factor, $\psi(-)$ & 1.15 & 1.25 \\
\hline Port diameter, $\mathrm{D}_{\mathrm{p}}(\mathrm{m})$ & 0.1 & 0.4 \\
\hline Vertical distance between ports, $\mathrm{L}_{\mathrm{v}}(\mathrm{m})$ & 1.0 & 2.0 \\
\hline Horizontal distance between ports, $\mathrm{L}_{\mathrm{h}}(\mathrm{m})$ & 0.4 & 1.0 \\
\hline Total plate length, $\mathrm{L}_{\mathrm{c}}(\mathrm{m})$ & 0.3 & 1.0 \\
\hline Chevron angle, $\beta\left({ }^{\circ}\right)$ & 30 & 65 \\
\hline Number of plates, $\mathrm{N}_{\mathrm{t}}(-)$ & 50 & 300 \\
\hline
\end{tabular}

\subsection{Single objective design optimization}

Optimization success of the proposed GBEST is assessed with its ability to attain the minimum values of total cost and total weight plate frame heat exchanger, as well as to obtain the maximum overall heat transfer coefficient rates. Table 7 reports the optimal parameters obtained by GBEST and compared optimization algorithms along with the preliminary results for minimum total cost of heat exchanger. When looking at the results given in Table 7, one can see the increase in total effective heat transfer area by $348.21 \%$ which also gives a considerable rise to investment cost levels. However, a great deal of decrease in total pressure drop rates for both hot and cold side leads to a marked reduction in operational cost values (a decrease by 40,436 \$). This overall decline leads a huge discount in total cost values $(40,142 \$)$ when compared to preliminary design made in Kakaç et al. (2012). A designer should also consider the respective influences of this decrease on overall heat transfer coefficient values and its corresponding outcomes with respect to general modelling issues. This controversial relationship between two optimization objectives will be evaluated in multi objective design considerations in upcoming sections. Total overall cost reduction made by the compared algorithms of ACS, BAT, and QPSO are respectively on the order of $40,136 \$, 40,125 \$$, 40,111 \$. Fig. 3 depicts the convergence histories of the mentioned algorithms for minimum cost of heat exchanger case. It can be seen that GBEST algorithm arrives its optimum point after 98521 function evaluations. Table 8 presents the optimization results of GBEST accompanied with best solutions of compared metaheuristic algorithms for maximum overall heat transfer coefficient case. Comparison between preliminary results shows that heat transfer coefficient rates are increased by $11.6 \%$ when the proposed GBEST is applied. This increase is brought about due to the certain increase in Reynolds number rates for both hot $(37.1 \%)$ and cold $(37.5 \%)$ sides caused by the weighted combined effects of chevron angles, mean channel spacing, port diameters, and horizontal distance between port rates on dimensionless Reynolds numbers which greatly shapes the magnitude of heat transfer coefficient. In addition, it also shows a remarkable decline $(58.0 \%)$ in total heat exchanger weight rates apart from this increase, which is very favourable for design considerations. Fig. 4 shows the convergence characteristics of the all compared algorithms for this design case. Followed by several stepwise increases in fitness values, optimum point is reached after 94799 function evaluations by GBEST algorithm. Table 9 compares the optimum results found by the GBEST, ACS, QPSO, and BAT algorithms as well as the preliminary design reported in Kakaç et al. (2012) for minimum weight of heat exchanger design case. In this optimization case, total weight of heat exchanger is considered as a function of plate thickness, number of plates in the compact heat exchanger pack, and vertical and horizontal distances between ports. Therefore, a reduction in any of these parameters will result in a decrease in total mass of heat exchanger rates. Optimum results of GBEST shows that there is a significant level of decline in plate thickness (16.5\%), port diameter (49.5\%), vertical distance between ports $(35.4 \%)$, horizontal distance between ports $(6.9 \%)$, and number of plates (\%50) compared to initial design. This cumulative decrease in design parameters causes a considerable decrease $(76.1 \%)$ in total weight. If it is to evaluate the tendencies of other optimization objectives in minimum weight consideration, a slight decrease $(1.2 \%)$ in overall cost and a marked decrease (24.9\%) in overall heat transfer coefficient rates are also observed. Fig. 5 shows the evolution histories of the compared optimization algorithms for this design case. Each algorithm in the figure nearly shows similar convergence characteristics nevertheless, GBEST is the most successful one among them as it obtains the minimum optimal value after completing successive iterations. 
Table 7. Best overall cost values for compared algorithms along with preliminary design rates

\begin{tabular}{|c|c|c|c|c|c|}
\hline & $\begin{array}{l}\text { Preliminary design } \\
\text { (Kakac et al. 2012) }\end{array}$ & GBEST & ACS & BAT & QPSO \\
\hline Plate thickness, $\mathrm{t}(\mathrm{m})$ & 0.0006 & 0.000501 & 0.000513 & 0.000500 & 0.000563 \\
\hline Enlargement factor, $\psi(-)$ & 1.25 & 1.150036 & 1.150497 & 1.150003 & 1.154658 \\
\hline Port diameter, $\mathrm{D}_{\mathrm{p}}(\mathrm{m})$ & 0.2 & 0.399842 & 0.397681 & 0.398493 & 0.395609 \\
\hline Vertical distance between ports, $\mathrm{L}_{\mathrm{v}}(\mathrm{m})$ & 1.55 & 1.995588 & 1.986751 & 1.854428 & 1.866451 \\
\hline Horizontal distance between ports, Lh (m) & 0.43 & 0.930296 & 0.926603 & 0.831679 & 0.848670 \\
\hline Total plate length, $\mathrm{L}_{\mathrm{c}}(\mathrm{m})$ & 0.38 & 0.999503 & 0.999035 & 0.997127 & 0.988865 \\
\hline Chevron angle, $\beta\left(^{\circ}\right)$ & $45^{\circ}$ & $65^{\circ}$ & $65^{\circ}$ & $65^{\circ}$ & $65^{\circ}$ \\
\hline Number of plates, $\mathrm{N}_{\mathrm{t}}(-)$ & 110 & 182 & 182 & 182 & 178 \\
\hline Plate pitch, $\mathrm{p}(\mathrm{m})$ & 0.003619 & 0.005491 & 0.005489 & 0.005478 & 0.005555 \\
\hline Mean channel spacing, b (m) & 0.003019 & 0.004990 & 0.004975 & 0.004976 & 0.004992 \\
\hline Channel flow area, $\mathrm{A}_{\mathrm{ch}}\left(\mathrm{m}^{2}\right)$ & 0.001902 & 0.006638 & 0.006589 & 0.006122 & 0.006211 \\
\hline Hydraulic diameter, $\mathrm{D}_{\mathrm{h}}(\mathrm{m})$ & 0.004830 & 0.008678 & 0.008649 & 0.008655 & 0.008646 \\
\hline Hot side Reynolds number, $\operatorname{Re}_{h}(-)$ & 13433.41 & 3951.753 & 3967.634 & 4273.010 & 4302.080 \\
\hline Cold side Reynolds number, $\operatorname{Re}_{c}(-)$ & 8926.379 & 2625.903 & 2636.456 & 2839.376 & 2858.693 \\
\hline Hot side heat transfer coefficient, $\mathrm{h}_{\text {hot }}\left(\mathrm{W} / \mathrm{m}^{2} \mathrm{~K}\right)$ & 32550.71 & 3681.233 & 3704.336 & 3904.275 & 3927.218 \\
\hline Cold side heat transfer coefficient, $\mathrm{h}_{\text {cold }}\left(\mathrm{W} / \mathrm{m}^{2} \mathrm{~K}\right)$ & 27606.93 & 3052.726 & 3071.885 & 3237.688 & 3256.714 \\
\hline Total effective heat transfer area, $A_{\text {eff }}\left(\mathrm{m}^{2}\right)$ & 78.90249 & 353.6701 & 352.0859 & 335.8272 & 335.9388 \\
\hline Hot side frictional pressure drop, $\left(\Delta \mathrm{P}_{h}\right)_{\mathrm{f}}(\mathrm{Pa})$ & 265473.6 & 2745.841 & 2781.385 & 2958.010 & 3022.464 \\
\hline Cold side frictional pressure drop, $\left(\Delta \mathrm{P}_{\mathrm{c}}\right)_{\mathrm{f}}(\mathrm{Pa})$ & 285891.9 & 2965.503 & 3003.890 & 3194.645 & 3264.256 \\
\hline Hot side port pressure drop, $\left(\Delta \mathrm{P}_{\mathrm{h}}\right)_{\mathrm{p}} \quad(\mathrm{Pa})$ & 14112.96 & 883.4482 & 902.8091 & 895.4773 & 921.8736 \\
\hline Cold side port pressure drop, $\left(\Delta \mathrm{P}_{c}\right)_{\mathrm{p}} \quad(\mathrm{Pa})$ & 13971.12 & 874.5629 & 893.7362 & 886.4777 & 912.6086 \\
\hline Total pressure drop for hot side, $\left(\Delta \mathrm{P}_{\mathrm{h}}\right)_{\mathrm{t}}(\mathrm{Pa})$ & 279586.6 & 3629.289 & 3684.195 & 3853.487 & 3944.338 \\
\hline Total pressure drop for cold side, $\left(\Delta \mathrm{P}_{\mathrm{c}}\right)_{\mathrm{t}}(\mathrm{Pa})$ & 299863.0 & 3840.073 & 3897.627 & 4081.122 & 4176.864 \\
\hline Investment cost, $C_{\text {inv }}(\$)$ & 1237.362 & 3043.701 & 3035.510 & 2950.611 & 2951.199 \\
\hline Operational cost, $C_{\text {oper }}(\$)$ & 40964.99 & 528.0749 & 536.0258 & 560.9660 & 574.1580 \\
\hline Overall heat transfer coefficient, $\mathrm{U}\left(\mathrm{W} / \mathrm{m}^{2} \mathrm{~K}\right)$ & 6612.454 & 1475.211 & 1481.851 & 1553.594 & 1553.077 \\
\hline Total mass (kg) & 492.3273 & 1958.970 & 1989.512 & 1660.587 & 1863.538 \\
\hline Total overall cost (\$) & 41166.36 & 1023.421 & 1030.041 & 1041.164 & 1054.452 \\
\hline
\end{tabular}


Table 8. Best overall heat transfer coefficient values for compared algorith ms along with preliminary design rates

\begin{tabular}{|c|c|c|c|c|c|}
\hline & $\begin{array}{l}\text { Preliminary design } \\
\text { (Kakac et al. 2012) }\end{array}$ & GBEST & ACS & BAT & QPSO \\
\hline Plate thickness, $\mathrm{t}(\mathrm{m})$ & 0.0006 & 0.000500 & 0.000500 & 0.000500 & 0.000501 \\
\hline Enlargement factor, $\psi(-)$ & 1.25 & 1.166883 & 1.243162 & 1.177726 & 1.244693 \\
\hline Port diameter, $\mathrm{D}_{\mathrm{p}}(\mathrm{m})$ & 0.2 & 0.193537 & 0.205250 & 0.221373 & 0.208243 \\
\hline Vertical distance between ports, $\mathrm{L}_{\mathrm{v}}(\mathrm{m})$ & 1.55 & 1.001059 & 1.010209 & 1.003247 & 1.024014 \\
\hline Horizontal distance between ports, $\mathrm{L}_{\mathrm{h}}(\mathrm{m})$ & 0.43 & 0.401952 & 0.410432 & 0.445984 & 0.444378 \\
\hline Total plate length, $\mathrm{L}_{\mathrm{c}}(\mathrm{m})$ & 0.38 & 0.300172 & 0.301332 & 0.307323 & 0.316251 \\
\hline Chevron angle, $\beta\left(^{\circ}\right)$ & $45^{\circ}$ & $45^{\circ}$ & $45^{\circ}$ & $45^{\circ}$ & $45^{\circ}$ \\
\hline Number of plates, $\mathrm{N}_{\mathrm{t}}(-)$ & 110 & 87 & 87 & 103 & 102 \\
\hline Plate pitch, $\mathrm{p}(\mathrm{m})$ & 0.003619 & 0.003450 & 0.003463 & 0.002983 & 0.003100 \\
\hline Mean channel spacing, b (m) & 0.003019 & 0.002950 & 0.002963 & 0.002482 & 0.002598 \\
\hline Channel flow area, $\mathrm{A}_{\mathrm{ch}}\left(\mathrm{m}^{2}\right)$ & 0.001902 & 0.001756 & 0.001824 & 0.001657 & 0.001696 \\
\hline Hydraulic diameter, $\mathrm{D}_{\mathrm{h}}(\mathrm{m})$ & 0.004830 & 0.005056 & 0.004767 & 0.004216 & 0.004176 \\
\hline Hot side Reynolds number, $\operatorname{Re}_{h}(-)$ & 13433.41 & 18410.66 & 16714.28 & 13723.56 & 13277.20 \\
\hline Cold side Reynolds number, $\operatorname{Re}_{c}(-)$ & 8926.379 & 12233.71 & 11106.48 & 9119.183 & 8822.581 \\
\hline Hot side heat transfer coefficient, $\mathrm{h}_{\text {hot }}\left(\mathrm{W} / \mathrm{m}^{2} \mathrm{~K}\right)$ & 32550.71 & 38321.94 & 38123.28 & 37822.28 & 37360.32 \\
\hline Cold side heat transfer coefficient, $\mathrm{h}_{\text {cold }}\left(\mathrm{W} / \mathrm{m}^{2} \mathrm{~K}\right)$ & 27606.93 & 32501.63 & 32333.15 & 32077.86 & 31686.07 \\
\hline Total effective heat transfer area, $A_{\text {eff }}\left(\mathrm{m}^{2}\right)$ & 78.90249 & 70.66237 & 70.82413 & 71.07531 & 71.46912 \\
\hline Hot side frictional pressure drop, $\left(\Delta \mathrm{P}_{\mathrm{h}}\right)_{\mathrm{f}}(\mathrm{Pa})$ & 265473.6 & 263098.6 & 266369.7 & 268441.4 & 265788.9 \\
\hline Cold side frictional pressure drop, $\left(\Delta \mathrm{P}_{\mathrm{c}}\right)_{\mathrm{f}}(\mathrm{Pa})$ & 285891.9 & 283334.2 & 286856.8 & 289088.1 & 286231.4 \\
\hline Hot side port pressure drop, $\left(\Delta \mathrm{P}_{\mathrm{h}}\right)_{\mathrm{p}} \quad(\mathrm{Pa})$ & 14112.96 & 16094.37 & 12723.38 & 9402.391 & 12007.58 \\
\hline Cold side port pressure drop, $\left(\Delta \mathrm{P}_{\mathrm{c}}\right)_{\mathrm{p}}(\mathrm{Pa})$ & 13971.12 & 15932.61 & 12595.51 & 9307.082 & 11886.90 \\
\hline Total pressure drop for hot side, $\left(\Delta \mathrm{P}_{\mathrm{h}}\right)_{\mathrm{t}}(\mathrm{Pa})$ & 279586.6 & 279193.0 & 279093.0 & 268441.5 & 277776.5 \\
\hline Total pressure drop for cold side, $\left(\Delta \mathrm{P}_{c}\right)_{\mathrm{t}}(\mathrm{Pa})$ & 299863.0 & 299266.8 & 299452.3 & 289088.0 & 298118.3 \\
\hline Investment cost, $C_{\text {inv }}(\$)$ & 1237.362 & 1158.124 & 1159.713 & 1162.185 & 1166.041 \\
\hline Operational cost, $C_{\text {oper }}(\$)$ & 40964.99 & 40895.08 & 40901.02 & 40737.93 & 40715.03 \\
\hline Total overall cost (\$) & 41166.36 & 41083.55 & 41089.76 & 40927.92 & 40904.80 \\
\hline Total mass (kg) & 492.3273 & 206.6250 & 214.4863 & 273.5984 & 273.3865 \\
\hline Overall heat transfer coefficient, $\mathrm{U}\left(\mathrm{W} / \mathrm{m}^{2} \mathrm{~K}\right)$ & 6612.454 & 7383.541 & 7366.685 & 7340.608 & 7300.120 \\
\hline
\end{tabular}


Table 9. Minimum total mass values for compared algorithms along with preliminary design rates

\begin{tabular}{|c|c|c|c|c|c|}
\hline & $\begin{array}{l}\text { Preliminary design } \\
\text { (Kakac et al. 2012) }\end{array}$ & GBEST & ACS & BAT & QPSO \\
\hline Plate thickness, $\mathrm{t}(\mathrm{m})$ & 0.0006 & 0.000501 & 0.000504 & 0.000502 & 0.000509 \\
\hline Enlargement factor, $\psi(-)$ & 1.25 & 1.185205 & 1.150923 & 1.168240 & 1.193784 \\
\hline Port diameter, $\mathrm{D}_{\mathrm{p}}(\mathrm{m})$ & 0.2 & 0.101609 & 0.105217 & 0.122447 & 0.136066 \\
\hline Vertical distance between ports, $\mathrm{L}_{\mathrm{v}}(\mathrm{m})$ & 1.55 & 1.000416 & 1.002595 & 1.014729 & 1.007411 \\
\hline Horizontal distance between ports, $L_{h}(m)$ & 0.43 & 0.400195 & 0.402247 & 0.400777 & 0.406336 \\
\hline Total plate length, $\mathrm{L}_{\mathrm{c}}(\mathrm{m})$ & 0.38 & 0.301183 & 0.300389 & 0.300346 & 0.300255 \\
\hline Chevron angle, $\beta\left(^{\circ}\right)$ & $45^{\circ}$ & $65^{\circ}$ & $60^{\circ}$ & $50^{\circ}$ & $60^{\circ}$ \\
\hline Number of plates, $\mathrm{N}_{t}(-)$ & 110 & 55 & 55 & 55 & 55 \\
\hline Plate pitch, p (m) & 0.003619 & 0.005476 & 0.005461 & 0.005460 & 0.005459 \\
\hline Mean channel spacing, $\mathrm{b}(\mathrm{m})$ & 0.003019 & 0.004975 & 0.004957 & 0.004958 & 0.004950 \\
\hline Channel flow area, $A_{\mathrm{ch}}\left(\mathrm{m}^{2}\right)$ & 0.001902 & 0.002496 & 0.002515 & 0.002594 & 0.002684 \\
\hline Hydraulic diameter, $\mathrm{D}_{\mathrm{h}}(\mathrm{m})$ & 0.004830 & 0.008396 & 0.008614 & 0.008489 & 0.008293 \\
\hline Hot side Reynolds number, $\operatorname{Re}_{h}(-)$ & 13433.41 & 34256.92 & 34883.86 & 33331.55 & 31465.06 \\
\hline Cold side Reynolds number, $\operatorname{Re}_{c}(-)$ & 8926.379 & 22763.41 & 23180.00 & 22148.51 & 20908.24 \\
\hline Hot side heat transfer coefficient, $h_{\text {hot }}\left(\mathrm{W} / \mathrm{m}^{2} \mathrm{~K}\right)$ & 32550.71 & 17940.10 & 18797.54 & 30077.93 & 18159.93 \\
\hline Cold side heat transfer coefficient, $\mathrm{h}_{\text {cold }}\left(\mathrm{W} / \mathrm{m}^{2} \mathrm{~K}\right)$ & 27606.93 & 14877.14 & 15684.05 & 24800.33 & 15152.05 \\
\hline Total effective heat transfer area, $A_{\text {eff }}\left(\mathrm{m}^{2}\right)$ & 78.90249 & 105.1582 & 102.1439 & 79.44074 & 104.4263 \\
\hline Hot side frictional pressure drop, $\left(\Delta \mathrm{P}_{\mathrm{h}}\right)_{\mathrm{f}}(\mathrm{Pa})$ & 265473.6 & 72119.13 & 80512.86 & 139935.0 & 75422.30 \\
\hline Cold side frictional pressure drop, $\left(\Delta \mathrm{P}_{\mathrm{c}}\right)_{\mathrm{f}}(\mathrm{Pa})$ & 285891.9 & 77888.52 & 87024.85 & 147951.3 & 81522.55 \\
\hline Hot side port pressure drop, $\left(\Delta \mathrm{P}_{\mathrm{h}}\right)_{\mathrm{p}} \quad(\mathrm{Pa})$ & 14112.96 & 211838.6 & 184242.0 & 100448.5 & 65877.07 \\
\hline Cold side port pressure drop, $\left(\Delta \mathrm{P}_{\mathrm{c}}\right)_{\mathrm{p}}(\mathrm{Pa})$ & 13971.12 & 209709.6 & 182390.3 & 99438.99 & 65214.99 \\
\hline Total pressure drop for hot side, $\left(\Delta \mathrm{P}_{h}\right)_{\mathrm{t}}(\mathrm{Pa})$ & 279586.6 & 283957.7 & 264754.9 & 240383.5 & 141299.3 \\
\hline Total pressure drop for cold side, $\left(\Delta \mathrm{P}_{c}\right)_{t}(\mathrm{~Pa})$ & 299863.0 & 287598.1 & 269415.2 & 247390.3 & 146737.5 \\
\hline Investment cost, $C_{\text {inv }}(\$)$ & 1237.362 & 1470.105 & 1444.674 & 1242.419 & 1463.951 \\
\hline Operational cost, $\mathrm{C}_{\text {oper }}(\$)$ & 40964.99 & 40412.77 & 37768.90 & 34487.44 & 20364.82 \\
\hline Total overall cost (\$) & 41166.36 & 40652.02 & 38004.02 & 34689.64 & 20603.07 \\
\hline Overall heat transfer coefficient, $\mathrm{U}\left(\mathrm{W} / \mathrm{m}^{2} \mathrm{~K}\right)$ & 6612.454 & 4961.462 & 5107.879 & 6567.651 & 4966.231 \\
\hline Total mass (kg) & 492.3273 & 114.6192 & 117.0306 & 121.0478 & 125.8835 \\
\hline
\end{tabular}




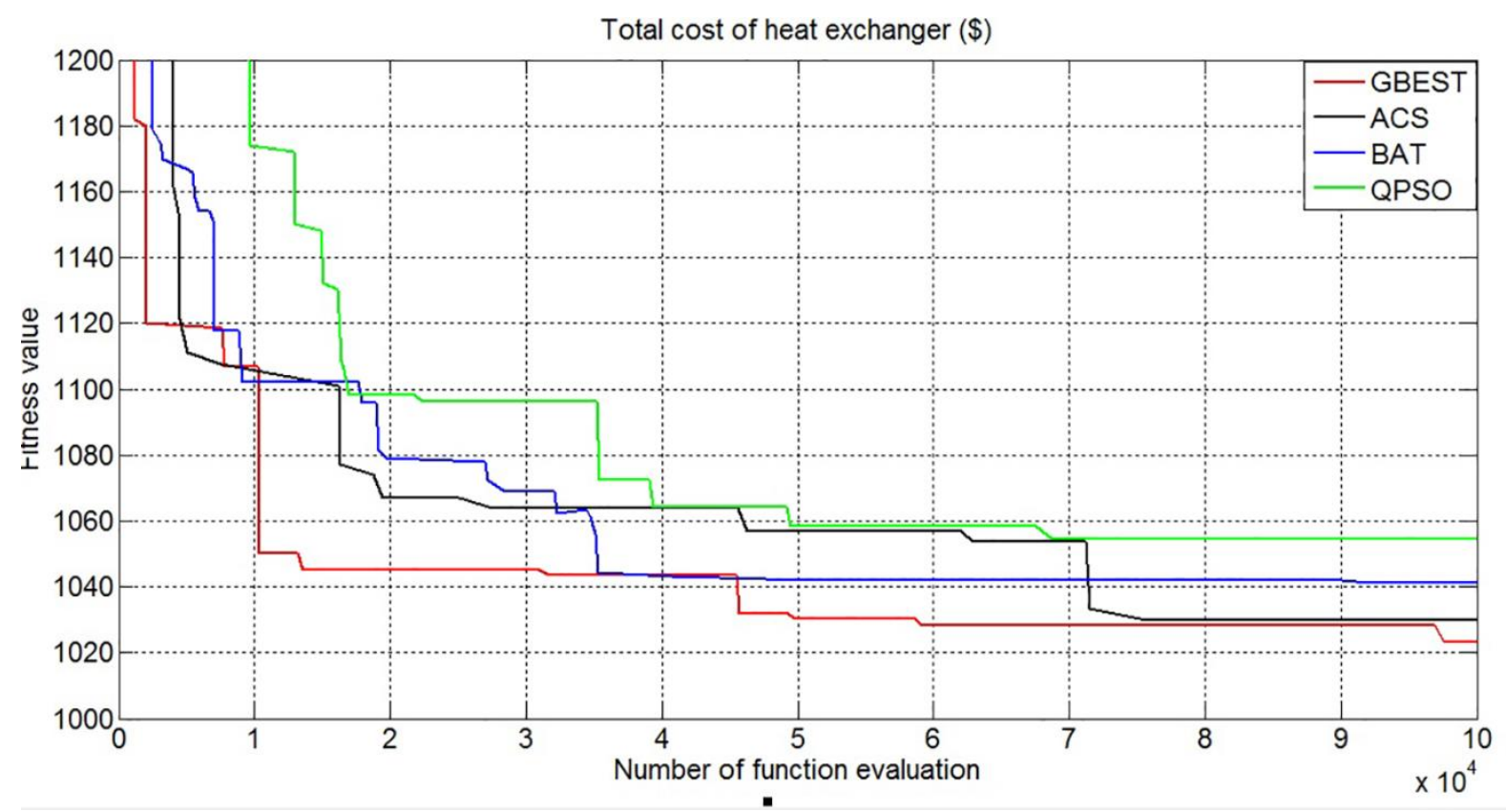

Fig. 3 Convergence histories of the compared algorithms for minimum total cost of heat exchanger

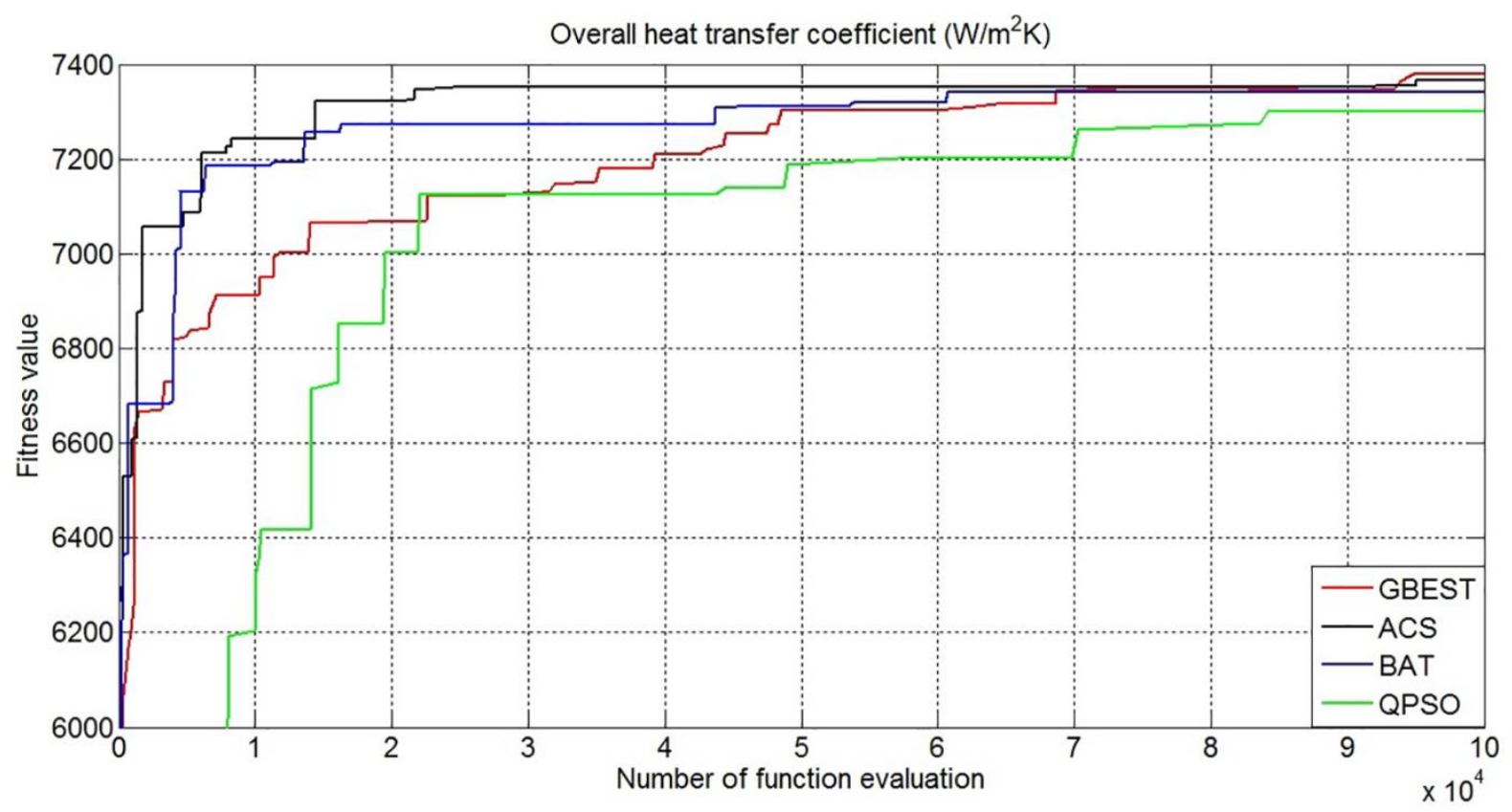

Figure 4. Evolution histories of the compared algorithms for maximum overall heat transfer coefficient 


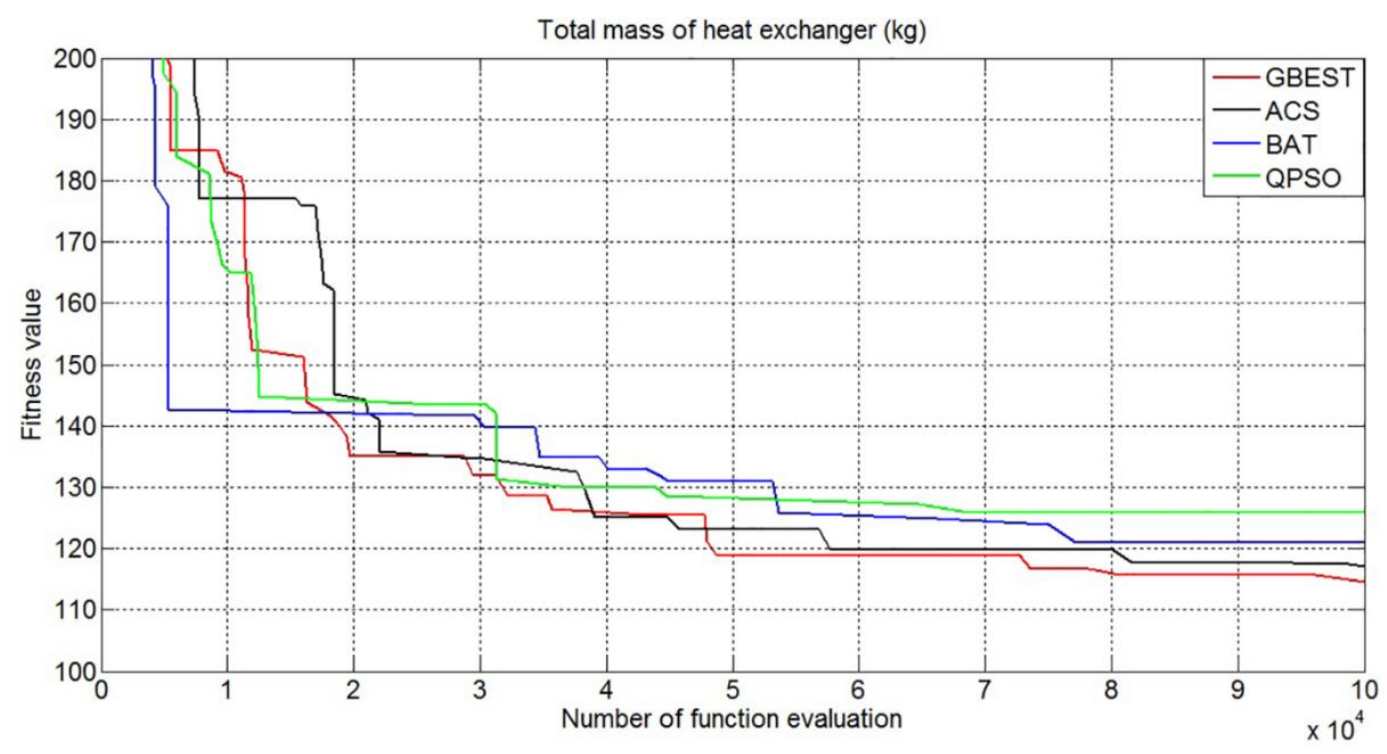

Figure 5. Convergence characteristics of the compared algorithms for minimum total weight of heat exchanger

\subsection{Multi objective design optimization}

As seen in single objective optimization for total weight and total cost of heat exchanger cases, total cost of heat exchanger increases with decreasing total weight or vice versa. This contradictory and conflicting situation should prompt a designer to accomplish multi objective optimization task with a dual as well as triple objective manner. GBEST algorithm is considered for the simultaneous optimization of cases which have been solved separately in previous section. 50 sequential algorithm runs along with 100,000 function evaluations are made for each trial solution. Pareto curves constructed for each optimization case has different number of trial solutions due to the nature of the optimization objectives as well as the restrictions imposed by the problem constraints. Best solutions on the pareto frontier will be selected by means of the renowned decision making theories of LINMAP, TOPSIS, and Shannon's entropy theory methods. Descriptions and formulations of these decision making methods will not be given in this paper due to the space restrictions. Interested readers could find the detailed information on these mentioned methods in (Arora et al., 2016).

\subsubsection{Total mass of heat exchanger - total cost of heat exchanger consideration}

Fig. 6 visualizes the set of non-dominated solution obtained through Multi Objective Global Best Algorithm (MO-GBEST) for concurrent dual objective optimization of total cost and total mas of the plate frame heat exchanger. Fig. 6 shows that optimum (minimum) total cost takes place at design point $\mathrm{A}$ where respective cost value is $1023.421 \$$ and its corresponding total mass value is $1958.970 \mathrm{~kg}$, in line with optimum results for single objective consideration for minimum total cost case. At design point $\mathrm{H}$, total mass gets its minimum with a function value of $114.6192 \mathrm{~kg}$ and its corresponding total cost value of $40652.52 \$$. Table 10 reports some of the optimal results (design points $\mathrm{A}$ to $\mathrm{H}$ ) on the pareto front shown in Fig. 6. Optimal results show that a great deal of reduction is observed in number of plates (182 to 55), vertical ( $1.99 \mathrm{~m}$ to $1.00 \mathrm{~m})$ and horizontal $(0.93 \mathrm{~m}$ to $0.40 \mathrm{~m})$ distance between ports, and correspondingly length of the compact pack $(0.99 \mathrm{~m}$ to $0.30 \mathrm{~m})$ as it is moved from design point $A$ to $\mathrm{H}$. These marginal decreases for each mentioned design variable above result in a marked decrease $11958.9 \mathrm{~kg}$ to $114.6 \mathrm{~kg}$ ) in total mass values while giving a considerable huge rise in total cost rates (1023.4 \$ to $40652.0 \$$ ). In order to gain more detailed insight on the effect of these two conflicting objectives on the variations of decision variables, their distribution on the solution space based on weighted combinatorial influences of two objectives have been plotted in Fig. 7. It is seen in Fig. 7 that chevron angle nearly stays constant on the curve however, great variational changes occur in $D_{p}, L_{h}, L_{v}, L_{c}$, and $N_{t}$ values due to conflicting nature of the problem objectives. Table 11 reports the best compromising solutions on the Pareto curve found by the decision making theories of LINMAP, TOPSIS, and Shannon's entropy theory. In Table 11, the term "deviation index" delineates the suitability of the solution obtained by the corresponding decision making theory for the optimization problem at hand. Lower deviation index value reflects its closeness to ideal point on the objective domain. That is, the lesser value it attains, the more suitable and ideal solution it is (Kumar et al., 2016). According to this definition, one can see that the minimum deviation index value is 0.1287 which shows that total cost and total mass value selected by TOPSIS and LINMAP methods are more ideal than the pareto solution found by the Shannon's entropy theory whose respective deviation index value is 0.1752 . Formulation of this term can be found in (Kumar et al., 2016). 


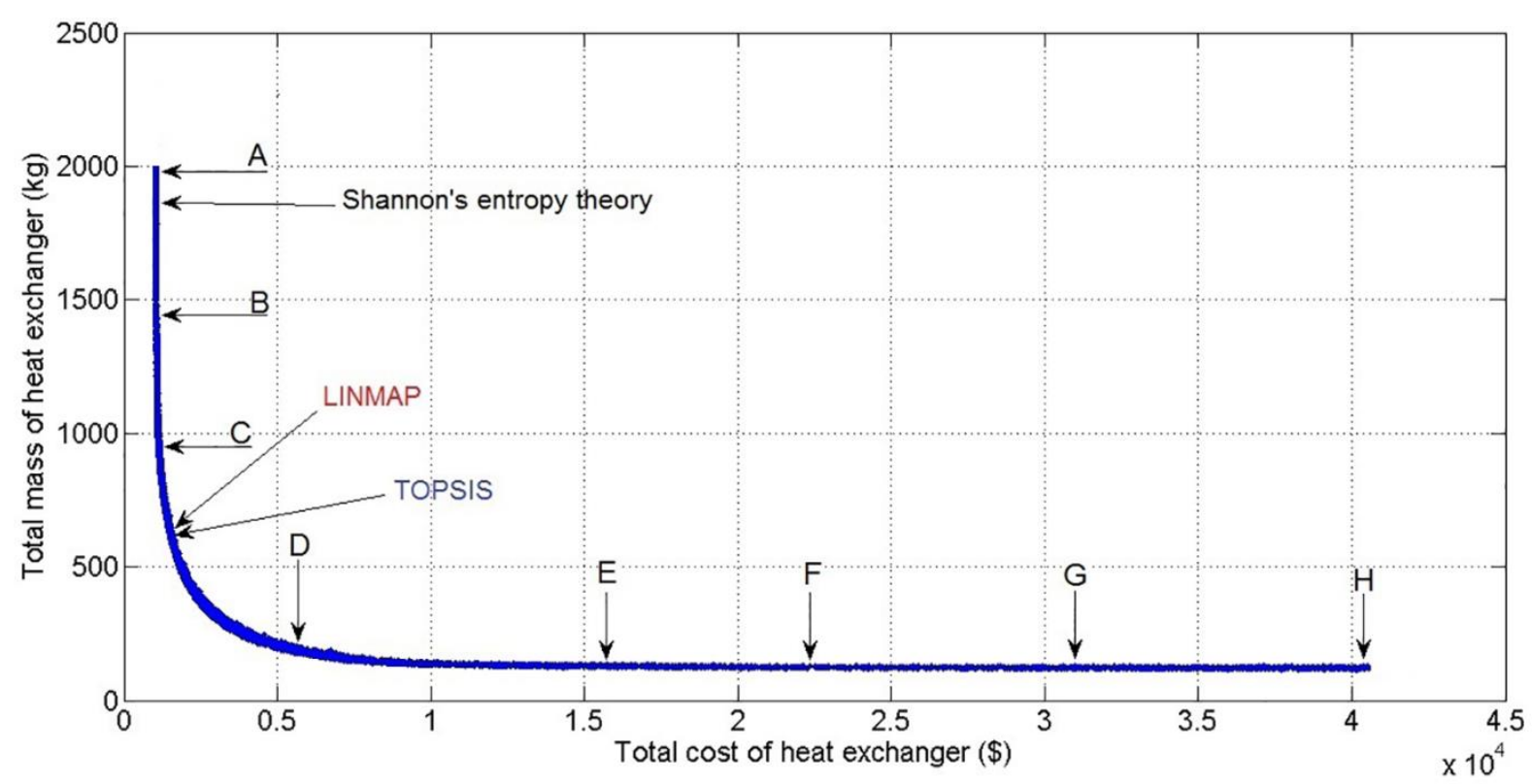

Figure 6. Pareto frontier for dual objective (total mass - total cost) of plate frame heat exchanger
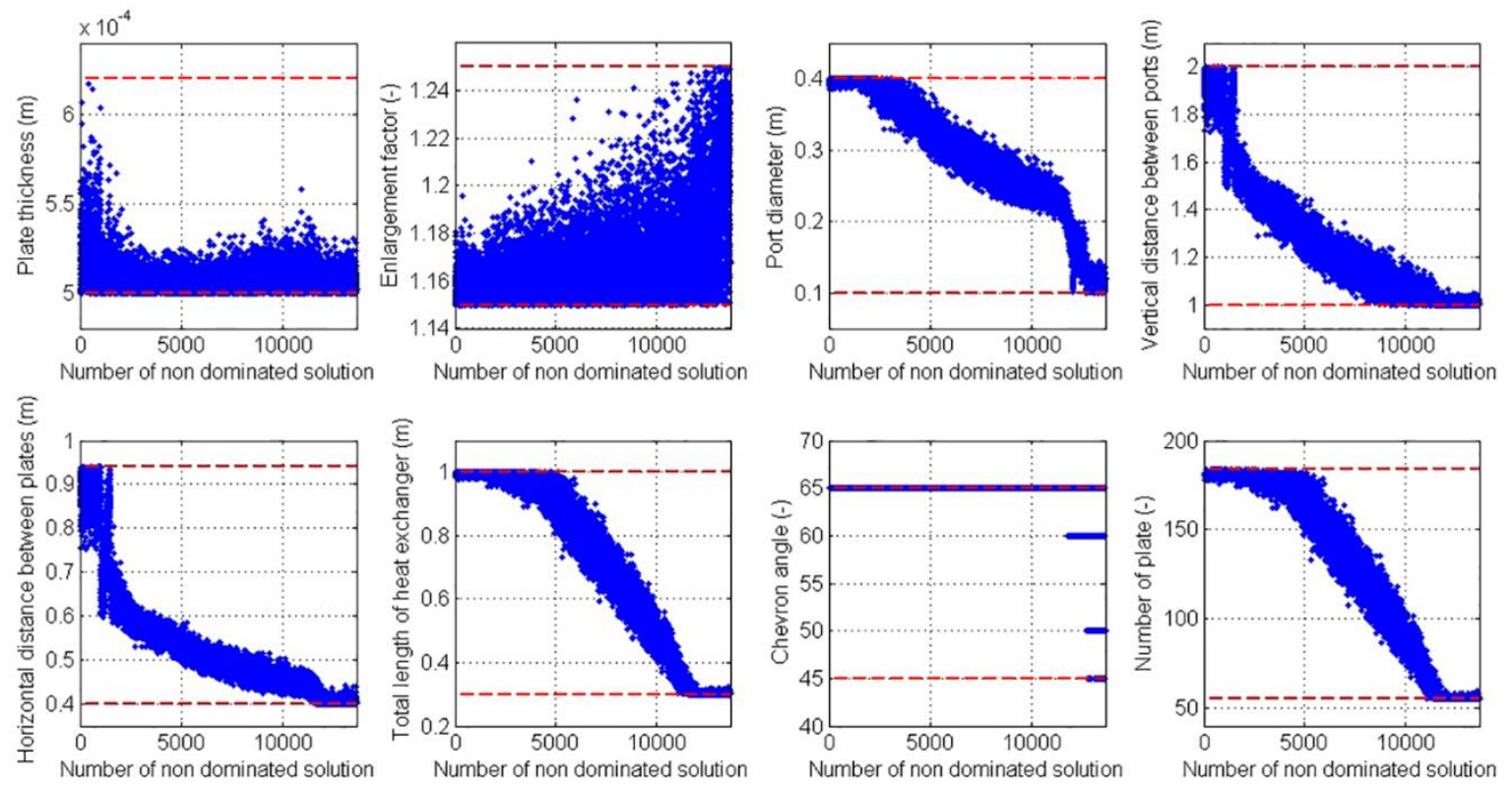

Figure 7. Scatter plot of design variables for optimum solutions on the Pareto frontier for simultaneous optimization of total cost and total mass of heat exchanger 
Bitlis Eren University Journal of Science and Technology 7(1) (2017) 33-73

Table 10. Optimum design points A to H specified on the pareto front in Fig.6

\begin{tabular}{|c|c|c|c|c|c|c|c|c|}
\hline & A & B & C & D & E & $\mathbf{F}$ & G & $\mathrm{H}$ \\
\hline $\mathrm{t}(\mathrm{m})$ & 0.000501 & 0.000514 & 0.000505 & 0.000509 & 0.000501 & 0.000504 & 0.000521 & 0.000501 \\
\hline$\psi(-)$ & 1.150036 & 1.151401 & 1.158691 & 1.168885 & 1.197293 & 1.193712 & 1.156341 & 1.185205 \\
\hline$D_{p}(m)$ & 0.399842 & 0.398830 & 0.368715 & 0.235876 & 0.147857 & 0.128580 & 0.110765 & 0.101609 \\
\hline $\mathrm{L}_{\mathrm{v}}(\mathrm{m})$ & 1.995588 & 1.732764 & 1.448784 & 1.066264 & 1.013104 & 1.016495 & 1.027861 & 1.000416 \\
\hline $\mathrm{L}_{\mathrm{h}}(\mathrm{m})$ & 0.930296 & 0.745215 & 0.582445 & 0.455557 & 0.400537 & 0.400257 & 0.404026 & 0.400195 \\
\hline $\mathrm{L}_{\mathrm{c}}(\mathrm{m})$ & 0.999503 & 0.999044 & 0.969925 & 0.371155 & 0.306227 & 0.306475 & 0.303034 & 0.301183 \\
\hline$\beta\left({ }^{\circ}\right)$ & 65.0 & 65.0 & 65.0 & 65.0 & 65.0 & 60.0 & 65.0 & 65.0 \\
\hline $\mathrm{N}_{\mathrm{t}}(-)$ & 182 & 182 & 177 & 68 & 56 & 56 & 55 & 55 \\
\hline $\mathrm{U}\left(\mathrm{W} / \mathrm{m}^{2} \mathrm{~K}\right)$ & 1475.211 & 1625.237 & 1964.944 & 3826.675 & 4704.533 & 4967.972 & 4848.680 & 4961.462 \\
\hline Overall cost (\$) & 1023.421 & 1056.921 & 1179.840 & 5506.468 & 15635.86 & 22720.67 & 31379.84 & 40652.02 \\
\hline Total mass (kg) & 1958.970 & 1452.197 & 932.2886 & 198.1245 & 127.6644 & 125.1660 & 125.7628 & 114.6192 \\
\hline
\end{tabular}

Table 11. Optimal results attained by three different decision making methods

\begin{tabular}{llll}
\hline & LINMAP & TOPSIS & Shannon's entropy theory \\
\hline Decision variables & & & \\
\hline Plate thickness, $\mathrm{t}(\mathrm{m})$ & 0.000500 & 0.000500 & 0.000536 \\
\hline Enlargement factor, $\psi(-)$ & 1.157824 & 1.157824 & 1.155694 \\
\hline Port diameter, $\mathrm{D}_{\mathrm{p}}(\mathrm{m})$ & 0.314224 & 0.314224 & 0.394219 \\
\hline Vertical distance between ports, $\mathrm{L}_{\mathrm{v}}(\mathrm{m})$ & 1.249378 & 1.249378 & 1.909581 \\
\hline Horizontal distance between ports, $\mathrm{Lh}_{\mathrm{h}}(\mathrm{m})$ & 0.517040 & 0.517040 & 0.864237 \\
\hline Total plate length, $\mathrm{L}_{\mathrm{c}}(\mathrm{m})$ & 0.868892 & 0.868892 & 0.992515 \\
\hline Chevron angle, $\beta\left({ }^{\circ}\right)$ & 65 & 65 & 65 \\
\hline Number of plates, $\mathrm{N}_{\mathrm{t}}(-)$ & 158 & 158 & 180 \\
\hline Objective function & & & \\
\hline Total cost of heat exchanger $(\$)$ & 1477.070 & 1477.070 & 1055.626 \\
\hline Total mass of heat exchanger $(\mathrm{kg})$ & 625.5732 & 625.5732 & 1863.581 \\
\hline Overall heat transfer coefficient $\left(\mathrm{W} / \mathrm{m}^{2} \mathrm{~K}\right)$ & 2151.458 & 2151.458 & 1539.245 \\
\hline Deviation index & 0.1287 & 0.1278 & 0.1752 \\
\hline
\end{tabular}




\subsubsection{Total cost of heat exchanger - overall heat transfer coefficient consideration}

Fig. 8 shows the Pareto frontier constructed by the proposed MO-GBEST for simultaneous optimization of total cost of heat exchanger and overall heat transfer coefficient rates. Similar with the previous case study, between the parametric changes in these mutually opposed objectives, any increase in heat transfer values also results in an increase in total cost rates which is undesirable for the effective design. As it is seen from Fig. 8, overall heat transfer coefficient value is at its maximum $\left(7383.541 \mathrm{~W} / \mathrm{m}^{2} \mathrm{~K}\right)$ at design point A where its corresponding total cost value is (41083.55\$). However, overall heat transfer coefficient descends to $1475.211 \mathrm{~W} / \mathrm{m}^{2} \mathrm{~K}$ while its respective total cost rate becomes $1023.421 \$$. In addition, gradual increases in $D_{p}(0.19 \mathrm{~m}$ to 0.39$)$, $\mathrm{Lv}_{\mathrm{v}}(1.00 \mathrm{~m}$ to $1.99 \mathrm{~m})$, $\mathrm{Lh}(0.40$ $\mathrm{m}$ to $0.93 \mathrm{~m}$ ), and $\mathrm{N}_{\mathrm{t}}$ (87 to 182 ) values are observed as cruising through $\mathrm{A}$ to $\mathrm{H}$ design points. Table 12 reports the pareto optimum solutions obtained by MO-GBEST for eight design points from A to H shown in Fig. 8. Outcomes of the Table 12 reveal that total reduction in overall heat transfer coefficient rates $(80.0 \%)$ and total cost $(97.1 \%)$ are clearly seen. Mentioned gradual decreases occurred as a result of moving from design points $\mathrm{A}$ to $\mathrm{H}$ on the frontier can be attributed to the mutual contradictive characteristics of the optimization objectives. Fig. 9 shows the combined influences of the two optimization objectives on the distribution of the design variables in their corresponding search domain. Plate thickness values are mainly cumulated at its lower bound while enlargement factor rates homogenously spread over the search domain. Optimal values of the remaining design variables change variationally in their corresponding solution space when moving from $\mathrm{A}$ to $\mathrm{H}$ on the frontier. Table 13 gives a comparison between the optimal solutions found by three different decision making theories along with their respective deviation indexes. The deviation index values for LINMAP, TOPSIS, and Shannon's entropy theory are respectively $0.12944,0.08751$, and 0.35921. According to the deviation index values, it can be said that optimal solution acquired by TOPSIS are more preferable.

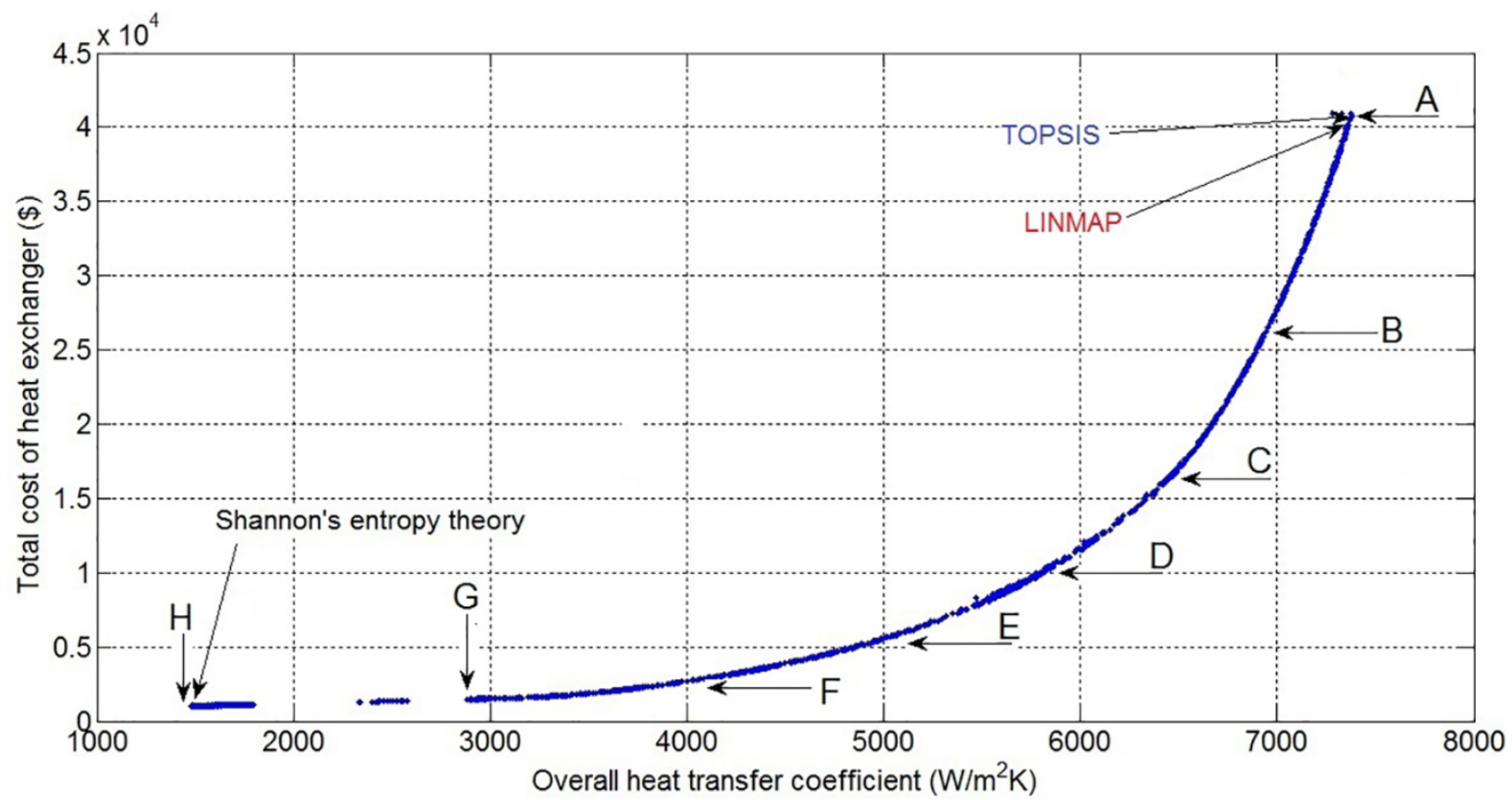

Figure 8. Pareto frontier for dual objective (overall heat transfer coefficient - total cost) of plate frame heat exchanger 
Bitlis Eren University Journal of Science and Technology 7(1) (2017) 33-73

Table 12. Non dominated solutions and their respective design variables at the design points from $A$ to $H$ shown in Fig. 8

\begin{tabular}{lllllllll}
\hline & A & B & C & D & E & F & G & H \\
\hline $\mathrm{t}(\mathrm{m})$ & 0.000500 & 0.000500 & 0.000500 & 0.000502 & 0.000506 & 0.000500 & 0.000508 & 0.000501 \\
\hline$\psi(-)$ & 1.166883 & 1.156651 & 1.164463 & 1.157557 & 1.176999 & 1.153487 & 1.161439 & 1.150036 \\
\hline $\mathrm{D}_{\mathrm{p}}(\mathrm{m})$ & 0.193537 & 0.208411 & 0.227721 & 0.244708 & 0.261012 & 0.293429 & 0.397151 & 0.399842 \\
\hline $\mathrm{L}_{\mathrm{v}}(\mathrm{m})$ & 1.001059 & 1.000629 & 1.005215 & 1.042056 & 1.094148 & 1.196598 & 1.970993 & 1.995588 \\
\hline $\mathrm{L}_{\mathrm{h}}(\mathrm{m})$ & 0.401952 & 0.409286 & 0.441656 & 0.447917 & 0.467692 & 0.500441 & 0.904840 & 0.930296 \\
\hline $\mathrm{L}_{\mathrm{c}}(\mathrm{m})$ & 0.300172 & 0.300704 & 0.302107 & 0.398143 & 0.537871 & 0.806004 & 0.9962243 & 0.999503 \\
\hline$\beta\left({ }^{\circ}\right)$ & 45.0 & 45.0 & 45.0 & 45.0 & 45.0 & 45.0 & 45.0 \\
\hline $\mathrm{N}_{\mathrm{t}}(-)$ & 87 & 69 & 55 & 73 & 98 & 148 & 182 \\
\hline $\mathrm{U}\left(\mathrm{W} / \mathrm{m}^{2} \mathrm{~K}\right)$ & 7383.541 & 6944.2665 & 6450.0312 & 5792.2042 & 5047.8486 & 4089.3687 & 2909.5457 & 14775.211 \\
\hline Overall cost $(\$)$ & 41083.55 & 26277.059 & 16306.467 & 9926.4569 & 5783.3399 & 2875.9428 & 1469.1924 & 1023.421 \\
\hline Total mass $(\mathrm{kg})$ & 260.6250 & 168.76798 & 145.92853 & 205.36133 & 303.56138 & 540.14667 & 1891.0236 & 1958.970 \\
\hline
\end{tabular}

Table 13. Comparison of the optimal solutions obtained by three decision making methods

\begin{tabular}{llll}
\hline & LINMAP & TOPSIS & Shannon's entropy theory \\
\hline Decision variables & & & \\
\hline Plate thickness, $\mathrm{t}(\mathrm{m})$ & 0.000500 & 0.000515 & 0.000537 \\
\hline Enlargement factor, $\psi(-)$ & 1.152198 & 1.165799 & 1.151129 \\
\hline Port diameter, $\mathrm{D}_{\mathrm{p}}(\mathrm{m})$ & 0.200249 & 0.200666 & 0.393592 \\
\hline Vertical distance between ports, $\mathrm{L}_{\mathrm{v}}(\mathrm{m})$ & 1.000406 & 1.001330 & 1.944634 \\
\hline Horizontal distance between ports, $\mathrm{L}_{\mathrm{h}}(\mathrm{m})$ & 0.403176 & 0.405915 & 0.902333 \\
\hline Total plate length, $\mathrm{L}_{\mathrm{c}}(\mathrm{m})$ & 0.300181 & 0.300336 & 0.996501 \\
\hline Chevron angle, $\beta\left({ }^{\circ}\right)$ & 45 & 45 & 65 \\
\hline Number of plates, $\mathrm{N}_{\mathrm{t}}(-)$ & 89 & 89 & 180 \\
\hline Objective functions & & & \\
\hline Total cost of heat exchanger $(\$)$ & 40751.38 & 40890.26 & 1041.006 \\
\hline Overall heat transfer coefficient $\left(\mathrm{W} / \mathrm{m}^{2} \mathrm{~K}\right)$ & 7378.299 & 7377.745 & 1503.853 \\
\hline Total mass of heat exchanger & 213.0971 & 214.5949 & 1969.742 \\
\hline Deviation index & 0.12944 & 0.08751 & 0.35921 \\
\hline
\end{tabular}



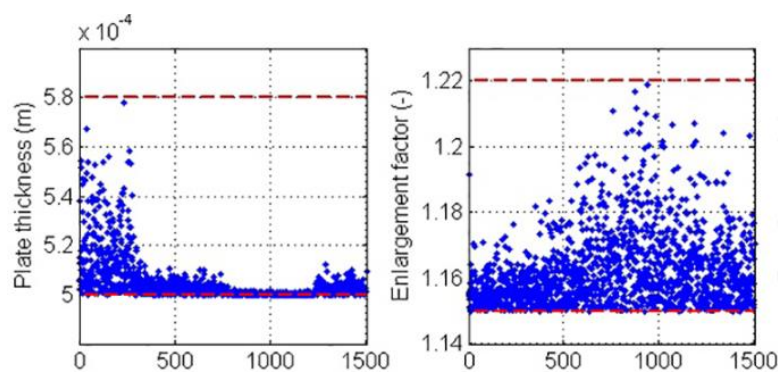

Number of non dominated solution
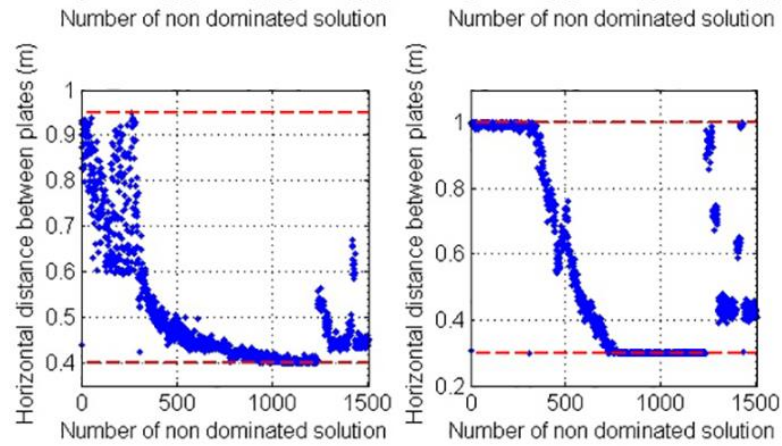
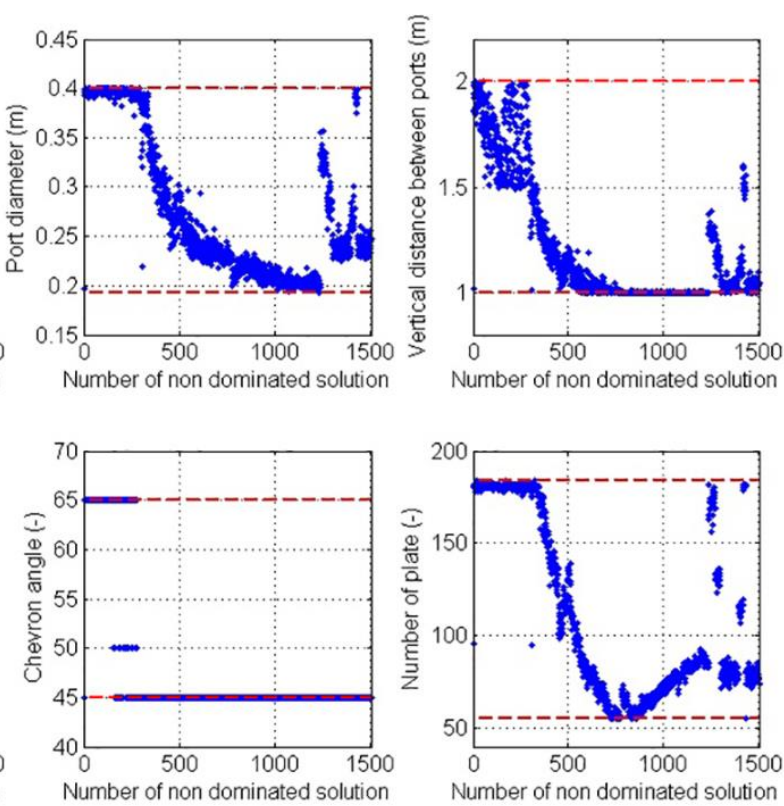

Figure 9. Distribution of the decision variables for optimum solutions on the Pareto frontier for concurrent optimization of overall heat transfer coefficient and total cost of plate frame heat exchanger

\subsubsection{Overall heat transfer coefficient - total mass of the heat exchanger consideration}

Pareto optimal solution curve constructed by utilizing the favourable merits of the proposed MO-GBEST for concurrent optimization of conflicting problem objectives including overall heat transfer coefficient and total mass of heat exchanger is depicted in Fig. 10. One can see the long gaps between some of the non-dominated Pareto solutions on the frontier. This is because of the imposed design constraints which does not allow GBEST optimizer to find feasible solutions at these empty regions on the pareto curve. It is clear to see the contradiction between these two problem objectives such that overall heat transfer coefficient descends from $7383.541 \mathrm{~W} / \mathrm{m}^{2} \mathrm{~K}$ to $4961.461 \mathrm{~W} / \mathrm{m}^{2} \mathrm{~K}$ while total mass decreases from $260.625 \mathrm{~kg}$ to $114.619 \mathrm{~kg}$ when moving from A to $\mathrm{E}$ on the frontier. Table 14 reports the variational changes of objective function values in tabular from. When looking at the tendencies of the design variables throughout the frontier, number of plates in the pack decreases from 87 to 55 whereas chevron angle varies between $45.0^{\circ}$ and $65.0^{\circ}$ apart from the remaining ones those do not show any significant change in values. Pareto optimal solutions along with their respective deviation indexes found by three different decision making theories are reported in Table 15. Deviation index value of 0.18533 obtained by TOPSIS method is lower than those of obtained by other methods, which indicates that optimal solution found by TOPSIS is more relevant. Fig. 11 demonstrates a scatter plot based on the variation of the decision variables on the pareto front. It can be observed from the figure that plate thickness, vertical and horizontal distance between ports, and total length of heat exchanger reach their minimum values while chevron angle nearly stays constant and enlargement factor is uniformly distributed over the solution space. 
Table 14. Optimal solutions at the design points from A to E shown in Fig. 10

\begin{tabular}{llllll}
\hline & A & B & C & D & E \\
\hline $\mathrm{t}(\mathrm{m})$ & 0.000500 & 0.000502 & 0.000501 & 0.000502 & 0.000501 \\
\hline$\psi(-)$ & 1.166883 & 1.248934 & 1.243797 & 1.194019 & 1.185205 \\
\hline $\mathrm{D}_{\mathrm{p}}(\mathrm{m})$ & 0.193537 & 0.161691 & 0.125005 & 0.129195 & 0.101609 \\
\hline $\mathrm{L}_{\mathrm{v}}(\mathrm{m})$ & 1.001059 & 1.011172 & 1.012170 & 1.004421 & 1.000416 \\
\hline $\mathrm{L}_{\mathrm{h}}(\mathrm{m})$ & 0.401952 & 0.408434 & 0.400976 & 0.421317 & 0.400195 \\
\hline $\mathrm{L}_{\mathrm{c}}(\mathrm{m})$ & 0.300172 & 0.306393 & 0.300112 & 0.300070 & 0.301183 \\
\hline$\beta\left({ }^{\circ}\right)$ & 45.0 & 45.0 & 45.0 & 50.0 & 65.0 \\
\hline $\mathrm{N}_{\mathrm{t}}(-)$ & 87 & 79 & 57 & 55 & 55 \\
\hline $\mathrm{U}\left(\mathrm{W} / \mathrm{m}^{2} \mathrm{~K}\right)$ & 7383.541 & 7320.003 & 7096.190 & 6470.695 & 4961.462 \\
\hline Overall cost $(\$)$ & 41083.55 & 41240.02 & 40231.21 & 30488.86 & 40652.02 \\
\hline Total mass $(\mathrm{kg})$ & 260.6250 & 186.1434 & 125.4995 & 126.3777 & 114.6192 \\
\hline
\end{tabular}

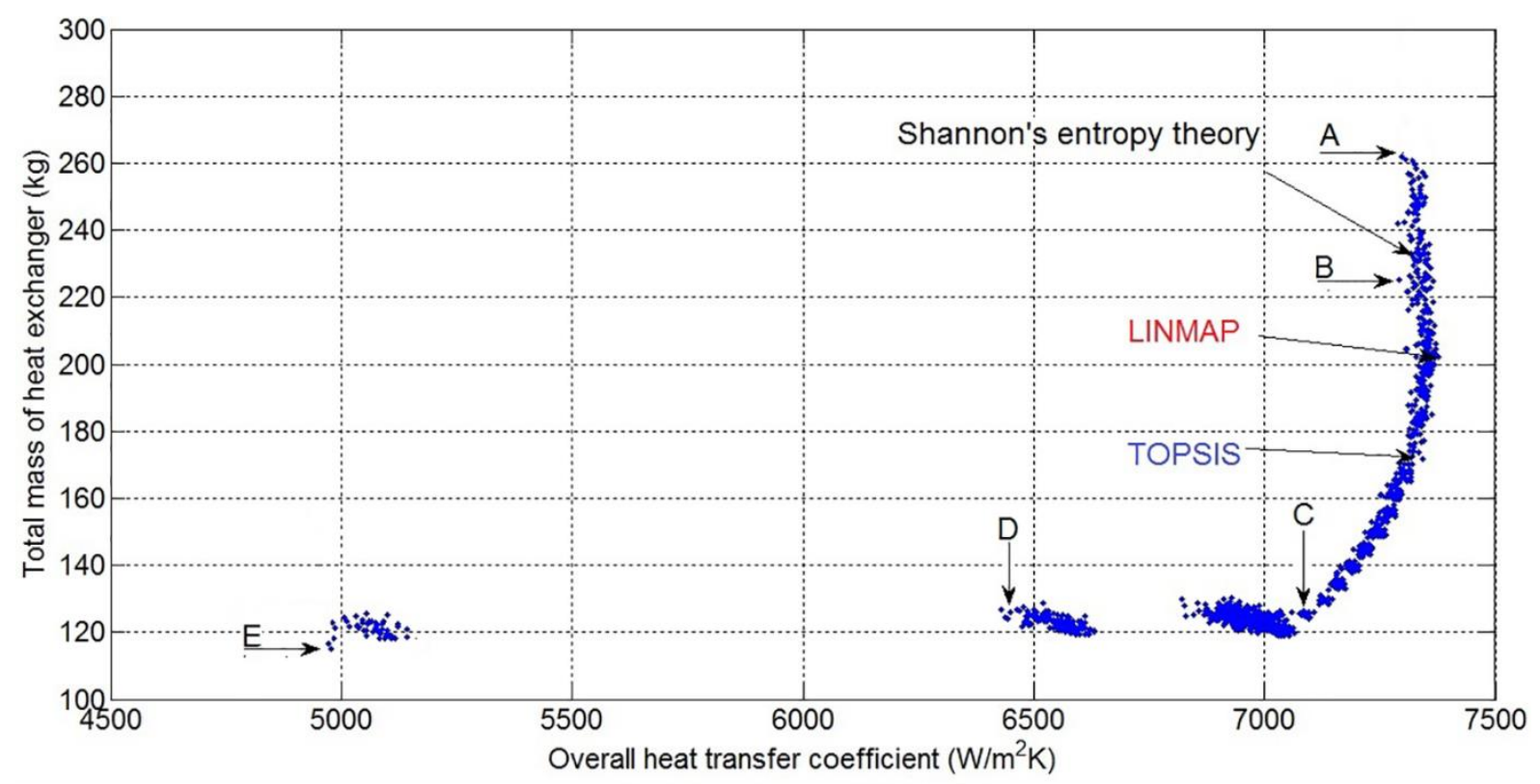

Figure 10. Pareto frontier for dual objective (overall heat transfer coefficient - total mass) of plate frame heat exchanger 

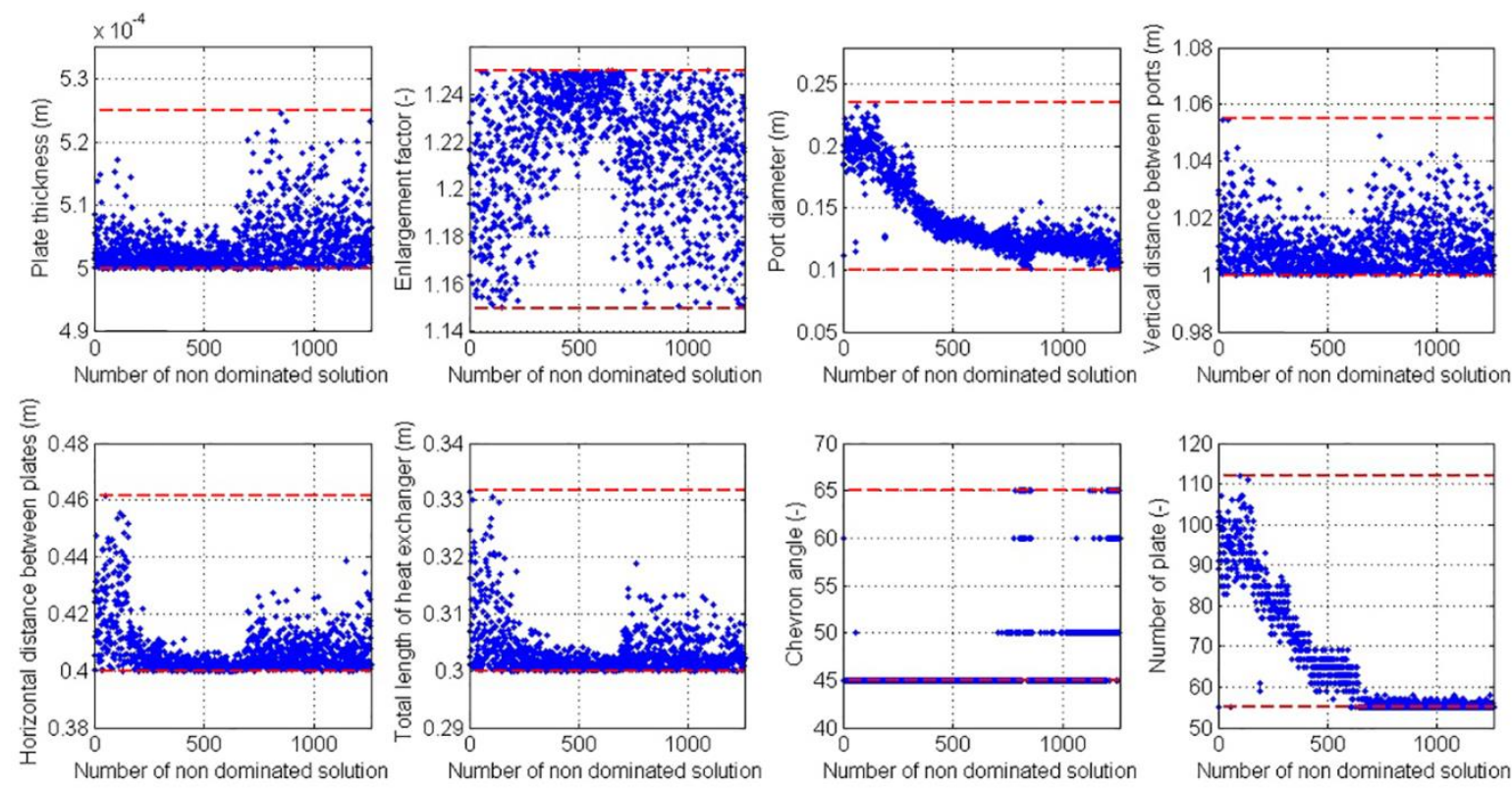

Figure 11. Scatter plot of design variables for optimum solutions on the Pareto frontier for simultaneous optimization of overall heat transfer coefficient and total mass of heat exchanger 
Table 15. Optimal solutions along with their corresponding deviation indexes found by different decision making methods

\begin{tabular}{llll}
\hline & LINMAP & TOPSIS & Shannon's Entropy Theory \\
\hline Decision variables & & & \\
\hline Plate thickness, $\mathrm{t}(\mathrm{m})$ & 0.000500 & 0.000500 & 0.000505 \\
\hline Enlargement factor, $\psi(-)$ & 1.186391 & 1.237096 & 1.216976 \\
\hline Port diameter, $\mathrm{D}_{\mathrm{p}}(\mathrm{m})$ & 0.190172 & 0.158879 & 0.200761 \\
\hline Vertical distance between ports, $\mathrm{L}_{\mathrm{v}}(\mathrm{m})$ & 1.005423 & 1.001200 & 1.028487 \\
\hline Horizontal distance between ports, $\mathrm{Lh}_{\mathrm{h}}(\mathrm{m})$ & 0.401555 & 0.402691 & 0.424275 \\
\hline Total plate length, $\mathrm{L}_{\mathrm{c}}(\mathrm{m})$ & 0.300148 & 0.300093 & 0.302397 \\
\hline Chevron angle, $\beta\left({ }^{\circ}\right)$ & 45 & 45 & 45 \\
\hline Number of plates, $\mathrm{N}_{\mathrm{t}}(-)$ & 80 & 75 & 89 \\
\hline Objective functions & & & \\
\hline Total mass of heat exchanger $(\mathrm{kg})$ & 202.27754 & 171.7414 & 230.9937 \\
\hline Overall heat transfer coefficient $\left(\mathrm{W} / \mathrm{m}^{2} \mathrm{~K}\right)$ & 7376.5814 & 7342.664 & 7325.328 \\
\hline Total cost of heat exchanger $(\$)$ & 41156.766 & 41264.05 & 41136.52 \\
\hline Deviation index & 0.21869 & 0.18533 & 0.25031 \\
\hline
\end{tabular}




\subsubsection{Overall heat transfer coefficient - total cost of heat exchanger - total mass of the heat exchanger consideration}

Fig. 12 visualizes the pareto space composed of the optimal solutions of the objective functions of overall heat transfer coefficient, total cost and total mass of the heat exchanger. As seen from the figure, LINMAP and TOPSIS methods find the same best compromising solution. Table 16 lists the optimal results found by decision making methods along with their associated deviation index values. According to the results, it can be said that outcomes of TOPSIS and LINMAP methods are more promising as deviation index (0.25942) obtained by these two methods are lower than that $(0.34859)$ of acquired by Shannon's entropy theory. Optimal valued retained by TOPSIS and LINMAP methods for overall heat transfer coefficient, total cost and total mass of the heat exchanger are respectively $6681.47 \mathrm{~W} / \mathrm{m}^{2} \mathrm{~K}, 26097.37 \$$, and $466.65 \mathrm{~kg}$ as tabulated in Table 16.

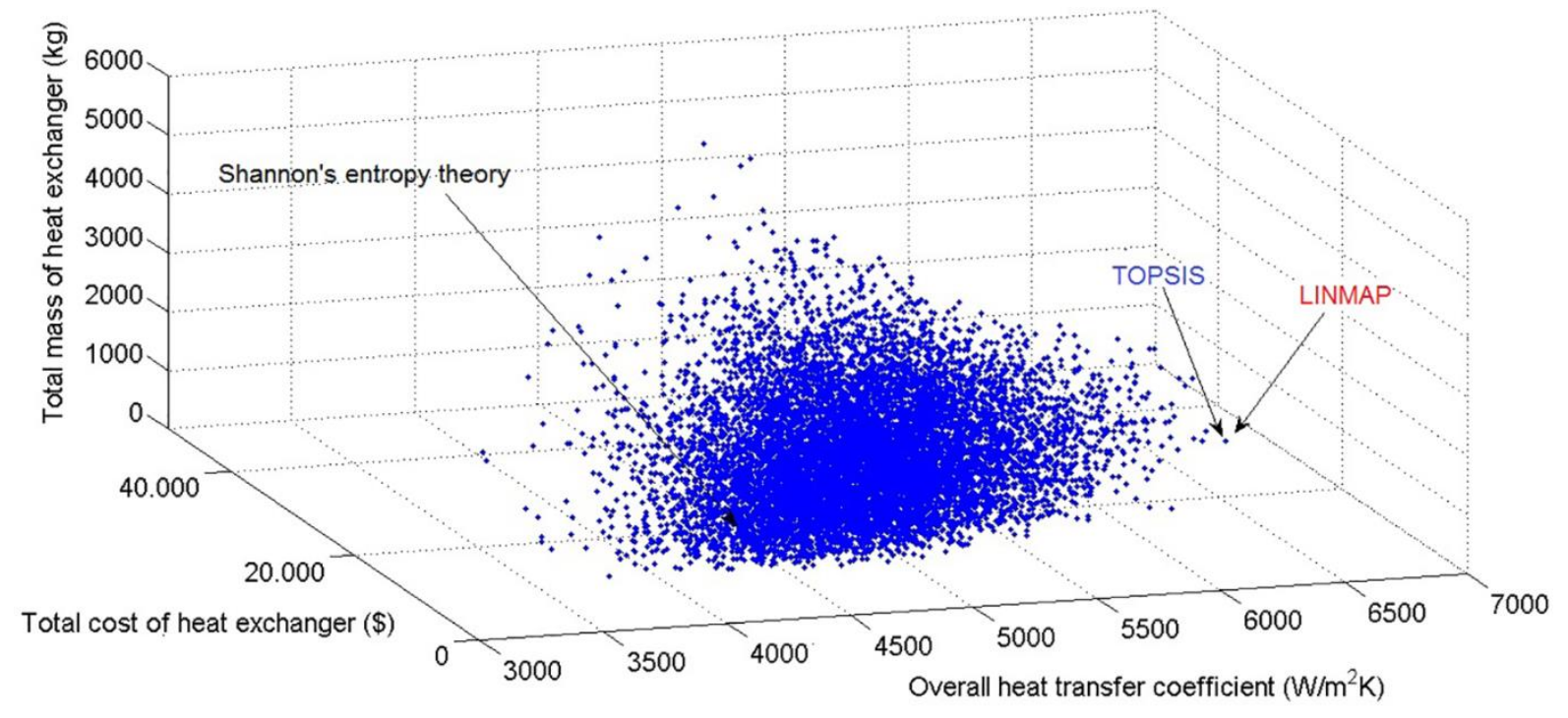

Figure 12. Pareto frontier for triple objective (overall heat transfer coefficient - total mass - total cost) of plate frame heat exchanger 
Bitlis Eren University Journal of Science and Technology 7(1) (2017) 33-73

Table 16. Optimal solutions obtained from three decision making strategies for triple objective

\begin{tabular}{llll}
\hline & LINMAP & TOPSIS & Shannon's Entropy Theory \\
\hline Decision variables & & & \\
\hline Plate thickness, $\mathrm{t}(\mathrm{m})$ & 0.000513 & 0.000513 & 0.000529 \\
\hline Enlargement factor, $\psi(-)$ & 1.191735 & 1.191735 & 1.191481 \\
\hline Port diameter, $\mathrm{D}_{\mathrm{p}}(\mathrm{m})$ & 0.206202 & 0.206202 & 0.268935 \\
\hline Vertical distance between ports, $\mathrm{L}_{\mathrm{v}}(\mathrm{m})$ & 1.010872 & 1.010872 & 1.702523 \\
\hline Horizontal distance between ports, $\mathrm{Lh}_{\mathrm{h}}(\mathrm{m})$ & 0.408501 & 0.408501 & 0.631732 \\
\hline Total plate length, $\mathrm{L}_{\mathrm{c}}(\mathrm{m})$ & 0.497078 & 0.497078 & 0.782119 \\
\hline Chevron angle, $\beta\left(^{\circ}\right)$ & 45 & 45 & 45 \\
\hline Number of plates, $\mathrm{N}_{\mathrm{t}}(-)$ & 185 & 185 & 176 \\
\hline Objective functions & & & \\
\hline Total mass of heat exchanger & 466.65837 & 466.65837 & 1153.791 \\
\hline Overall heat transfer coefficient $\left(\mathrm{W} / \mathrm{m}^{2} \mathrm{~K}\right)$ & 6681.4709 & 6681.4709 & 4189.166 \\
\hline Total cost of heat exchanger $(\$)$ & 26097.377 & 26097.377 & 4671.063 \\
\hline Deviation index & 0.25942 & 0.25942 & 0.34859 \\
\hline
\end{tabular}




\subsection{Sensitivity analysis}

The influences of each design parameter on problem objectives of overall heat transfer coefficient and total cost of heat exchangers are shown in Fig. 13(a-f). Best optimum solutions of design variables obtained by TOPSIS methods are taken from Table 11. Remaining parameters stay constant during the analysis. Fig.13(a) shows the influences of plate thickness on both overall heat transfer coefficient and total cost of heat exchanger rates. It is found that as plate thickness increase from its lower to upper limit, overall heat transfer coefficient decreases while total cost increases. This behaviour is also in agreement with the best result obtained from TOPSIS, by which two optimization objectives reach their optimum when plate thickness is around $0.5 \mathrm{~mm}$. Fig. $13(\mathrm{~b}-\mathrm{d})$ visualizes the variational effects of three design parameters of port diameters, horizontal distance between ports, and total length of the plate pack on these two abovementioned problem objectives. As seen from figures, any increase in design variables within their prescribed ranges leads to a significant decrease in both total cost and overall heat transfer coefficient. Increase in vertical distance between ports induces a huge rise total cost while imposing no effect on heat transfer coefficient rates, as shown in Fig. 13(e). Fig. 13(f) shows the variational influences of chevron angles over optimization objectives. It is observable that as chevron angles increase from $30^{\circ}$ to $65^{\circ}$, considerable decreases are seen in objective function values.

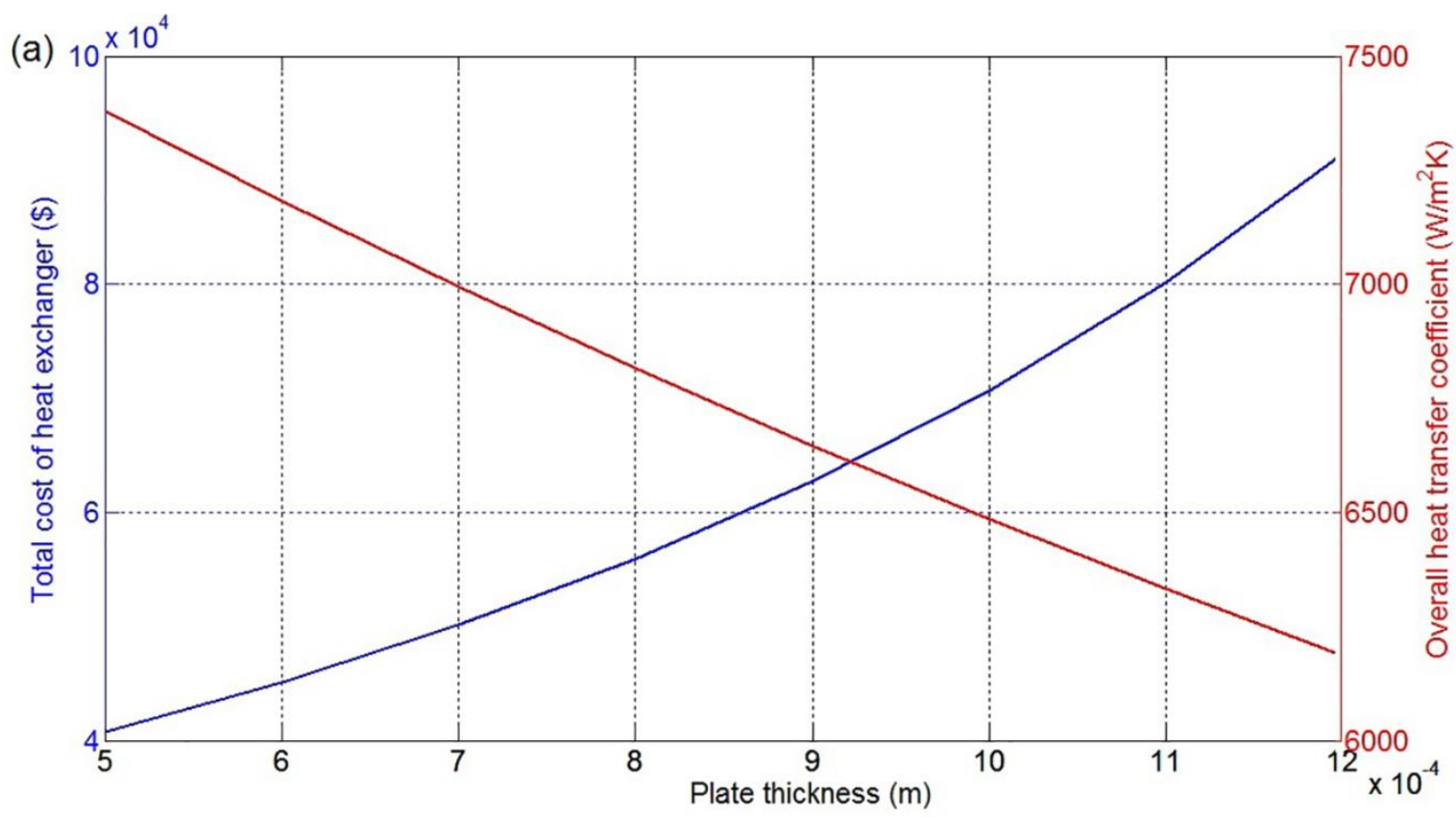



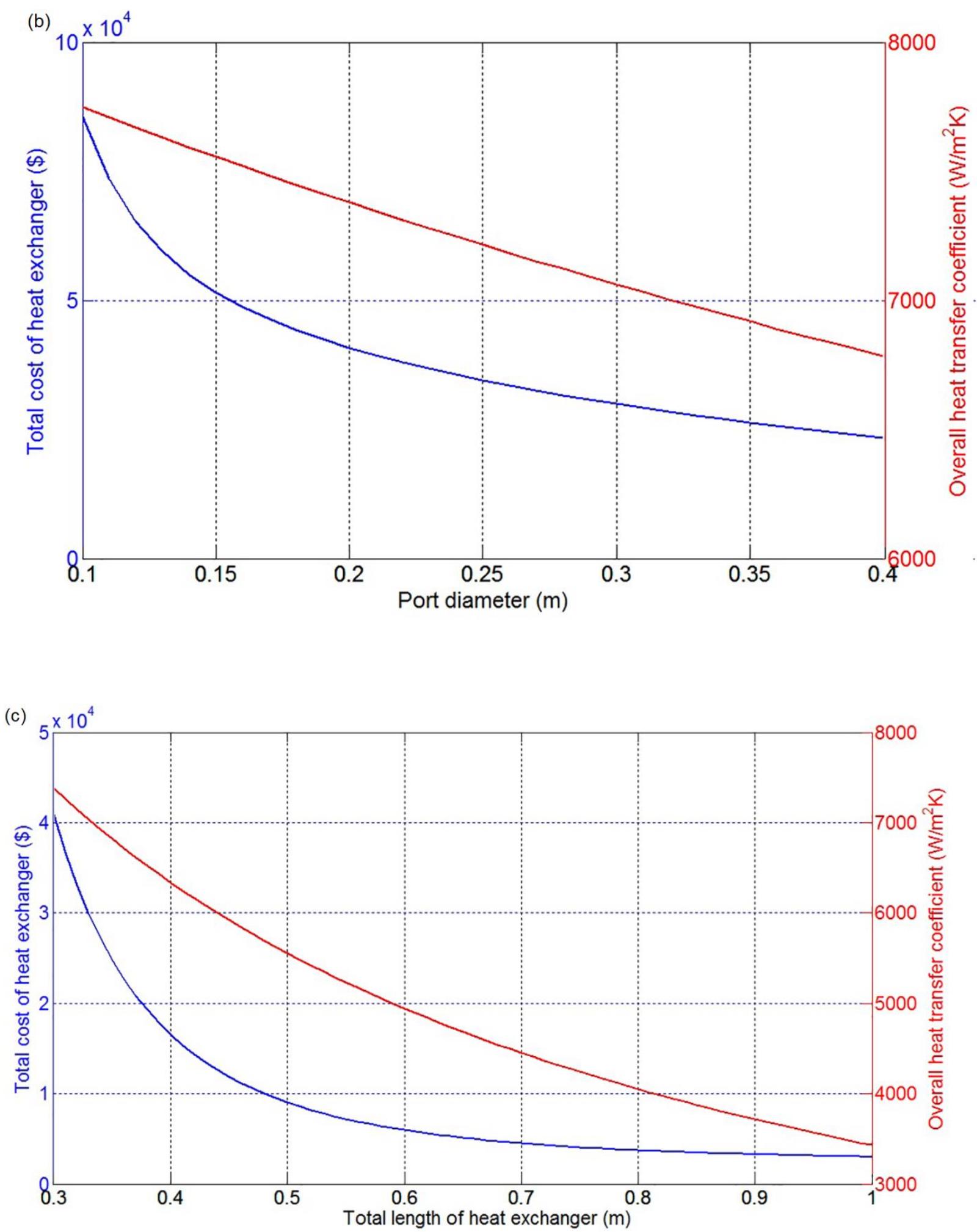
(d)
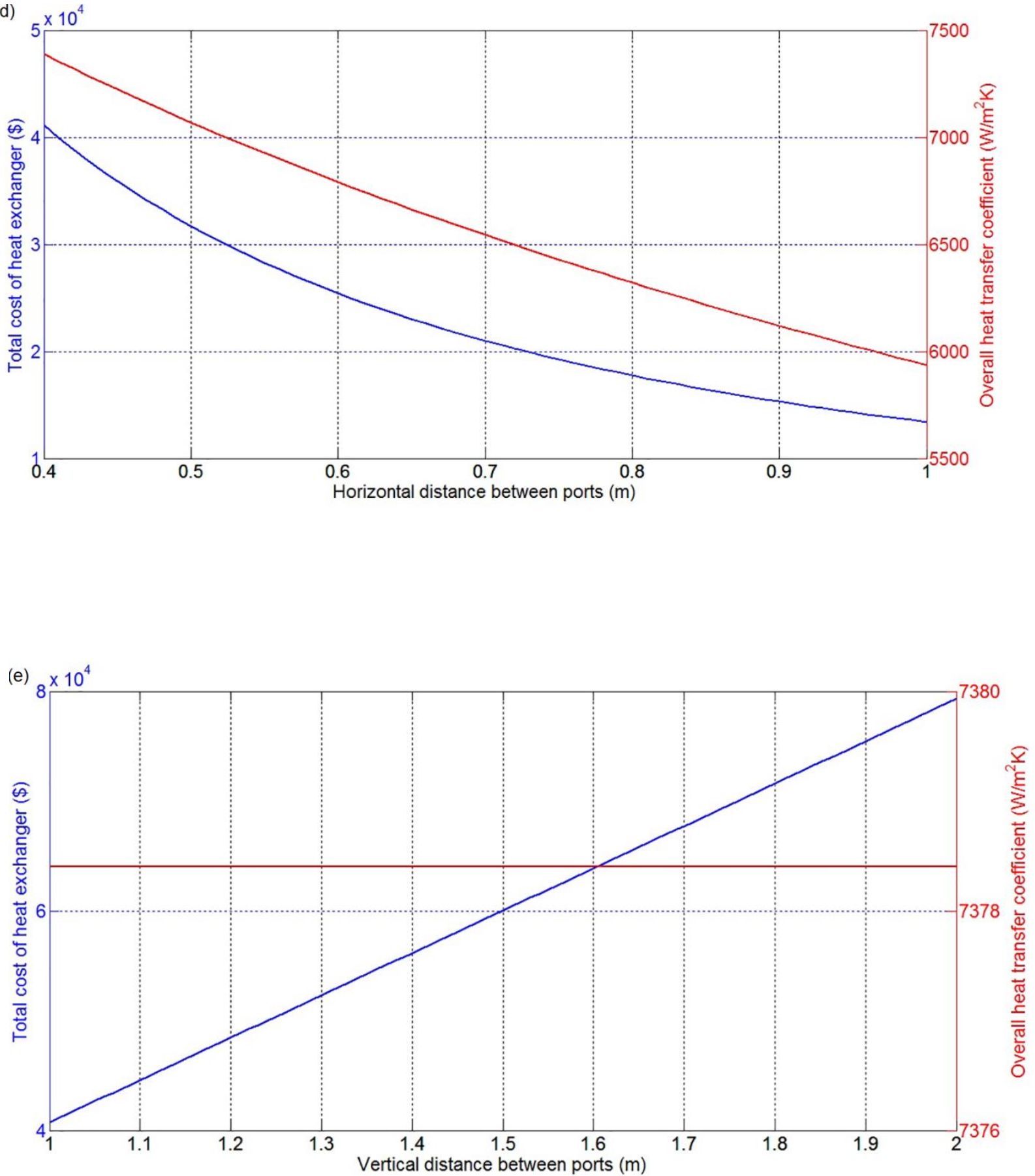


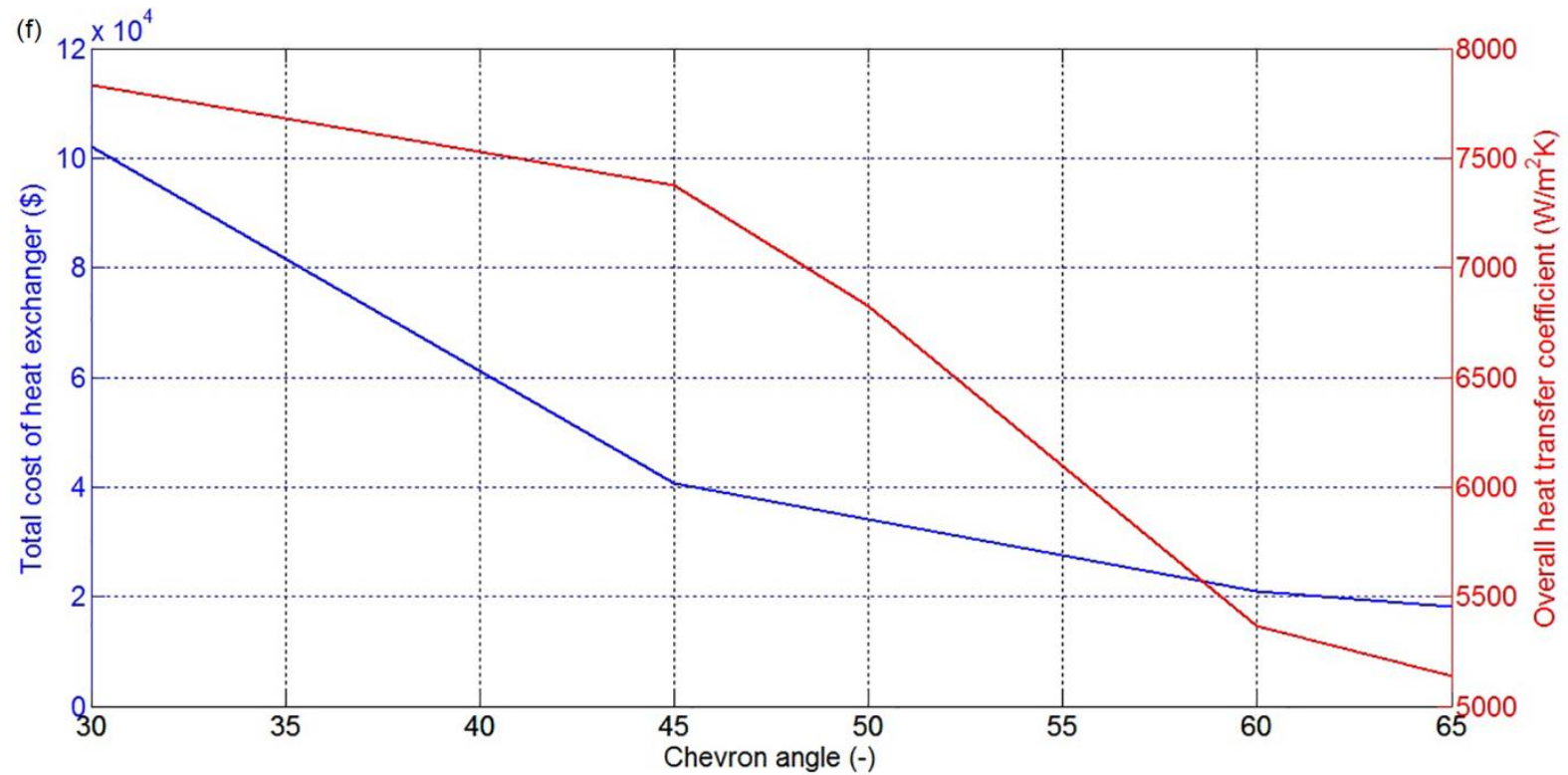

Figure 13. Influences of (a) plate thickness, (b) port diameter, (c) total length of the heat exchanger (d) horizontal and (e) vertical distance between ports, and (f) chevron angles on overall heat transfer coefficient and total cost of heat exchanger

\section{Conclusion}

This study proposes Global Best Algorithm based multiobjective optimization of plate frame heat exchangers. Global Best Algorithm uses the fundamental merits of Differential Evolution and Differential Search algorithms and gives weight to intensification rather than diversification which are two major phases of optimization algorithms. Firstly, efficiency of the proposed algorithm has been tested over 16 benchmark problems and corresponding results have been compared with the highly reputed recently emerged optimization algorithms. Overall heat transfer coefficient, total cost and weight of the heat exchanger are considered as problem objectives to be optimized separately as well as simultaneously. The pareto frontier constructed for triple and dual objective optimization is utilized to choose best compromising solution among the pareto curve through the highly reputed decision making methods of LINMAP, TOPSIS, and Shannon's entropy theory. Corresponding deviation indexes found by each decision making methods are compared with each other and the best optimal solution among the frontier for each case is selected. Sensitivity analysis is performed to observe the effect of some design parameters such as plate thickness, port diameters, chevron angles, horizontal and vertical distance between ports, and total length of plate pack on the functional values of overall heat transfer coefficient and total cost of heat exchanger. It is found that these two main optimization objectives are strongly dependent of these mentioned design variables. Optimal solutions attained in this study can be used as a guiding sample for the researchers who has been involved in modelling and designing plate frame heat exchangers.

\section{Nomenclature}

Aact Actual heat transfer area $\left(\mathrm{m}^{2}\right)$

$\mathrm{A}_{\mathrm{p}} \quad$ Projected heat transfer area $\left(\mathrm{m}^{2}\right)$

Atot Total heat transfer area $\left(\mathrm{m}^{2}\right)$

b Mean flow channel gap (m)

Cinv Investment cost (\$)

$\mathrm{C}_{\text {oper }}$ Operational cost (\$)

$\mathrm{C}_{\mathrm{p}} \quad$ Specific heat capacity $(\mathrm{J} / \mathrm{kgK})$

$\mathrm{C}_{\text {total }}$ Total cost (\$)

$\mathrm{C}_{\mathrm{h}} \quad$ Model parameter

CR Crossover probability

D Problem dimension

Dhc Channel hydraulic diameter (m)

$\mathrm{D}_{\mathrm{p}} \quad$ Port diameter $(\mathrm{m})$

F Scaling factor

$f \quad$ Friction factor

G Mass velocity $\left(\mathrm{kg} / \mathrm{m}^{2} \mathrm{~s}\right)$

h Heat transfer coefficient $\left(\mathrm{W} / \mathrm{m}^{2} \mathrm{~K}\right)$

$\mathrm{k}$ Thermal conductivity $(\mathrm{W} / \mathrm{mK})$

kel Cost of electricity (\$/MWh)

$\mathrm{K}_{\mathrm{p}} \quad$ Model parameter 


$\begin{array}{ll}\mathrm{L}_{c} & \text { Compact plate pack length (m) } \\ \mathrm{Lh}_{\mathrm{b}} & \text { Horizontal distance between ports }(\mathrm{m}) \\ \mathrm{L}_{\mathrm{p}} & \text { Projected plate length }(\mathrm{m}) \\ \mathrm{L}_{\mathrm{w}} & \text { Projected plate width }(\mathrm{m}) \\ \mathrm{L}_{\mathrm{v}} & \text { Vertical distance between plates }(\mathrm{m}) \\ \dot{\mathrm{m}} & \text { Mass flow rate }(\mathrm{kg} / \mathrm{s}) \\ \mathrm{n} & \text { Model parameter } \\ \mathrm{N}_{\mathrm{cp}} & \text { Number of channels per pass } \\ \mathrm{N}_{\mathrm{t}} & \text { Number of plates in the pack } \\ \mathrm{N}_{\mathrm{p}} & \text { Number of passes } \\ \Delta \mathrm{P} & \text { Pressure drop (Pa) } \\ \mathrm{P} & \text { Static penalty factor } \\ \mathrm{p} & \text { Plate pitch (m) } \\ \mathrm{Pr} & \text { Prandtl number } \\ \mathrm{r} & \text { Discount rate } \\ \mathrm{R} & \text { Fouling factor }\left(\mathrm{m}^{2} \mathrm{~K} / \mathrm{W}\right) \\ \mathrm{Re} & \text { Reynolds number } \\ \mathrm{t} & \text { Plate thickness (m) } \\ \mathrm{U} & \text { Overall heat transfer coefficient }\left(\mathrm{W} / \mathrm{m}^{2} \mathrm{~K}\right) \\ \mathrm{y} & \text { Depreciation time (year) }\end{array}$

\section{Greek Letters}

$\beta \quad$ Chevron angle

$\eta \quad$ Pump efficiency

$\mu \quad$ Dynamic viscosity (Pa.s)

$\rho \quad$ Density $\left(\mathrm{kg} / \mathrm{m}^{3}\right)$

$\sigma \quad$ Algorithm parameter

$\tau \quad$ Total operation hour in a year

$\varphi \quad$ Chaotic random number

$\psi \quad$ Enlargement factor

\section{Subscripts}

b Bulk

c $\quad$ Cold side

f Related to the frictional issues

h Hot side

$\mathrm{p} \quad$ Related to the ports

w Wall

\section{References}

Amini, M., and Bazargan, M., 2014. Two objective optimization in shelland-tube heat exchangers using genetic algorithm, Applied Thermal Engineering, 69, 278-285.
Arora, R., Kaushik, S.C., Kumar, R., and Arora, R., 2016. Soft computing based multi objective optimization of Brayton cycle power plant with isothermal heat addition using evolutionary algorithm and decision making, Applied Soft Computing, 46, 267 - 283.

Arora, R., Kaushik, S.C., and Arora, R., 2016. Thermodynamic modelling and multi-objective optimization of two stage thermoelectric generator in electrically series and parallel configuration, Applied Thermal Engineering, 103, 1312-1323.

Askarzadeh, A., 2014. Bird mating optimizer: An optimization algorithm inspired by bird mating strategies, Communications in Nonlinear Science and Numerical Simulation, 19,1213-1228.

Asadi, M., Song, Y., Sunden, G., and Xie, G., 2014. Economic optimization design of shell and tube heat exchangers by a cuckoo search algorithm, Applied Thermal Engineering, 73, 1032-1040.

Brest, J., Greiner, S., Boscovic, B., Mernik, M., and Zumer, V., 2006. Selfadaptive control parameters in differential evolution: a comparative study on numerical benchmark problems, IEEE Transactions in Evolutionary Computation, 10, 646-657.

Civicioglu, P., 2013. Artificial cooperative search algorithm for numerical optimization problems, Information Sciences, 229, 58-76.

Civicioglu, P., 2013. Backtracking Search Optimization Algorithm for numerical optimization problems, Applied Mathematical Computing , 219, 8121-8144.

Civicioglu, P., 2012. Transforming geocentric cartesian coordinates to geodetic coordinates by using differential search algorithm Computers\&Geosciences, 46, 229 - 247.

Edwards, M.F., Changal, A.A., and Parott, D.L., 1974. Heat transfer and pressure drop characteristics of a plate heat exchanger using Newtonian and non-Newtonian liquids, Chemical Engineering Journal, 286-293.

Erol, O.K., and Eksin, I., 2006. A new optimization method: Big Bang Big Crunch, Advanced Engineering Software, 37, 106-111.

Fettaka, S., Thibault, J., and Gupta, Y., 2013. Design of shell and tube heat exchangers using multi objective optimization, International Journal of Heat Mass Transfer, 60, 343-354.

Focke, W.W., 1986. Selecting optimum plate heat exchanger surface pattern, Journal of Heat Transfer, 108, 153-160.

Galeazzo, F.C.C., Miura, R.Y., Gut, J.A.W., and Tadini, C.C., 2006. Experimental and numerical heat transfer in a plate heat exchanger, Chemical Engineering Science, 61, 7133-7138.

Gamperle, R., Müller, S.D., and Koumoutsakos, P., 2002. A parameter study for differential evolution, In: Advances in Intelligent Systems, Fuzzy Systems, Evolutionary Computation, WSEAS Press, Interlaken, Switzerland, pp. 293-298.

Gandomi, A.H., and Yang, X.S., 2012. Evolutionary boundary constraint handling scheme, Neural Computing and Applications, 21, 1449-1462.

Geem, Z.W., Kim, J.H., and Loganthan, G.V., 2001. A new heuristic optimization algorithm: Harmony Search. Simulation, Engineering Optimization, 76, $60-68$.

Gherasim, I., Taws, M., Galanis, N., and Nguyen, C.T., 2011. Heat transfer and fluid flow in a plate heat exchanger part I. Experimental investigation, International Journal of Thermal Sciences, 50, 14921498.

Gong, W., Fialho, A., Cai, Z., and Li, H., 2011. Adaptive strategy selection in differential evolution for numerical optimization: an empirical study, Information Sciences, 181, 5364-5386.

Guo, J., Cheng, L., and Xu, M., 2009. Optimization design of shell and tube heat exchanger by entropy generation minimization and genetic algorithm, Applied Thermal Engineering, 29, 2954-2960. 
Gut, J.A.W., and Pinto, J.M., 2004. Optimal configuration design for plate heat exchangers, International Journal of Heat Mass Transfer, 47, 4833-4848.

Gut, J.A.W., Fernandes, R., Pinto, J.M., and Tadini, C.C., 2004. Thermal model validation of plate heat exchangers with generalized configurations, Chemical Engineering Sciences, 59, 4591 - 4600.

Hadidi, A., and Nazari, A., 2013. Design and economic optimization of shell and tube heat exchangers using biogeography based (BBO) algorithm, Applied Thermal Engineering, 51, 1263 - 1272.

Hadidi, A., Hadidi, M., and Nazari, A., 2013. A new design approach for shell and tube heat exchangers using imperialist competitive algorithm (ICA) from economic point of view, Energy Conversion and Management, 67, 66-74.

Hajabdollahi, F., Hajabdolahi, Z., and Hajabdollahi, H., 2013. Optimum design of gasket plate heat exchanger using multimodal genetic algorithm, Heat Transfer Research, 44,1-19.

Han, X.H., Cui, L.Q., Chen, S.J., Chen, G.M., and Wang, Q., 2010. A numerical and experimental study of chevron, corrugated plate exchangers, International Communications on Heat Mass Transfer, 37 1008-1014.

Jassim, E.W., Newell, T.A., and Chato, J.C., 2006. Refrigerant pressure drop in chevron and bumpy style flat plate heat exchangers, Experimental Thermal Fluid Sciences, 30, 213-222.

Jia, G., Wang, Y., Cai, Z., and Jin, Y., 2013. An improved $(\mu+\lambda)-$ constraint differential evolution for constrained optimization, Information Sciences, 222, 302-322.

Kakaç, S., Liu, H., and Pramuanjaroenkij, A., 2012. Heat exchangers: selection, rating, and thermal design, Taylor\& Francis, Boca Raton.

Kandlikar, S.G., and Shah, R.K., 1989. Multi pass heat exchangers effectiveness-NTU results and guidelines for selecting pass arrangements, Journal of Heat Transfer, 111, 300-313.

Kennedy, J., and Eberhart, R., 1995. Particle Swarm Optimization. In: Proceedings of IEEE International Conference on Neural Networks, $1942-1948$.

Khosravi, R., Khosravi, A., Nahavandi, S., and Hajabdollahi, H., 2015. Effectiveness of evolutionary algorithms for optimization of heat exchangers, Energy Conversion and Management, 89, 281 - 288.

Kumar, R., Kaushik, S.C., Kumar, R., and Hans, R., 2016. Multi-objective thermodynamic optimization of an irreversible regenerative Brayton cycle using evolutionary algorithm and decision making. Ain Shams Engineering Journal, 7, 741-753.

Kumar, H., 1984. The plate heat exchanger: construction and design. In: $1^{\text {st }}$ UK National Conference on Heat Transfer, University of Leeds, 3-5 July, Institution of Chemical Engineers Symposium Series, pp.1275 128.

Liang, J., Suganthan, P.N., 2005. Dynamic multi-swarm particle swarm optimizer. In: Proceedings 2005 IEEE Swarm Intelligence Symposium, IEEE, pp. 124-129.

Luan, Z., Zhang, G., Tian, M., and Fan, M., 2008. Flow resistance and heat transfer characteristics of a new type plate heat exchanger, Journal of Hydrodynamics Series B, 20, 524-529.

Martin, H., 1996. A theoretical approach to predict the performance of chevron-type plate heat exchangers, Chemical Engineering and Processes: Process Intensification, 35, 301-310.

May, R., 1976. Simple mathematical models with very complicated dynamics, Nature, 261, $459-467$.

Mirjalili, S., 2015. Moth-flame optimization algorithm :A novel natureinspired heuristic paradigm, Knowledge Based Systems, 89, 228 - 249.
Mirjalili, S., Mirjalili, S.M., and Hatamlou, A., 2016. Multi-Verse Optimizer: a nature inspired algorithm for global optimization, Neural Computing \& Applications, 27, 495 - 513.

Mohanty, D.K., 2016a. Application of firefly algorithm for design optimization of a shell and tube heat exchanger from economic point of view, International Journal of Thermal Sciences, 102, 228 -238.

Mohanty, D.K., 2016b. Gravitational search algorithm for economic optimization design of a shell and tube heat exchanger, Applied Thermal Engineering, 107, $184-193$.

Najafi, H., and Najafi, B., 2010. Multi-objective optimization of a plate and frame heat exchanger via genetic algorithm, Heat and Mass Transfer, 46, 639-647.

Novoa-Hernandez, P., Cruz-Corona, C., and Pelta, D.A., 2013. Selfadaptive, multi-population differential evolution in dynamic environments, Soft Computing, 17, 1861-1881.

Patel, V.K., and Rao, R.V., 2010. Design optimization of shell-and tube heat exchanger using particle swarm optimization technique, Applied Thermal Engineering, 30, 1417-1425.

Patel, V., and Savsani, V., 2014. Optimization of a plate -fin heat exchanger deign through an improved multi objective teaching learning based optimization (MO-ITLBO) algorithm, Chemical Engineering Research and Design, 92, 2371 - 2382.

Ponce-Ortega, J.M., Serna-Gonzalez, M., and Jimenez-Gutierrez, A., 2009. Use of genetic algorithms for the optimal design of shell and tube heat exchangers, Applied Thermal Engineering, 29, 203 - 209.

Qin, A.K., Huang, V.L., and Suganthan, P.N., 2009. Differential evolution algorithm with strategy adaptation for global numerical optimization, IEEE Transactions on Evolutionary Computing, 13, 398-417.

Rao, R.V., and Patel, V., 2013. Multi objective optimization of heat exchangers using a modified taching learning based optimization algorithm, Applied Mathematical Modeling, 37, 1146 - 1162.

Rao, R.V., and Waghmare, G.G., 2015. Multiobjective design optimization of a plate fin heat sink using a teaching learning based optimization algorithm, Applied Thermal Engineering, 76, 521-529.

Rönkkönen, K., Kukkonen, S., and Price, K.V., 2005. Real-parameter optimization with differential evolution, In: IEEE Congress on Evolutionary Computation, pp.506-513.

Sahin, A.S., Kılıç B., and Kılıç, U., 2011. Design and economic optimization of shell and tube heat exchangers using artificial bee colony (ABC) algorithm, Energy Conversion and Management, 52, $3356-3362$.

Selbas, R., Kizılkan, O., and Reppich, M., 2006. A new design approach for shell-and-tube heat exchangers using genetic algorithms from economic point of view, Chemical Engineering and Processes: Process Intensification, 45, 268-275.

Storn., R., and Price, K., 1997. Differential evolution - a simple and efficient heuristic for global optimization over continuous spaces, Journal of Global Optimization, 11, 341- 359.

Storn, R., 1996. On the usage of differential evolution for function optimization, In: Biennial Conference of the North American Fuzzy Information Processing Society (NAFIPS), IEEE, pp.519-523.

Sun, J., Feng, B., and Xu, W.B., 2004a. Particle swarm optimization with particles having quantum behaviour, IEEE Proceedings of Congress on Evolutionary Computation, pp. 325-331.

Sun, J., Xu, W., and Feng, B., 2004b. A global search strategy of quantum behaved particle swarm optimization, Cybernetics and Intelligent Systems Proceedings of the 2004, IEEE Conference, pp. 111-116.

Tiwari, A.K., Ghosh, P., and Sarkar, J., 2013. Heat transfer and pressure drop characteristics of $\mathrm{CeO}_{2}$ /water nanofluid in plate heat exchanger, Applied Thermal Engineering, 57, 24-32. 
Tiwari, A.K., Ghosh, P., and Sarkar, J., 2013. Performance comparison of the plate heat exchanger using different nanofluids, Experimental Thermal and Fluid Science, 49, 141-151.

Turgut, O.E., and Coban, M.T., 2016. Thermal design of spiral heat exchangers and heat pipes through global best algorithm, Heat and Mass Transfer. doi:10.1007/s00231-016-1861-y

Wang, L., and Sunden, B., 2003. Optimal design of plate heat exchangers with and without pressure drop specifications, Applied Thermal Engineering, 23, 295-311.

Yadav, P., Kumar, R., Panda, S.K., and Chang, C.S., 2012. An Intelligent Tuned Harmony Search algorithm for optimisation, Information Sciences, 196, $47-72$.

Yang, X.S., 2010. A new metaheuristic bat-inspired algorithm, In: Nature Inspired Cooperative Strategies for Optimization (NISCO 2010) Studies in Computational Intelligence, pp. 65-74.

Yu, W.J., and Zhang, J., 2011. Multi population differential evolution with adaptive parameter control for global optimization, In: Gecco2011: Proceedings of the $13^{\text {th }}$ Annual Genetic and Evolutionary Computation Conference, pp.1093-1098.

Zaleski, T., and Klepacka, K., 1992. Plate heat exchanger method of calculations, charts and guidelines for selecting plate heat exchanger configurations, Chemical Engineering and Processes: Process Intensification, 31, 45-56.

Zhang, J., and Ding, X., 2011. A multi swarm self-adaptive and cooperative particle swarm optimization, Engineering Applications of Artificial Intelligence, 24, 958-967.

Zhao, S.Z., Suganthan, P.N., Pan, Q.K., and Tasgetiren, M.F., 2011. Dynamic multi-swarm particle swarm optimizer with harmony search, Expert Systems with Applications, 38, 3735-3742. 